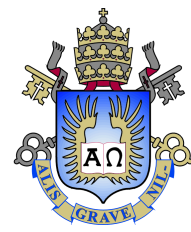

Priscilla Sieira Chaves

\title{
Impact of spinning conditions on the structure and tensile properties of mesophase pitch carbon fibers
}

Dissertação de Mestrado

Dissertation presented to the Programa de Pós-graduação em Engenharia Mecânica of PUC-Rio in partial fulfillment of the requirements for the degree of Mestre em Engenharia Mecânica.

Advisor : Prof. Paulo Roberto de Souza Mendes Co-advisor: Prof. Florian Alain Yannick Pradelle 


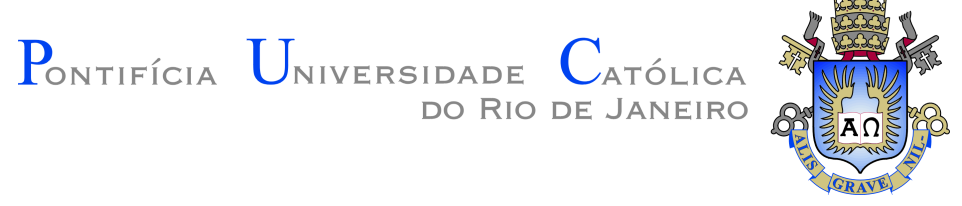

Priscilla Sieira Chaves

\title{
Impact of spinning conditions on the structure and tensile properties of mesophase pitch \\ carbon fibers
}

\begin{abstract}
Dissertation presented to the Programa de Pós-graduação em Engenharia Mecânica of PUC-Rio in partial fulfillment of the requirements for the degree of Mestre em Engenharia Mecânica. Approved by the Examination Committee.
\end{abstract}

Prof. Paulo Roberto de Souza Mendes

Advisor

Departamento de Engenharia Mecânica - PUC-Rio

Prof. Florian Alain Yannick Pradelle

Co-advisor

Departamento de Engenharia Mecânica - PUC-Rio

Prof. Márcio da Silveira Carvalho

Departamento de Engenharia Mecânica - PUC-Rio

Prof. Mônica Feijó Naccache

Departamento de Engenharia Mecânica - PUC-Rio

Prof. Erick Braga Ferrão Galante

Seção de Engenharia Química - IME

Rio de Janeiro, November 22nd, 2019 
All rights reserved.

\section{Priscilla Sieira Chaves}

Chemical Engineer, first Lieutenant of the Brazilian Army, bachelor's degree from Instituto Militar de Engenharia (IMERio de Janeiro, Brazil). Experience in the biochemistry laboratory of the University of East Anglia (UK) as part of the program Ciências sem Fronteiras. Since 2014 working on the production of strategic carbon materials, a project that resulted from the partnership between the Centro Tecnológico do Exercito (CTEx) and Petrobras. Acted in the graphite manufacturing plant and in graphite's characterization, with emphasis on thermogravimetry and thermal conductivity. Currently working with pitch rheology and extrusion of this material for the production of carbon fibers.

Bibliographic data

Chaves, Priscilla Sieira

Impact of spinning conditions on the structure and tensile properties of mesophase pitch carbon fibers / Priscilla Sieira Chaves; advisor: Paulo Roberto de Souza Mendes; co-advisor: Florian Alain Yannick Pradelle. - 2019.

83 f.: il. color.; $30 \mathrm{~cm}$

Dissertação (mestrado) - Pontifícia Universidade Católica do Rio de Janeiro, Departamento de Engenharia Mecânica, 2019.

Inclui bibliografia

1. Engenharia Mecânica - Teses. 2. Piche mesofásico. 3. Fibra de carbono. 4. Planejamento de experimentos. I. Mendes, Paulo Roberto de Souza. II. Pradelle, Florian Alain Yannick. III. Pontifícia Universidade Católica do Rio de Janeiro. Departamento de Engenharia Mecânica. IV. Título. 


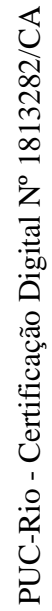

In memory of Lela and Zala 


\section{Acknowledgments}

I would like to thank Dr. Paulo Roberto de Souza Mendes, for being so kind to accept advising me. I thank him for the invaluable support he has provided before starting the program, during the courses and on my research. I am thankful for the time dedicated on teaching me rheology, on the measurements tips and on the critical analysis of this work. A special thank to Dr. Florian Pradelle, for promptly accepting co-advising and without whose support the completion of this work would not have been possible. I am extremely thankful for his availability and for the detailed review of my work.

I would also like to thank Dr. Márcio and Dr. Mônica for being part of this committee, and Dr. Erick Galante, my former graduation advisor, who happily agreed to participate. A special thank to Dr. Avillez, for the helpful suggestions on the X-ray measurements. I really appreciate Dr. Ivan's kindness and cheer through these years. Thanks for allowing me in the program. I thank all my teachers and the administrative section of the mechanical department for helping me achieve this.

I thank Colonel Cruz Jr. for making me enjoy transport phenomena. A special acknowledgement to Dr. Depine for all the support and for trusting my habilites. I thank him for the time dedicated on making me understanding a little about this wonderful field that is carbon science. I thank Dr. Taschetto for the early encouragement in pursuing a master degree. I thank him for the research ideas and for guiding me towards the successful completion of this work. Dr. Helena for tutoring me since my first working day. Dr. Franceschi for making me see that materials engineering is not so bad. Dr. Henrique for stimulating the research on this material and for providing the pitch. Dr. Victor for always being supportive and amusing and for introducing me to the multivariate analysis. Jovine and Amanda, for the friendship, the training and also for teaching me to use the microscope, the tensile tester and the furnace. Bramigk, for the brains and help with the codes. I thank you all for helping me become a better researcher.

I thank Renan, for the support and patience in tutoring me on the use of Latex and CorelDraw. I am also thankful for the friendship and the candies. I thank Major Zylberberg for sharing ideas, instruments and a studying place. Acknowledgements to Ricardo, for early helping me with rheological experimental procedures; to Paulo, for handling fluid mechanics; to Verônica, for the thermodynamics knowledge and Isabela and Marisa, for being inspirations. Thank you for the comforting culture in PUC. Finally, I would also like to thank my parents for their support and for always stimulating 
me to study. To Flávia, for showing that is also possible to study more. To Letícia for showing that sometimes a rest is more adequate. To Guilherme, for the companionship, for understanding and for being the best study partner. I thank Exército Brasileiro and Centro Tecnológico do Exército for allowing me to use their facilities.

This study was financed in part by the Coordenação de Aperfeiçoamento de Pessoal de Nível Superior - Brasil (CAPES) - Finance Code 001. 


\section{Abstract}

Chaves, Priscilla Sieira; Mendes, Paulo Roberto de Souza (Advisor); Pradelle, Florian Alain Yannick (Co-Advisor). Impact of spinning conditions on the structure and tensile properties of mesophase pitch carbon fibers. Rio de Janeiro, 2019. 83p. Dissertação de Mestrado - Departamento de Engenharia Mecânica, Pontifícia Universidade Católica do Rio de Janeiro.

The structure of a mesophase pitch carbon fiber is largely developed during the fiber spinning process and is perfected in stabilization and carbonization steps. It is of critical importance to strictly control the extrusion parameters to form standard carbon fibers. Designs of experiments were employed in melt spinning under 17 conditions to investigate the influence of three process variables - screw velocity, spinning temperature and winding speed on the diameter of petroleum-derived pitch filaments. Screw velocity was found to be the most significant factor to produce thinner fibers. Optimized conditions were validated in an experiment that produced a filament with average diameter of $14 \mu \mathrm{m}$, proving that design of experiments is a powerful tool to be used in carbon fibers production. The data collected on experiments were used to model the elongational flow that occurs during the fiber formation. Tensile strength at which the material can be subjected under extrusion without breaking was evaluated. The relation between the degree of orientation of the carbon layers parallel to the fiber axis and the diameter of the fibers was also analyzed. Despite the fact that the thickness of the fiber improved the axial alignment of molecules, there is a limiting diameter at which the diffusion of oxygen, needed to form stabilized fibers, do not occur. Only diameters smaller than $45 \mu \mathrm{m}$ could be fully stabilised in air. Insufficient stabilization of the thicker filaments induced defects on their structure that reflected on their tensile strength and modulus. While thinner fibers reached strengths of 1000 $\mathrm{MPa}$ and $90 \mathrm{GPa}$ modulus, thicker fibers have only supported $200 \mathrm{MPa}$ with $17 \mathrm{GPa}$ modulus.

\section{Keywords}

Mesophase Pitch; Carbon Fiber; Design of Experiments. 


\section{Resumo}

Chaves, Priscilla Sieira; Mendes, Paulo Roberto de Souza; Pradelle, Florian Alain Yannick. Impacto das condições de processo de extrusão na estrutura e propriedades mecânicas de fibras de carbono de piche mesofásico. Rio de Janeiro, 2019. 83p. Dissertação de Mestrado Departamento de Engenharia Mecânica, Pontifícia Universidade Católica do Rio de Janeiro.

A estrutura de uma fibra de carbono de piche mesofásico é desenvolvida durante a extrusão e é aperfeiçoada nos processos de estabilização e carbonização. É extremamente importante ter um controle rígido dos parâmetros do processo de extrusão para formar fibras de carbono de qualidade. Planejamentos de experimentos foram aplicados em 17 condições de extrusão para investigar a influência de três variáveis do processo - velocidade do parafuso, temperatura e velocidade da bobina - no diâmetro de fibras de piche de petróleo. A velocidade do parafuso foi apontada como o fator de maior impacto na produção de fibras finas. Condições ótimas foram validadas em um experimento que produziu filamentos com um diâmetro médio de $14 \mu \mathrm{m}$, mostrando que o planejamento de experimentos é uma ferramenta promissora para auxiliar a produção de fibras de carbono. Os dados coletados nos experimentos foram utilizados para modelar o escoamento extensional que ocorre durante a formação da fibra. Valores de tensão sob os quais o material pode ser submetido durante a extrusão sem rompimento foram avaliados. A relação entre o grau de orientação das moléculas de carbono e o diâmetro da fibra também foi analisada. Apesar de fibras mais grossas apresentarem maior alinhamento axial das moléculas, existe um valor de diâmetro a partir do qual a difusão de oxigênio, necessária para estabilização das fibras, não acontece. Apenas fibras com diâmetros menores que $45 \mu \mathrm{m}$ foram completamente estabilizadas em ar. Estabilizações incompletas das fibras mais grossas induziram defeitos nas estruturas delas e que refletiram em suas resistência a tração e módulo de Young. Enquanto fibras finas alcançaram resistências de $1000 \mathrm{MPa}$ e módulos de $90 \mathrm{GPa}$, fibras grossas aguentaram somente $200 \mathrm{MPa}$ com um módulo de $17 \mathrm{GPa}$.

\section{Palavras-chave}

Piche mesofásico; Fibra de carbono; Planejamento de experimentos. 


\section{Table of contents}

1 Introduction $\quad 19$

2 Review 22

2.1 Carbon fiber properties 22

2.2 Production of mesophase pitch carbon fibers 23

$\begin{array}{ll}2.3 & \text { Mesophase pitch rheology } \\ 2.4 & 28\end{array}$

$\begin{array}{lll}2.4 & \text { Fiber spinning } & 33\end{array}$

2.5 Impact of process variables on produced fiber 36

3 Materials and Methods $\quad 39$

3.1 Chemical properties of pitch 39

3.2 Shear flow experiments 40

$\begin{array}{ll}\text { 3.3 Design of experiments (DoE) } & 40\end{array}$

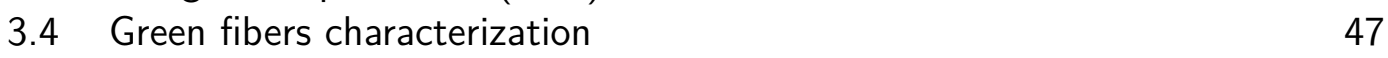

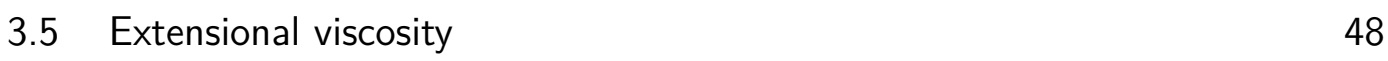

3.6 Stabilization and carbonization of fibers 49

3.7 Carbon fibers characterization 50

4 Results $\quad 51$

4.1 Shear flow $\quad 51$

4.2 Pitch fiber diameter investigation $\quad 54$

$\begin{array}{lll}4.3 & \text { Extensional viscosity } & 58\end{array}$

4.4 Pitch fiber orientation 62

4.5 Carbon Fibers 64

$\begin{array}{lll}5 & \text { Conclusions and future work } & 68\end{array}$

$\begin{array}{lll}6 & \text { References } & 70\end{array}$

$\begin{array}{lll}\text { A Experimental summary } & 77\end{array}$

$\begin{array}{lll}\text { B Extension codes } & 78\end{array}$

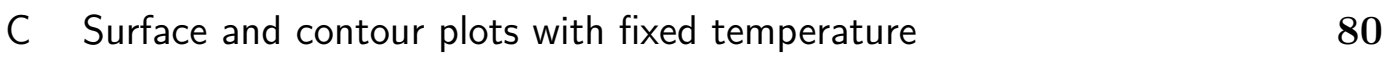

D Surface and contour plots with fixed screw velocity $\quad 82$ 


\section{List of figures}

$\begin{array}{lll}\text { Figure } 2.1 \quad \text { Graphite structure. } & 22\end{array}$

Figure 2.2 Scheme of Carbon Fiber production. 24

Figure 2.3 Scanning Electron Microscopy (SEM) image of carbonized mesophase spherules. Adapted from (22). 25

(a) Mesophase spherule 25

(b) Coalescence of mesophase 25

Figure 2.4 Extrusion. 25

(a) Extruder 25

(b) Mesophase flow 25

Figure 2.5 Scanning electron microscopy (SEM) images showing (a) and (b) thicker carbon fibers with defects; (c) and (d) thinner carbon fibers $\begin{array}{ll}\text { without major defects (adapted from (33)). } & 27\end{array}$

(a) "Pac-man" defect 27

(b) Voids $\quad 27$

(c) Flawless 27

(d) Thin fibers 27

Figure 2.6 Dependence of $\mathrm{d} 002$ and $\mathrm{g} \%$ with graphitizing temperature (34).

Figure 2.7 Dependency of dynamic viscosity on the inverse of temperature for Ashland 240 isotropic petroleum pitch, Nylon 6 (adapted from (38)), Methylene-bridged polymeric pitch (adapted from (39)) and Mesophase Pitch (adapted from (10)) with $\dot{\gamma}=1 \mathrm{~s}^{-1}$.

Figure 2.8 Flow curves from a commercial mesophase pitch at three distinct temperatures displaying the first two typical regions of liquid crystal systems. Adapted from (41).

Figure 2.9 Morphology and flow behaviour at $240^{\circ} \mathrm{C}$ for two different pitches. Adapted from (45).

(a) Morphology

(b) Flow

Figure 2.10 Dynamic oscillatory tests at several temperatures for pitches with different mesophase content. Adapted from (47).

(a) $100 \%$ of anisotropy

(b) $95 \%$ of anisotropy

Figure 2.11 Transient elongational viscosity and strain rate taken as a function of applied strain for the commercial liquid crystalline polymer Vectra B950 at $240^{\circ} \mathrm{C}$. Adapted from (51).

Figure 2.12 Single fiber formation.

Figure 2.13 Extensional stress as a function of DDR for the liquid crystalline polymer Vectra B950 at $310^{\circ} \mathrm{C}$ and $\dot{\gamma}=2000 \mathrm{~s}^{-1}$. Adapted from (57).

Figure 2.14 Pitch fiber orientation as a function of diameter produced varying spinning temperatures (o, from (58)) and draw down ratios ( $\square$, from (11)).

Figure 3.1 Composite design of two factors. Adapted from (65). 
Figure 3.2 Fiber extrusion apparatus.

Figure 4.1 Viscosity as a function of temperature. 51

Figure 4.2 Loss $\left(G^{\prime \prime}\right)$ and storage $\left(G^{\prime}\right)$ modulus at processing temperatures.

(a) $327^{\circ} \mathrm{C}, 331^{\circ} \mathrm{C}$ and $337^{\circ} \mathrm{C} \quad 52$

(b) $343^{\circ} \mathrm{C}$ and $347^{\circ} \mathrm{C} \quad 52$

Figure 4.3 Viscosity as a function of shear rate at 331,337 and $343^{\circ} \mathrm{C} . \quad 53$

Figure 4.4 First normal stress difference as a function of shear rate at 331,337 and $343^{\circ} \mathrm{C}$.

53

Figure 4.5 Extensional viscosity based on fiber spinning measurements. 59

Figure 4.6 Estimated extensional stress as a function of drawn down ratio from fiber extrusion measurements at different spinning temperatures.

Figure $4.7 \quad$ X-ray diffraction subtracted baseline gaussian fit for pitch filaments from 2, 9 and for central domain experiments.

Figure 4.8 Crystal axial alignment as a function of averaged precursor fiber diameter.

Figure 4.9 Carbon fibers from melt spinning experiments displayed in ascending order of diameter.

$\begin{array}{lll}\text { (a) } & 7 & 64 \\ \text { (b) } & 5 & 64 \\ \text { (c) } & 3 & 64 \\ \text { (d) } & 1 & 64 \\ \text { (e) } & 15 & 64 \\ \text { (f) } & 6 & 64 \\ \text { (g) } & 8 & 64 \\ \text { (h) } & 4 & 64 \\ \text { (i) } & 2 & 64\end{array}$

Figure 4.10 Tensile strength as a function of averaged precursor fiber diameter for as-spun (a) and carbonized (b) samples.

(a) Pitch filaments

66

(b) Carbon fibers

66

66

Figure 4.11 Young's modulus as a function of averaged precursor fiber diameter for carbonized samples.

67

Figure C.1 Diameter in central composite design as a function of coded screw velocity $\left(x_{1}\right)$ and coded winding speed $\left(x_{3}\right)$ with fixed spinning temperature of $327^{\circ} \mathrm{C}\left(x_{2}=-\alpha\right)$.

(a) Response surface

(b) Contour plot

Figure C.2 Diameter in central composite design as a function of coded screw velocity $\left(x_{1}\right)$ and coded winding speed $\left(x_{3}\right)$ with fixed spinning temperature of $331^{\circ} \mathrm{C}\left(x_{2}=-1\right)$.

(a) Response surface

(b) Contour plot

Figure C.3 Diameter in central composite design as a function of coded screw velocity $\left(x_{1}\right)$ and coded winding speed $\left(x_{3}\right)$ with fixed spinning temperature of $337^{\circ} \mathrm{C}\left(x_{2}=0\right)$.

(a) Response surface 
(b) Contour plot

Figure C.4 Diameter in central composite design as a function of coded screw velocity $\left(x_{1}\right)$ and coded winding speed $\left(x_{3}\right)$ with fixed spinning temperature of $343^{\circ} \mathrm{C}\left(x_{2}=1\right)$.

(a) Response surface

81

(b) Contour plot

81

81

Figure C.5 Diameter in central composite design as a function of coded screw velocity $\left(x_{1}\right)$ and coded winding speed $\left(x_{3}\right)$ with fixed spinning temperature of $347^{\circ} \mathrm{C}\left(x_{2}=\alpha\right)$.

(a) Response surface

(b) Contour plot

81

81

81

Figure D.1 Diameter in central composite design as a function of coded spinning temperature $\left(x_{2}\right)$ and coded winding speed $\left(x_{3}\right)$ with fixed screw velocity of $0.3 \mathrm{rpm}\left(x_{1}=-\alpha\right)$.

(a) Response surface $\quad 82$

(b) Contour plot 82

Figure D.2 Diameter in central composite design as a function of coded spinning temperature $\left(x_{2}\right)$ and coded winding speed $\left(x_{3}\right)$ with fixed screw velocity of $1 \mathrm{rpm}\left(x_{1}=-1\right)$.

(a) Response surface $\quad 82$

(b) Contour plot 82

Figure D.3 Diameter in central composite design as a function of coded spinning temperature $\left(x_{2}\right)$ and coded winding speed $\left(x_{3}\right)$ with fixed screw velocity of $2 \mathrm{rpm}\left(x_{1}=0\right)$.

(a) Response surface $\quad 83$

(b) Contour plot 83

Figure D.4 Diameter in central composite design as a function of coded spinning temperature $\left(x_{2}\right)$ and coded winding speed $\left(x_{3}\right)$ with fixed screw velocity of $3 \mathrm{rpm}\left(x_{1}=1\right)$.

(a) Response surface $\quad 83$

(b) Contour plot 83

Figure D.5 Diameter in central composite design as a function of coded spinning temperature $\left(x_{2}\right)$ and coded winding speed $\left(x_{3}\right)$ with fixed screw velocity of $3.7 \mathrm{rpm}\left(x_{1}=\alpha\right)$.

(a) Response surface $\quad 83$

(b) Contour plot 83 


\section{List of tables}

Table 1.1 Estimated production capacity of carbon fibers in 2014 (adapted from (5)).

Table 2.1 Comparison between several PAN and MP fibers from Solvay. 23

Table $3.1 \quad$ Pitch properties. 39

Table 3.2 Full factorial design matrix of three variables at two levels, adapted from (16).

Table 3.3 Calculation of parameters in ANOVA. 44

Table 3.4 Assignment of levels to the factors. 46

Table 3.5 Experiment Design. 47

Table 4.1 Reduced variables, experimental and predicted diameter for the models used.

Table $4.2 \quad R^{2}$ and p-values of models studied. 55

Table 4.3 Coefficients estimated for models used. 55

Table 4.4 Optimized parameters: predicted and actual values. 58

Table 4.5 Characteristic estimated viscosity and extension rate of experiments. $\quad 59$

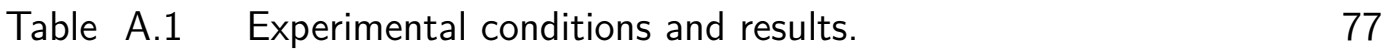




\section{List of abbreviations}

ANOVA - Analysis of Variance

ASTM - American Society for Testing and Materials

CC - Central Composite

CFRPs - Carbon Fiber Reinforced Plastics

CV - Coking Value

DoE - Design of experiments

DDR - Draw Down Ratio

FF3 - Full Factorial with 3 center repetitions

FF9 - Full Factorial with 9 center repetitions

FWHM - Full Width at Half Maximum

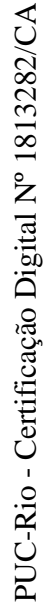

MP - Mesophase Pitch

PAH - Polycyclic Aromatic Hydrocarbons

PAN - Polyacrylonitrile

QI - Quinoline Insolubles

rpm - Revolutions per minute

SEM - Scanning Electron Microscopy

SP - Softening Point

TI - Toluene Insolubles

XRD - X-ray Diffraction 


\section{List of symbols}

$2 \theta$ - Angle between incident and reflected X-ray $\left(^{\circ}\right)$

$\alpha$ - Distance from the design center

$\varepsilon-$ Strain

$\dot{\varepsilon}-$ Rate of extension $\left(s^{-1}\right)$

$\dot{\varepsilon}_{a p}-$ Apparent rate of extension $\left(s^{-1}\right)$

$\dot{\varepsilon}_{z}$ - Rate of extension at a position $\mathrm{z}$ below the spinneret $\left(s^{-1}\right)$

$\eta_{a p}$ - Apparent uniaxial extensional viscosity (Pa.s)

$\eta_{E, a p}-$ Apparent uniaxial extensional viscosity (Pa.s)

$\eta_{E}-$ Extensional viscosity (Pa.s)

$\eta_{E, z}-$ Extensional viscosity at a position z below the spinneret (Pa.s)

$\mu$ - Dynamic Viscosity (Pa.s)

$\mu_{r}-$ dynamic viscosity at a reference temperature (Pa.s)

$\omega$ - Winding speed (rpm)

$\rho-$ Fluid density $\left(\mathrm{kg} / \mathrm{m}^{3}\right)$

$\tau_{r r}-$ Radial component of stress tensor $(\mathrm{Pa})$

$\tau_{z z}-$ Axial component of stress tensor $(\mathrm{Pa})$

$v^{0}-$ Air kinematic viscosity $\left(\mathrm{m}^{2} / \mathrm{s}\right)$

$a_{0}$ - Constant term (or average of experimental responses)

$a_{i}-$ Coefficient associated to the linear contribution of factor $\mathrm{i}$

$A_{z}-$ Filament cross sectional area at a distance $\mathrm{z}$ from the spinneret $\left(\mathrm{m}^{2}\right)$

$a_{i i}-$ Coefficient of quadratic contribution of factor i

$a_{i j k}-$ Coefficient of interaction between factors $\mathrm{i}, \mathrm{j}$ and $\mathrm{k}(i \neq j \neq k)$

$a_{i j}$ - Coefficient of interaction between factors $\mathrm{i}$ and $\mathrm{j}(i \neq j)$

$c_{p}-$ Fluid heat capacity $(J / K)$

$D_{s}-$ Spool diameter $(\mathrm{m})$

$D_{z}$ - Diameter at a position $\mathrm{z}$ below the spinneret $(\mathrm{z}=0$ : diameter of capillary hole; $\mathrm{z}=\mathrm{L}$ : filament final diameter) (m) 
$d_{002}$ - Interlayer space between graphene sheets $(\mathrm{nm})$

$e$ - Residual of the model

$E_{a}$ - Arrhenius Activation Energy $(k J / m o l)$

$F$ - Total force at extrusion (N)

$F$ - ratio - Fisher distribution parameter

$G^{\prime}-$ Loss modulus (Pa)

$G^{\prime \prime}$ - Storage modulus $(\mathrm{Pa})$

$g \%$ - Crystal degree of perfectness

$h$ - Coefficient of heat transfer $\left(W / m^{2} K\right)$

$\mathrm{i}$ or $\mathrm{j}$ - Identification of the factor $(\mathrm{i}=1$ : screw velocity; $\mathrm{i}=2$ : spinning tem-

perature; $\mathrm{i}=3$ : winding speed)

$k$ - Number of factors (or variables)

$k^{0}-$ Air heat conductivity $(W / m K)$

$L$ - Distance between spinneret and spool (m)

$L a-$ Crystallite Length (nm)

$L c$ - Crystallite Height (nm)

$n$ - Number of experiments

$N 1$ - Primary normal stress difference $(\mathrm{Pa})$

$N u$ - Nusselt number

$p$ - Number of coefficients in the model

$p$ - value - Measure of the probability that an event is rare

$Q-$ Flow Rate $\left(\mathrm{m}^{3} / \mathrm{s}\right)$

$R$ - Universal gas constant $(\mathrm{J} / \mathrm{mol} . K)$

$R^{2}$ - Coefficient of determination of models; ranges between 0 and 1

$R_{a d j}^{2}$ - Adjusted coefficient of determination; ranges between 0 and 1

$R e-$ Reynolds number

$s p^{2}-$ Hybridization of one orbital $\mathrm{s}$ and two orbitals $\mathrm{p}$

$\mathrm{t}$ - time (s)

$T$ - Local temperature (K) 
$T_{r}$ - Reference temperature at Arrhenious equation (K)

$T_{z}-$ Filament temperature at a position $\mathrm{z}$ below the spinneret $(\mathrm{z}=0$ : spinning temperature; $\mathrm{z}=\mathrm{L}$ : temperature at winder $)(\mathrm{K})$

$T_{\text {air }}$ - Air temperature $(\mathrm{K})$

$v_{z}-$ Filament axial velocity at a position $\mathrm{z}$ below the spinneret $(\mathrm{z}=0$ : velocity at exit of capillary hole; $\mathrm{z}=\mathrm{L}$ : velocity at spool device) $(\mathrm{m} / \mathrm{s})$

$x_{i}-$ Reduced (or normalized) independent variable i

$X_{i}-$ Real independent variable i

$X_{i}^{0}$ - Value of the real factor when $X_{i}=0$ (center of the experimental region)

$\Delta X_{i}-$ Half of the interval between the limit values of real variables

$y$ - Parameter to be modeled (or experimental response)

$\bar{y}$ - Mean of the responses 
If you can find a path with no obstacles, it probably doesn't lead anywhere.

Bear Grylls, Mud, Sweat and tears. 


\section{1 Introduction}

Composite materials, especially carbon fiber reinforced plastics (CFRPs), have several advantages over conventional materials, the most important being high strength to weight ratio. CFRP can be $35 \%$ lighter than aluminum and $60 \%$ lighter than steel for comparable structural stiffness and strength (1). This is particularly relevant in the context of environmental policies; for instance, it has been found that using CFRP in the vehicle's structure can reduce up to $10 \%$ of the curb weight which leads to significant fuel economy (1). Another study predicted the reduction of carbon dioxide emissions due to lightening the airplane in a 35-year period accounting the carbon fiber manufacture and the disposal of that particular piece made of fiber composite. It showed that the transition of a single section of the airplane architecture from aluminium to CFRP, as used in Boeing 737 dreamliner (2), would reduce up to $25 \%$ of $\mathrm{CO}_{2}$ emissions (3).

Carbon products are also widely used as structural materials in construction and sporting goods industries, and also as thermal management materials in high performance microelectronics. Those applications need different types of carbon fibers, that can be classified according to its mechanical strength. The current limitation in using CFRPs is the high cost of the carbon fiber, up to $\$ 80 / \mathrm{kg}$ for a standard modulus of $280 \mathrm{GPa}$, compared to $\$ 6 / \mathrm{kg}$ for a 190 GPa stainless steel (grade 304 ) or $\$ 5 / \mathrm{kg}$ for the $72 \mathrm{GPa}$ aluminum alloy (type 7075 ) (4). In 2017, it was estimated that by 2020, the automotive industry's reliance on carbon fiber will surge to 23,000 ton (1).

Carbon fibers are produced by thermal decomposition of various organic precursors. By far, the most used precursor material is polyacrylonitrile (PAN), followed by coal tar mesophase pitch (MP). MP carbon fibers have a superior crystal orientation and generally show better electric and thermal properties than PAN carbon fibers (1). In 2014, $96 \%$ of the carbon fiber being manufactured globally was PAN based. This data has been reproduced from Holmes (5) and is presented in Table 1.1. Recent researches do not suggest a change in this trend (6). 
Table 1.1: Estimated production capacity of carbon fibers in 2014 (adapted from (5)).

\begin{tabular}{cccc}
\hline \multirow{2}{*}{ No } & Manufacturer & \multicolumn{2}{c}{ Capacity (tons) } \\
\cline { 3 - 4 } & PAN & Pitch \\
\hline 1 & Toray Ind & 21100 & - \\
2 & Zoltek & 17400 & - \\
3 & Toho Tenax Rayon & 13900 & - \\
4 & Mitsubishi & 10200 & 1900 \\
5 & SGL Carbon Tech & 9000 & - \\
6 & Formosa Plastics & 8800 & - \\
7 & Hexcel & 7200 & - \\
8 & Solvay & 4000 & 1500 \\
& Total & 91600 & 3400 \\
\hline
\end{tabular}

Coal tar had been produced as a by-product of metallurgic cokes. Environmental policies regarding the emission of carcinogenic polycyclic aromatic hydrocarbons (PAH) during the heat treatment of coal and the closure of numerous coke plants have boosted the search for new materials capable of replacing, at least in part, these toxic pitches (7). Coal tar and petroleum pitches have different size and structure distribution of their constituents molecules and particularly difere in the degree of emission of their polycyclic aromatic hydrocarbons (PAH) components (8). Since petroleum pitch is less aromatic than coal tar pitch (9), the volatile components released from this alternative material are not as hazardous. On that concern, petroleum pitches could be a good option to substitute coal pitches (7).

To produce carbon fibers, mesophase pitch is melted inside an extruder furnace which cointains a rotating screw that pumps the melt into a spin pack. The spin pack contains a filter for removing solid particles. After passing through the filter, the melt exits the bottom of the spin pack through a spinneret. The spinneret is a plate containing a large number of individual capillaries. As the melt exits from these capillaries, it cools and forms a filament. The pitch solidified fiber, known as precursor or green fiber, is finally wound on a spinning spool (10).

Pitch fibers are submitted to temperatures around $200-400^{\circ} \mathrm{C}$ in air and are then subjected to a high temperature treatment above $1,000^{\circ} \mathrm{C}$ in an inert atmosphere, where they are converted into carbon fibers. Carbon fibers can be further graphitized at at temperatures around $3,000^{\circ} \mathrm{C}$, to achieve higher carbon content and higher crystal alignment (10). The stabilization process changes a mesophase pitch fiber from a thermoplastic solid to a thermosetting 
material and thereby imparts dimensional stability to the fiber whilst ripening the alignment of the structure developed during the melt extrusion (11).

The structure of the fiber is largely developed during the spinning process, whilst post-treatments are employed to refine and perfect it (12). The stabilization is the least efficient and most time consuming part of the production (1). Usually, as-spun mesophase pitch fibers of larger diameters exhibit a diffusion barrier in the oxidative treatment. Hence, it is of critical importance to strictly control the extrusion parameters to form thin carbon fibers that can be completely stabilized and subsequently carbonized and graphitized without deforming or introducing defects to its structure.

Many studies have been conducted to determine the effects of spinning conditions on coal tar pitch or synthetic pitch fibers $(10,11,13,14)$, but frequently only studying one variable at a time. Recently, Design of Experiments (DoE) have been used to verify the effects of multidimensional and interactions of input variables on the output responses of industrial products for improvement of their quality and reliability $(15,16,17,18)$. The aims of this work are: to use a wide range of spinning temperature, flow rate and winding speed to quantify how these parameters affect petroleum-derived pitch fibers diameters using different design of experiments approaches (full factorial and central composite designs) and statistic techniques; to provide experimental data for the viscosity of the precursor pitch measured in uniaxial elongational flow, acquiring its melt strength, drawability and orientation; and also to evaluate the tensile properties and morphology of the carbon fibers derived from that same pitch filaments. 


\section{Review}

\section{1}

\section{Carbon fiber properties}

The atomic structure of a carbon fiber is similar to that of graphite, consisting of carbon atom layers (graphene sheets) arranged in a regular hexagonal pattern, as shown in Figure 2.1. In graphitic crystalline region, the layer planes are stacked parallel to one another in a regular fashion. The atoms in a layer are strongly bonded through $s p^{2}$ bonding while the interaction between the sheets is due to Van der Waals forces. In a single graphitic crystal, the spacing between two graphene layers $\left(d_{002}\right)$ is about $0.335 \mathrm{~nm}(19)$.

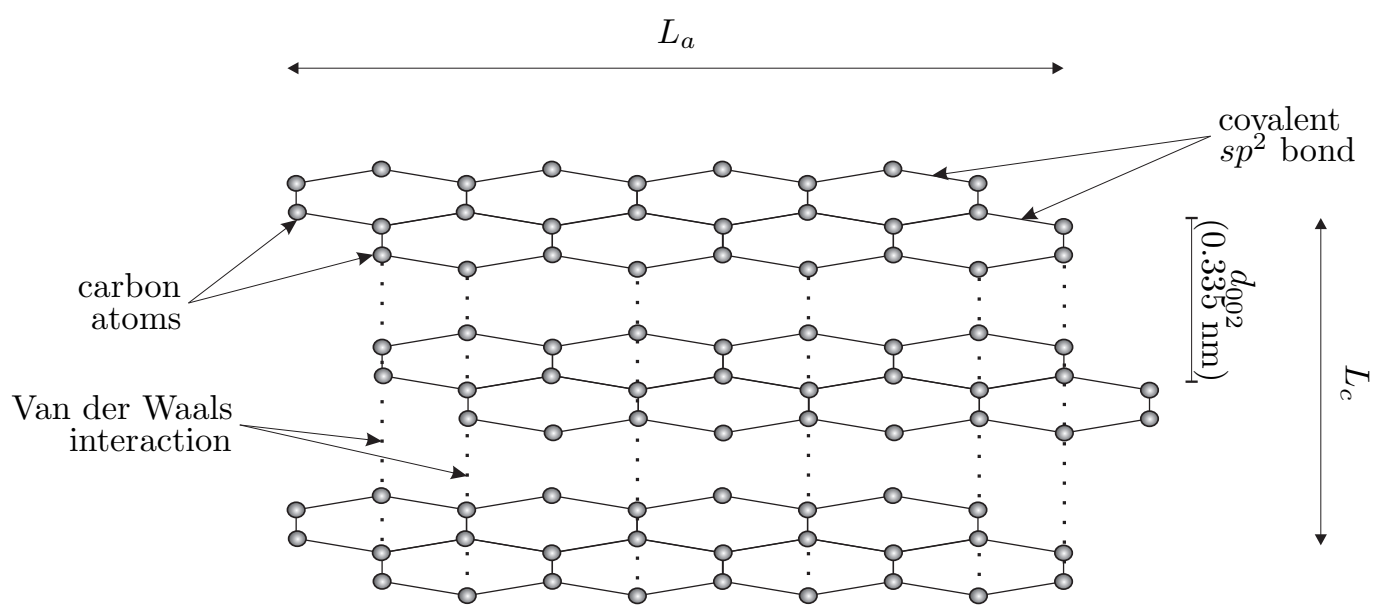

Figure 2.1: Graphite structure.

The high values of mechanical strength found on carbon fibers are due to the strong bond between carbon atoms and the alignment of graphene layers. It is commonly known that a fracture of a carbon fiber initiates at the crystal misorientation region around some inclusions or voids. In consequence, tensile strength decreases with defects size and distribution (20).

The tensile modulus (Young's modulus) of carbon fibers is governed by the preferred orientation of the carbon layers along the fiber axis and the perfectness of the crystallites. The modulus increases with decreasing interlayer spacing $\left(d_{002}\right)$ and with increasing crystallite height $\left(L_{c}\right)$ and crystallite length $\left(L_{a}\right)(19)$. MP carbon fibers have a superior crystal orientation and generally show better electric and thermal properties than PAN carbon fibers. The 
coefficient of thermal conductivity of mesophase pitch carbon fibers is in the range of $21-125 \mathrm{~W} / \mathrm{mK}$, which is close to that of metals. In the case of high modulus MP carbon fibers, thermal conductivity can be more than $500 \mathrm{~W} / \mathrm{mK}$ at room temperature (1). Table 2.1 shows the different properties achieved in MP and PAN fibers.

Table 2.1: Comparison between several PAN and MP fibers from Solvay.

\begin{tabular}{ccccccc}
\hline Precursor & Fiber & $\begin{array}{c}\text { Diameter } \\
(\mu \mathbf{m})\end{array}$ & $\begin{array}{c}\text { Tensile } \\
\text { Strength } \\
(\mathbf{G P a})\end{array}$ & $\begin{array}{c}\text { Tensile } \\
\text { Modulus } \\
(\mathbf{G P a})\end{array}$ & $\begin{array}{c}\text { Thermal } \\
\text { Conductivity } \\
(\mathbf{W} / \mathbf{m K})\end{array}$ & $\begin{array}{c}\text { Electrical } \\
\text { Conductivity } \\
(\mathbf{k S} / \mathbf{m})\end{array}$ \\
\hline PAN & T300 & 7 & 3.75 & 231 & 8 & 56 \\
PAN & T650 & 6.8 & 4.55 & 241 & 14 & 67 \\
MP & P25 & 11 & 1.56 & 172 & 26 & 77 \\
MP & P55 & 11 & 1.72 & 415 & 110 & 111 \\
MP & P75 & 10 & 1.90 & 520 & 185 & 185 \\
\hline
\end{tabular}

\section{2}

\section{Production of mesophase pitch carbon fibers}

The production of MP carbon fibers starts with the synthesis of pitch precursors. Mesophase pitches are typically produced by polymerization of aromatic compounds from petroleum or coal tar. Pitch is melt spun to provide precursor (or green) fibers. Pitch fibers are first stabilized at about $200-400^{\circ} \mathrm{C}$ in air by an oxidization process. The infusible, stabilized fibers are then subjected to a high temperature treatment at around $1000^{\circ} \mathrm{C}$ in an inert atmosphere to remove non-carbon elements. This step is often called carbonization. Carbonized fibers can be further graphitized at an even higher temperature up to around $3000^{\circ} \mathrm{C}$ to achieve higher carbon content and higher crystal alignment. The properties of the resultant carbon/graphite fibers are affected by many factors such as crystallinity, crystalline distribution, molecular orientation, carbon content, and the amount of defects (19). Figure 2.2 shows a scheme of the method. 


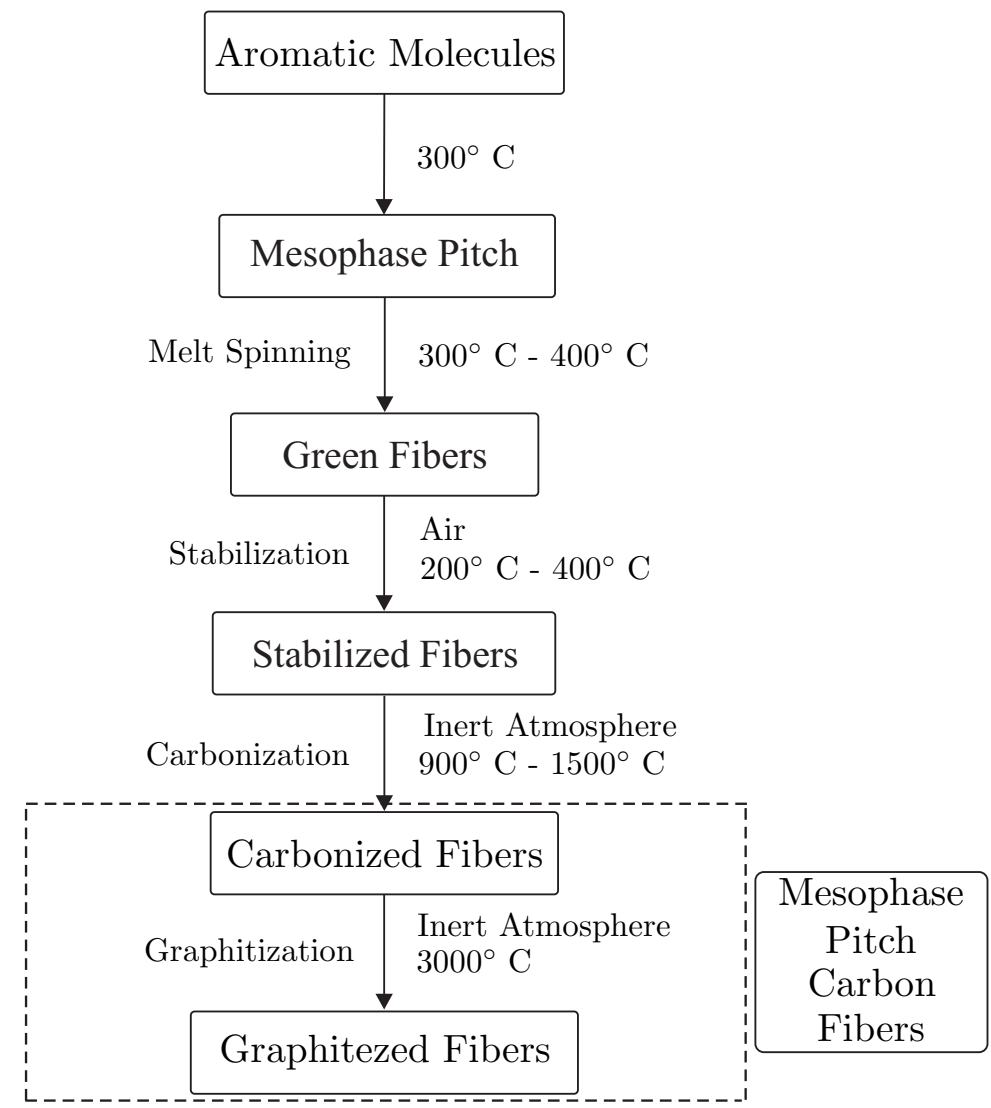

Figure 2.2: Scheme of Carbon Fiber production.

Polycondensed hydrocarbons are formed due to the volatilization of lower molecular weight components and successive condensation of the reactive species in the early stages of the heat treatment of heavy aromatic organic molecules (7). This first heavy fluid, yet uniform in all directions, is commonly known as isotropic pitch. As molecules grow, their interaction forces become stronger and orientation is originated. A mesophase spherule (Figure 2.3a) is formed by the accumulation of oriented polycondensed aromatic hydrocarbons in layers. As heat treatment progresses, these bodies, each of which with its single crystallographic orientation, swell until they begin to interfere with each other's growth (Figure 2.3b) and a polydomain structure is formed. Further heating produces larger droplets, leading eventually to bulk mesophase. This structure transformation is essential for the formation of precursors to be carbonized or graphitized (21). 


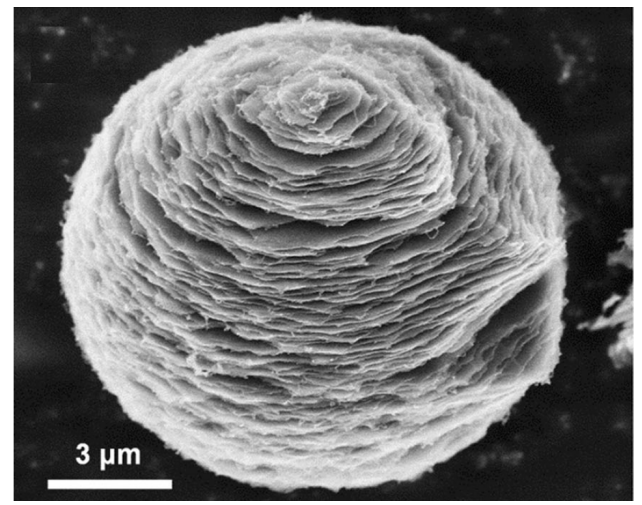

(a) Mesophase spherule

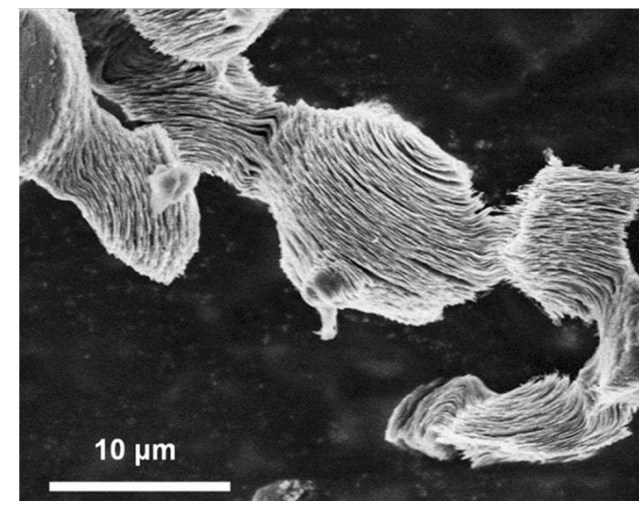

(b) Coalescence of mesophase

Figure 2.3: Scanning Electron Microscopy (SEM) image of carbonized mesophase spherules. Adapted from (22).

Mesophase pitch exhibits optical, electrical and magnetic anisotropy and also fluidity to deform at a given applied tension. That is, carbonaceous mesophase have the physical properties to fit the classification of liquid crystals. Such combination of properties are particularly interesting in a fiber extrusion process (23). In this stage, mesophase pitch is fed into an extruder where, through heating, its melting temperature is exceeded (Figure 2.4a). The fluid is then transported, under pressure, to a spin pack. The spin pack contains a filter for removing solid particles from the melt. After passing through the filter, the melt exits the bottom of the spin pack through a spinneret. Within the spinneret the melt flow is channelled into a number of individual capillary holes, each being responsible for the formation of a single filament $(10,24,25)$.

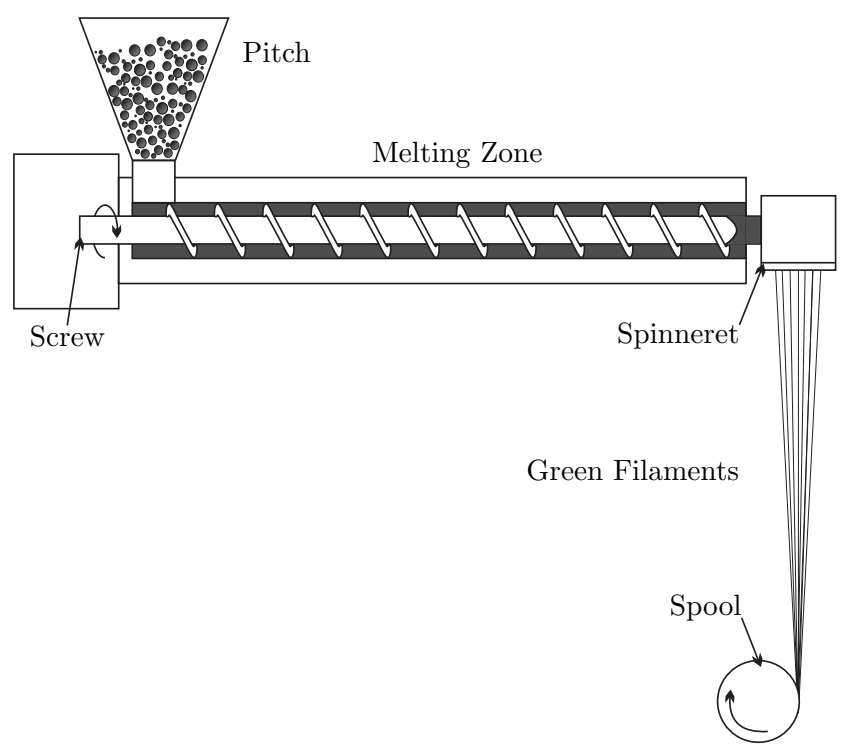

(a) Extruder

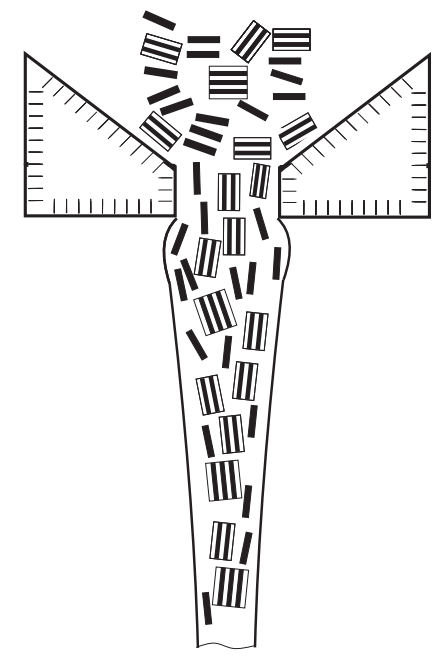

(b) Mesophase flow

Figure 2.4: Extrusion. 
As the melt exits from these capillaries, mesophase is oriented in the direction of filament axis until the pitch is solidified, as shown in Figure 2.4b. Spun fibers (or precursor fibers) are stabilized at about $200-400{ }^{\circ} \mathrm{C}$ in air by an oxidization process (10). The stabilization process changes a mesophase pitch fiber from a thermoplastic solid to a thermosetting material and thereby imparts dimensional stability to the fiber whilst ripening the alignment of the structure developed during the melt extrusion (11). Only a completely stabilized pitch fiber can be subsequently carbonized and graphitized without melting or deforming its structure (19).

The stabilization is the least efficient and most time consuming part of the production. In a PAN fiber line, the stabilization is responsible for at least $30 \%$ of process cost, and almost $80 \%$ of process time (1). It is performed in an oxidizing atmosphere that can change the chemical structure of the fiber, with minimum volatilization of carbonaceous material. It envolves the diffusion of oxygen thought the fiber with simultaneous reactions on the active sites of the molecules and creation of bonds between the hydrocarbon layers (26). The introduction of oxygen facilitates the three dimensional crosslinking, and interfere in the growth of crystallites (19).

Crosslinking reduces the mobility of the carbon layers and make oxygen diffusivity more difficult, thereby limiting the depth of penetration of the reactive molecule into the fiber (19). Typically, oxygen does not reach deeper than about $50 \mu \mathrm{m}$ from the surface of the fiber. In a sense, the outside of the fiber may have to be overoxidized to achieve sufficient internal stabilization. In some cases, the interior of the fiber, especially for a fat fiber in a bundle, will anneal to a coarser mesophase microstructure before stabilizing. In other cases, the centers of the fatter fibers are never oxidatively stabilized, and the central portion of the fiber may melt or even volatilize during carbonization (27). For that reason, usually as-spun mesophase pitch fibers with larger diameters exhibit a barrier in oxidative stabilization treatment, although some authors had reported successful stabilization at diameters of $30 \mu \mathrm{m}(28,29)$ and even of $50 \mu \mathrm{m}$ fibers $(11,30)$.

The infusible fibers are then subjected to a temperature treatment above $1000{ }^{\circ} \mathrm{C}$ in an inert atmosphere to promote aromatic growth and polymerization and to remove the oxygen introduced in the stabilization process as well as other non-carbon components. This step, which typically generates a fiber with an average of $95 \%$ carbon content, is called carbonization. The removal of volatiles followed by the molecular stacking may induce an homogeneous shrinkage in the fiber structure (31). Furthermore, the rapid excessive release of volatiles of can introduce defects or crack the fibers (19). 
Figures $2.5 \mathrm{c}$ and $2.5 \mathrm{~d}$ show thin carbon fibers, whereas figures $2.5 \mathrm{a}$ and $2.5 \mathrm{~b}$ illustrate defects introduced in the structures of the filaments after they have passed through the stabilization and carbonization steps. The "Pac-man" splitting of a fiber (figure 2.5a) is typical of a MP based fiber with radial alignment. The alignment of the mesophase molecules in the radial direction results in the material being fairly weak in the hoop direction, and the hoop stresses generated during carbonization, when non-carbon constituents are evolved, are relieved by the "Pac-man" pattern (32).

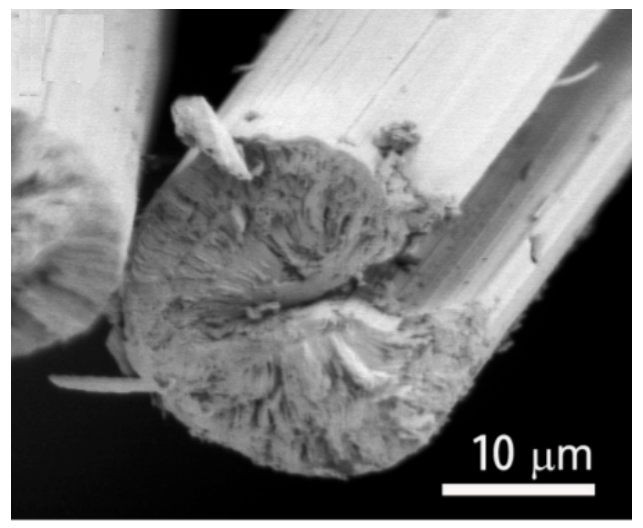

(a) "Pac-man" defect

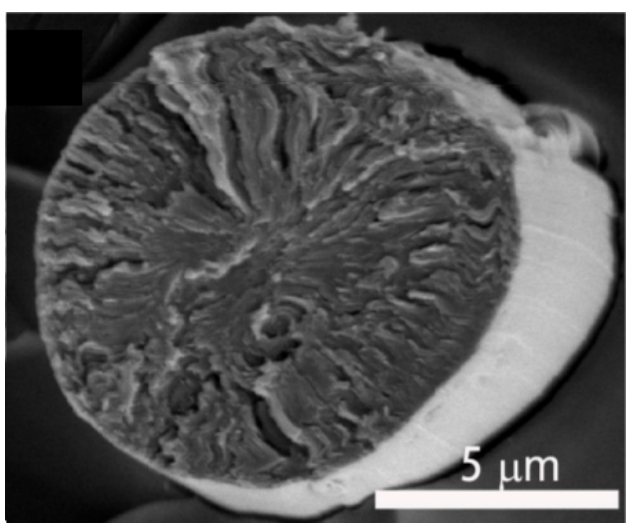

(c) Flawless

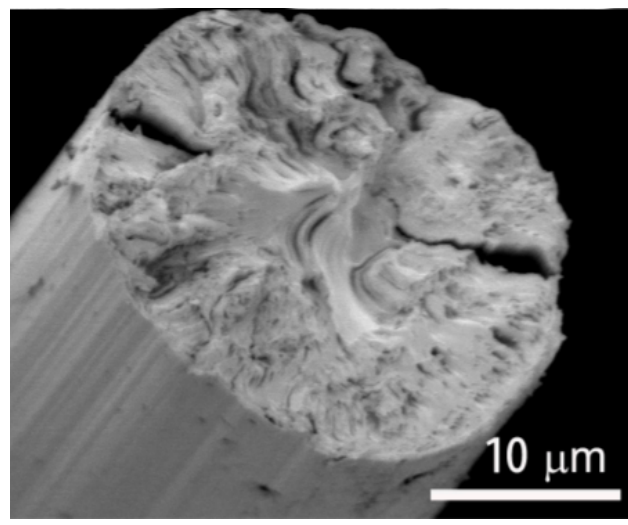

(b) Voids

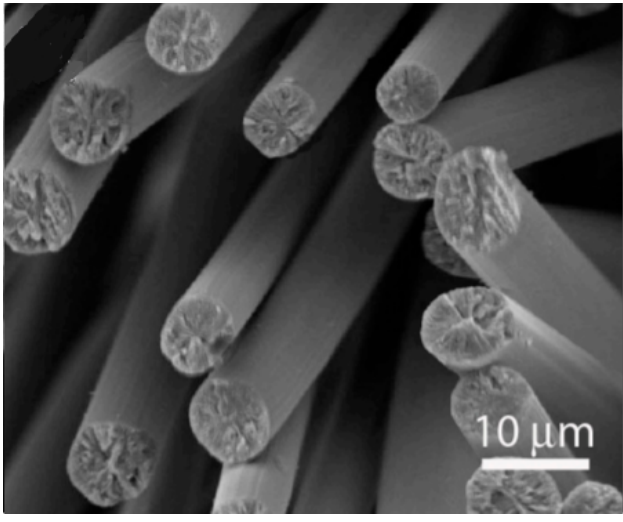

(d) Thin fibers

Figure 2.5: Scanning electron microscopy (SEM) images showing (a) and (b) thicker carbon fibers with defects; (c) and (d) thinner carbon fibers without major defects (adapted from (33)).

Carbonized fibers can be further graphitized at an even higher temperature up to around $3,000^{\circ} \mathrm{C}$ to achieve higher carbon content. Figure 2.6 shows that the higher the graphitizing temperature, the better crystal arrangement. At $3000^{\circ} \mathrm{C} d_{002}$ is closer to the typical value of $0,3350 \mathrm{~nm}$ and the degree of perfectness, $g=\left(3.44-d_{002}\right) / 0.086$, almost reaches $100 \%$. 


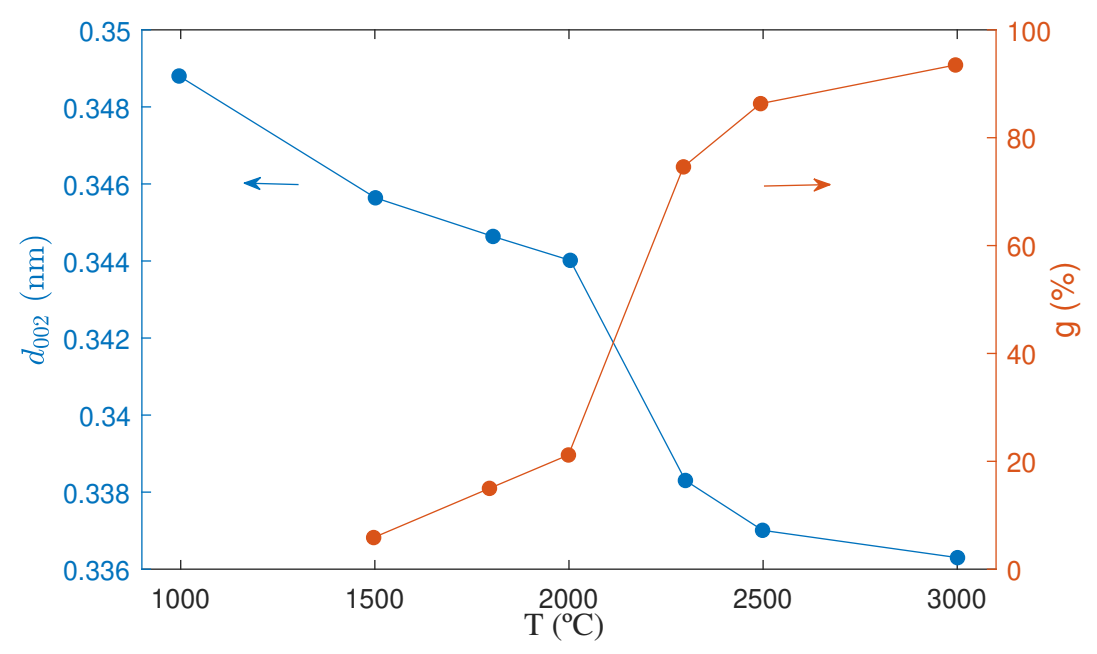

Figure 2.6: Dependence of d002 and g\% with graphitizing temperature (34).

Tensile strength of carbon fibers exhibits statistical type distribution and significant fiber size dependence (35): larger diameters fibers may have more defects that will directly affect the maximum tension beared. Jones showed that a rough correlation could be drawn between the size of a defect and the stress at which the fibre broke. Defects of $3 \mu \mathrm{m}$ in size or larger, anywhere in the filament cross-section, limited the strength to below $1.4 \mathrm{GPa}$. Interior flaws between 2 and $3 \mu \mathrm{m}$ in size or surface flaws between 1 and $3 \mu \mathrm{m}$ in size caused failure at strengths between 1.4 and 2.1GPa. Surface or interior flaws between 0.7 and $2 \mu \mathrm{m}$ caused failure at strengths between 2.1 and $2.8 \mathrm{GPa}$. Fibres with strengths above $3.5 \mathrm{GPa}$ failed at holes $0.5 \mu \mathrm{m}$ or less in size, at shallow surface pits, or at undetected defects (20).

A high modulus, high conductivity mesophase pitch carbon fiber is mainly a result from a high degree of preferred orientation of mesophase parallel to the fiber axis. The structure is largely developed during the fiber spinning process, while post-treatments are employed to refine and perfect the as-spun fibers (12). Thus, it is of critical importance to understand the mechanism of flow occurring in spinning step in order to strictly control the extrusion parameters to form thinner and highly ordered fibers.

\section{3}

\section{Mesophase pitch rheology}

Since mesophase precursors softens well below their degradation temperatures, melt spinning is one of the most used techniques to produce carbon fibers. At first, this technique is relatively simple, requiring just a melting apparatus that can force a fluid through a die containing a number of extrusion capillaries. The difficulty arises from the fact that mesophase is an 
extremely complex fluid, much more than the polymer solution used to form PAN fibers. This impacts both design and the control of the process parameters (36). As first noticed by Edie and Dunham (10), the viscosity of mesophase pitch changes dramatically with temperature. Figure 2.7 shows temperature data for a mesophase, a polymeric and an isotropic pitch, and a thermoplastic polymer (Nylon 6). All materials behave in agreement with Arrhenius equation

$$
\mu=\mu_{r} \exp \left[\frac{E_{a}}{R}\left(\frac{1}{T}-\frac{1}{T_{r}}\right)\right],
$$

where $\mu_{r}$ is the dynamic viscosity at a reference temperature, $E_{a}$ is the activation energy, $R$ is the universal gas constant, $T_{r}$ is the reference temperature and $T$ is local temperature. The plot also shows that pitches have higher slopes than Nylon 6 and thus they are more sensitive to temperature changes. In fact, the higher the anisotropic content in the pitch, the more sensitive the viscosity to a change in temperature (37).

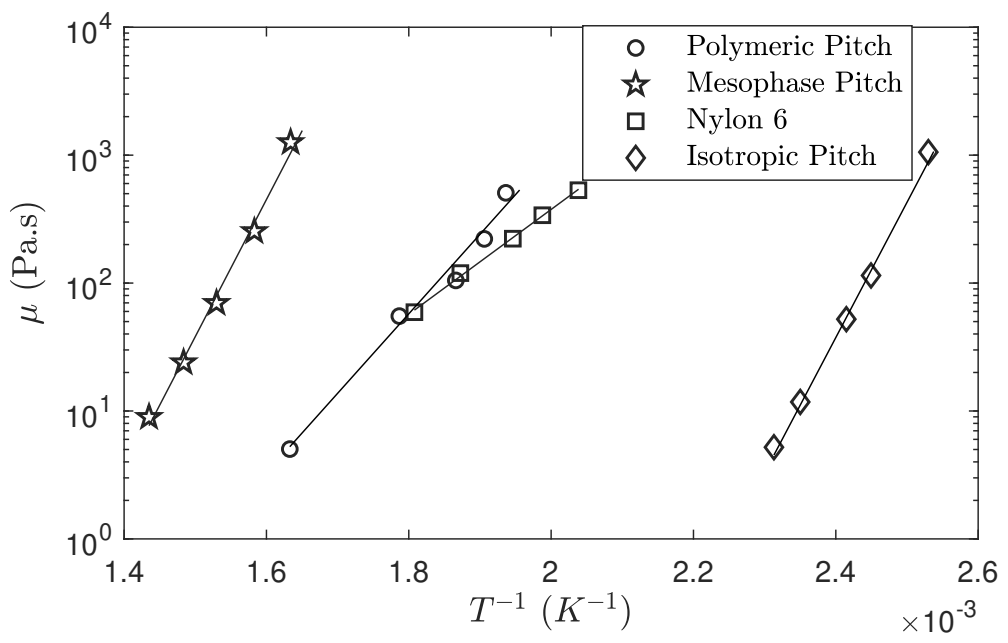

Figure 2.7: Dependency of dynamic viscosity on the inverse of temperature for Ashland 240 isotropic petroleum pitch, Nylon 6 (adapted from (38)), Methylene-bridged polymeric pitch (adapted from (39)) and Mesophase Pitch (adapted from (10)) with $\dot{\gamma}=1 s^{-1}$.

Isotropic pitches are frequently reported as simple Newtonian fluid (37). However, isotropic portions derived from centrifuged pitches with low mesophase content have been found to possess similar elastic properties as of the precursor pitch (40). The flow mechanics of liquid crystalline systems, such as mesophase pitch is more complicated than that of isotropic fluids (41). The dependence of the viscosity on the shear rate for those fluids can be divided into three regions according to the shear rate: in region I the apparent viscosity decreases rapidly with increasing shear rate; region II is a plateau region where viscosity remains fairly constant; and region III is a power-law shear thinning 
region (42). Cato and Edie (43) studied the flow of a comercial mesophase pitch produced by Mitsubishi and obtained a slope close to -0.5 for shear rates below $1 s^{-1}$. Also, they reported that at shear rates above $10 \mathrm{~s}^{-1}$, the first normal stress difference becomes positive and proportional to the shear rate (43). Figure 2.8 shows the flow behaviour of the studied pitch.

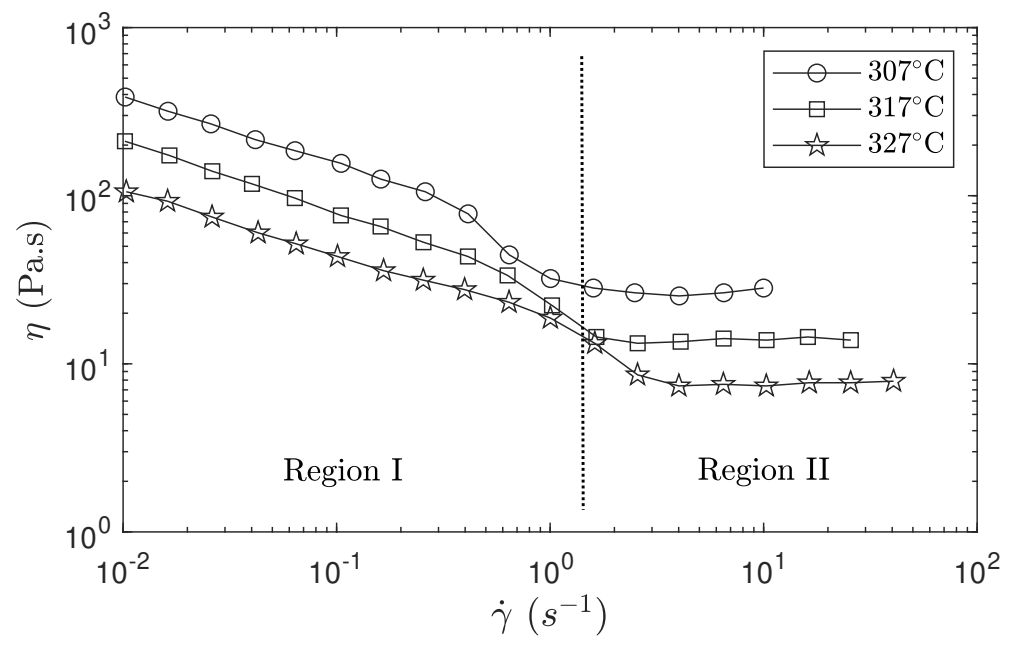

Figure 2.8: Flow curves from a commercial mesophase pitch at three distinct temperatures displaying the first two typical regions of liquid crystal systems. Adapted from (41).

Fleurot and Edie (44) observed that mesophase pitches exhibited large regions of uniform molecular alignment with no overall preferred orientation before being subjected to shear. This first report on the morphology of MPs suggested that they exhibited a polydomain structure at a static state. The decrease of the viscosity in region I (as in the left portion of figure 2.8) is a result of the stretching and deforming of domains. Eventually, the polydomain structure becomes fully deformed and the flow appears Newtonian (region II). Then, at region III, with high rates of shear, the polydomain structure transforms to a monodomain continuum, and molecular alignment occurs (36).

Figure 2.9a shows the morphology after a point shear stress has been given to two MP with different chemical structure and size of domains. The first pitch exhibits an orientated structure to the shear direction over the entire range of temperatures, which indicates that most of liquid crystalline domains are aligned. The second pitch develops fibrous orientation structure at temperatures above $350^{\circ} \mathrm{C}$ but some schlieren texture is still retained. As a consequence, the flow of the two fluids at $340^{\circ} \mathrm{C}$ have distinct behaviors (Figure 2.9b): even though they exhibit the three-regions type in the shear 
range studied, only the second pitch displays a clear viscosity plateau, reflecting the existence of deformed structure of polydomains (45).

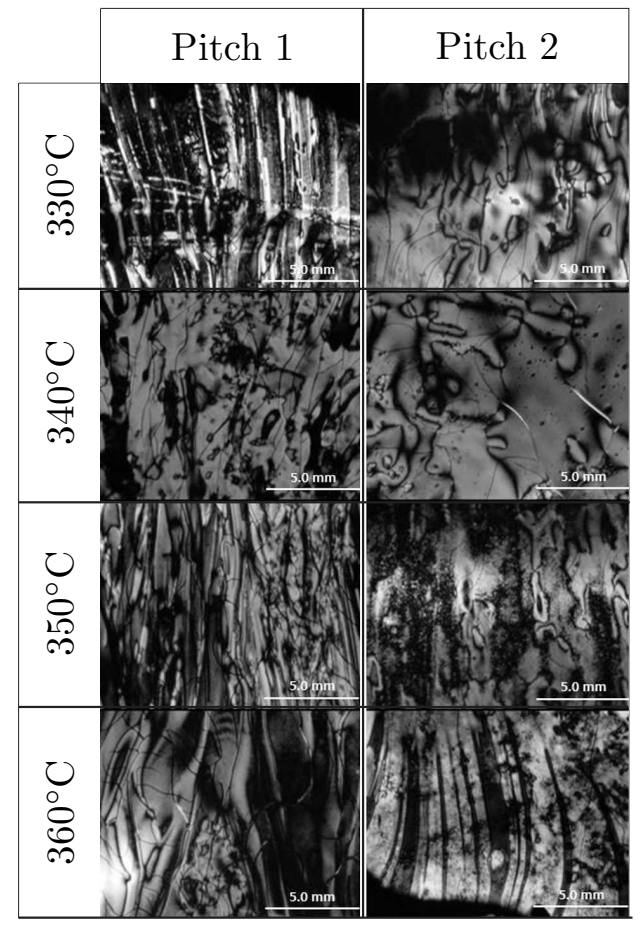

(a) Morphology

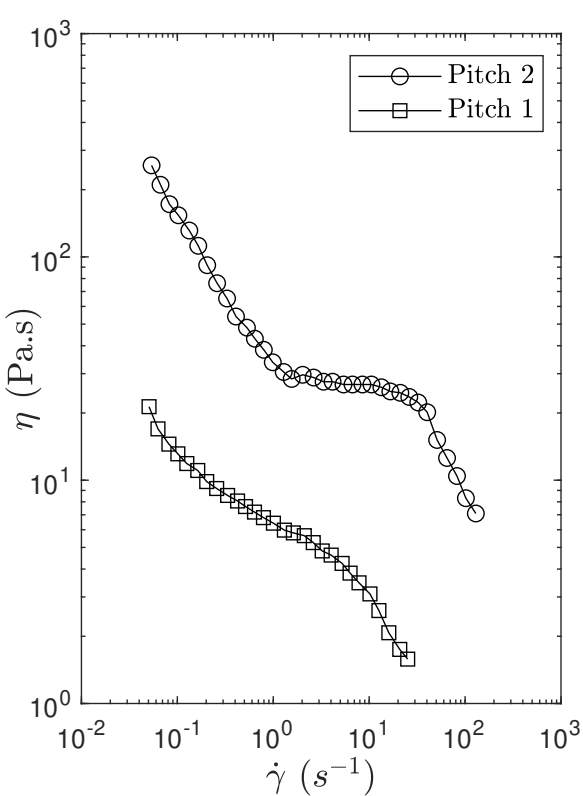

(b) Flow

Figure 2.9: Morphology and flow behaviour at $240^{\circ} \mathrm{C}$ for two different pitches. Adapted from (45).

If the velocity gradient of a flow is large enough, polymeric liquids behave nonlinearly. This occurs when the rate of molecular relaxation is taken over by the deformation rate due to flow. Since polymers are sluggish molecules, nonlinearities occur much more easily than for small molecules. For liquid crystals, there are some peculiar nonlinearities, the most striking of them being the behavior of the first normal stress difference, N1, in simple shear flow. For some LCPs, the first normal stress curve change sign. That behavior is due to the tumbling character of the polymeric nematic at low shear rates. The evidence of tumbling has been optically reported (41). The negative values of $\mathrm{N} 1$ are a manifestation of the rearrangement that takes place in the orientational distribution in the neighborhood of the transition from tumbling to flow aligning (46).

Dynamic oscillatory evaluation provides additional information to the flow behavior of mesophase pitches. If a sinusoidal stress is applied to a viscoelastic material, the in-phase, or storage modulus $\left(G^{\prime}\right)$ measures the portion of the oscillation energy that is stored elastically; while the out-ofphase, or loss modulus $\left(G^{\prime \prime}\right)$ represents the energy dissipated by the system. 
Generally, the viscous behavior of a MP is found to exponentially increase with frequency and to dominate at all frequency ranges. On the other hand, the amount of elastic storage depends on the domain size, the defects and on temperature. Consequently, divergences on the behavior of $G^{\prime}$ were reported for different pitches, as shown in Figure 2.10. $G^{\prime}$ increases in a relation similar to that $G^{\prime \prime}$ has with frequency at lower temperatures in the $100 \%$ anisotropic pitch. On the other hand, the storage modulus grows higher than exponentially in the lowest temperatures studied for the $95 \%$ mesophase by Turpin, Cheung and Rand (47).

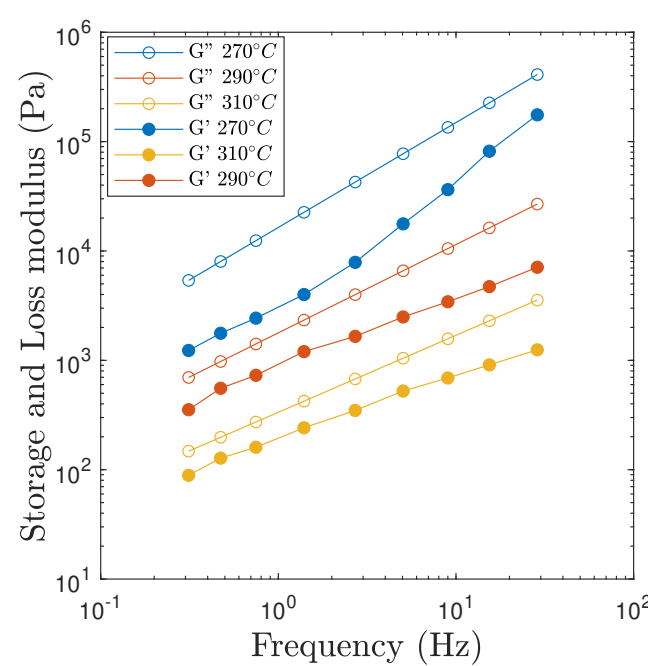

(a) $100 \%$ of anisotropy

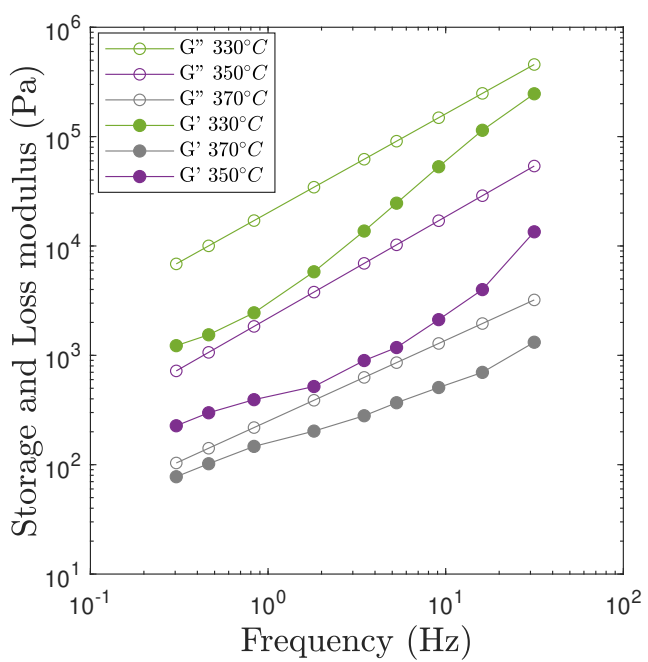

(b) $95 \%$ of anisotropy

Figure 2.10: Dynamic oscillatory tests at several temperatures for pitches with different mesophase content. Adapted from (47).

Different flow fields are encountered in melt spinning: the fluid is subjected to changing shear rates when passing from the screw pipe to the converging zone to the spinneret, while elongation occurs within the fibre formation zone until the melt stream solidifies to the final filament. Shear rates of the order of 1 to $10 \mathrm{~s}^{-1}$ are typical from pipe and converging flows. Within the capillary, wall shear rates range from 500 to $2000 s^{-1}$ (48). In this rate range, further domain deformation would be expected to be minimal, and molecular orientation should dominate the flow behavior (36). In a pure extensional flow, however, the stretching of the fluid causes stretching of the liquid crystalline domains and subsequent orientation of the molecules along the axis. Hence, extensional flows have been shown to be much more effective than shear flow in producing a high degree of molecular orientation (49).

While the shear rheology of mesophase pitch has been studied extensively, it can not be used for the evaluation of the melt strength, the drawability of 
the melt and neither to predict the orientation of the molecules. Due to the difficulty to measure the viscosity of liquid crystalline systems when subjected to extensional stresses accurately at the high temperatures needed to melt them, their elongational behavior has only become the target of very few studies (50).

Gotsis and Odrizola (50) reported the elongation of a commercial crystalline polymer generated in a capillary rheometer and Yu et al. (49) studied its flow behavior with a thread disintegration method. Both researches reported rate thinning behaviour for this type of fluid. Kernick and Wagner (51) studied the same polymer at extrusion and reported apparent elongational viscosity for various accumulated strains. Their results are reproduced in Figure 2.11.

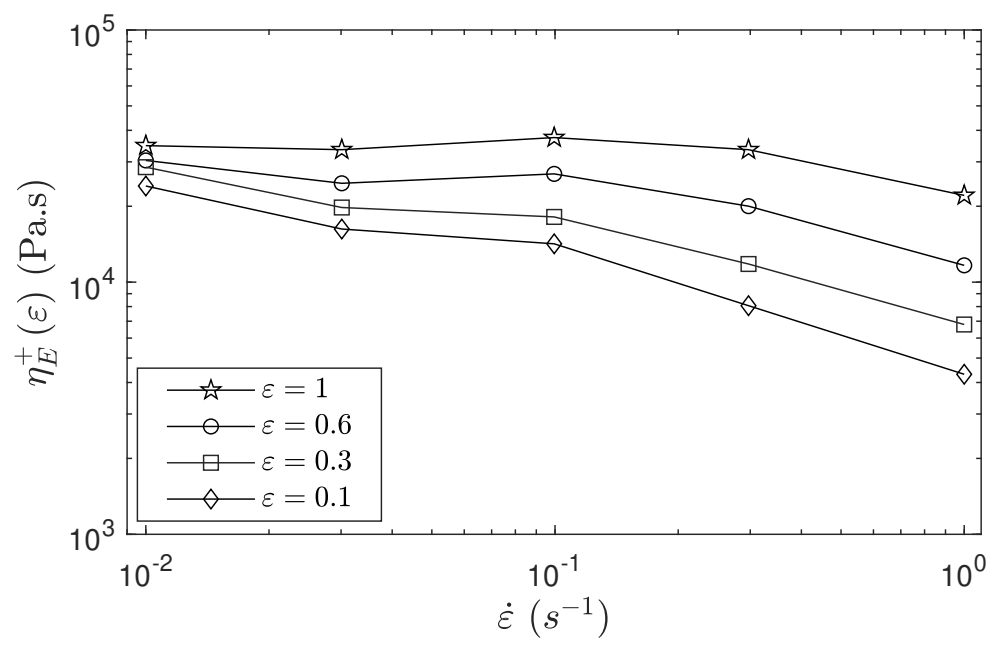

Figure 2.11: Transient elongational viscosity and strain rate taken as a function of applied strain for the commercial liquid crystalline polymer Vectra B950 at $240^{\circ} \mathrm{C}$. Adapted from (51).

\section{4}

\section{Fiber spinning}

On emerging from the die exit, stresses perpendicular to the direction of flow are relaxed, causing the extrudate a contraction in the flow direction and a growth in the normal direction, leading to an increase of diameter known as extrudate swell (region 1, figure 2.12). At the exit of the capillary holes (at distance $z=0$ ), the fluid is extruded with a given constant extrusion rate $Q$ and extrusion velocity $v_{0}$ at a constant extrusion temperature $T_{0}$. After swelling, the molten fluid accelerates in the axial direction, forming a thin filament (region 2, figure 2.12). The third region starts when the fluid temperature equals its softening point. At higher values of $\mathrm{z}$, the material is cooled to the point where it reaches the ambient temperature and the spool 
velocity. In that region, it behaves more like a solid and no further significant change in diameter occurs (52).

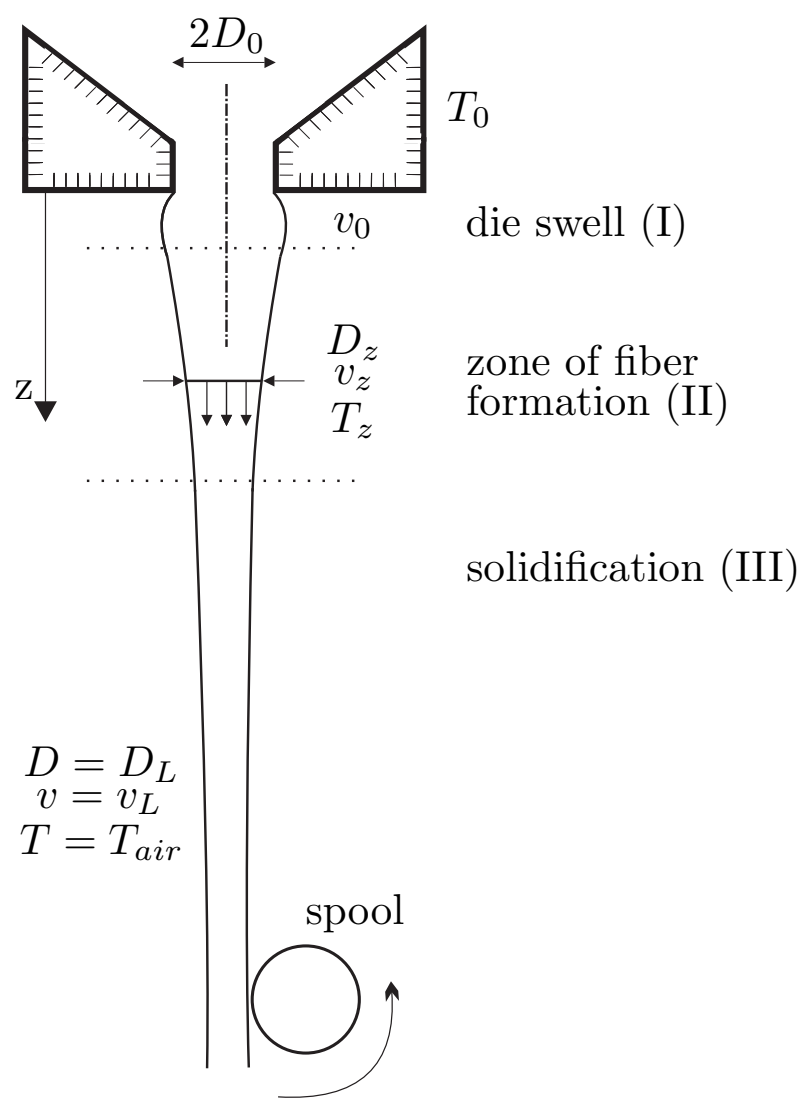

Figure 2.12: Single fiber formation.

The take-up device determines the final winding speed of the as-spun filaments. The ratio between the spinning velocity and the extrusion velocity at the spinneret exit defines the draw down ratio,

$$
D D R=\frac{v_{L}}{v_{0}} .
$$

The maximum possible draw down ratio is an important characteristic value for the spinnability of the fluid (24). The velocity, the diameter, the temperature, and the filament force depend upon the axial distance from the spinneret. Fiber's diameter is, in principle, a result of the fundamental physical balance equations and constitutive laws of mass, energy and momentum. The mass balance represents the continuity equation of the melt spinning process and is largely simplified because no mass exchange takes place between the filament and its environment. Additionally, it is often considered and absence of interaction of as-spun fibers in multi-filaments extrusion (24). The mass conservation formula connects the most important quantities, flow rate $Q$, 
filament cross sectional area $A_{z}$ (function of filament diameter), and the axial filament velocity,

$$
Q=A_{z} v_{z}=\frac{\pi D_{z}^{2}}{4} v_{z}
$$

The cooling of the filament is described by the energy balance. Considering a circular molten filament with uniform distribution of temperature on its cross section and neglecting the effects of radiation, the equation for heat exchange becomes

$$
v_{z} \frac{d T_{z}}{d z}=-\frac{2}{\rho c_{p}} \sqrt{\frac{\pi v_{z}}{Q}} h\left(T_{z}-T_{a i r}\right),
$$

where $\rho$ and $c_{p}$ are the density and the heat capacity of the material of the fluid, considered approximately constant during the solidification process; and $T_{a i r}$ is the surrounding air temperature. The coefficient of heat transfer $h$ and the air heat conductivity $k^{0}$ and is given by the formula developed by Kase and Matsuo (53),

$$
h=N u \frac{k^{0}}{D_{z}},
$$

with the empirical $\mathrm{Nu}$-Re relation for air (kinematic viscosity $v^{0}$ ) flowing parallel to a cylindrical body

$$
N u=0.42 \operatorname{Re}^{0.334}=0.42\left(\frac{v_{z} D_{z}}{v^{0}}\right)^{0.334}
$$

The total strength to which the fiber is subjected is a result of the extensional stress and the contributions of the inertial force, caused by acceleration of the material from $v_{0}$ to $v_{L}$; the gravitational force, represented by the filament weight; the air drag force; and the surface tension force. For high viscosity liquids, the correction terms can often be neglected (54), and the momentum equation can be analyzed by:

$$
\begin{gathered}
\rho Q \frac{d v_{z}}{d z}=\frac{d}{d z}\left[\frac{\pi D_{z}^{2}}{4}\left(\tau_{z z}-\tau_{r r}\right)\right], \text { where } \\
F=\int_{0}^{L} \rho Q \frac{d v_{z}}{d z} d z
\end{gathered}
$$

is the total force under which the filament is submitted during extrusion and $\tau_{z z}$ and $\tau_{r r}$ are the axial and radial components of the stress tensor, respectively. For uniaxial extension, the extensional viscosity is the difference between $\tau_{z z}$ and $\tau_{r r}$ divided by three times the extension rate $\dot{\varepsilon}(55)$.

For modelling the elongational flow, a suitable constitutive equation is necessary. It should describe the relation between stress and strain $\varepsilon$ of the fibre from the spinneret to the take-up device. For example, in a newtonian fluid, 


$$
\tau_{z z}-\tau_{r r}=3 \eta_{E} \dot{\varepsilon}=3 \eta_{E} \frac{d v_{z}}{d z}
$$

where the extensional viscosity $\eta_{E}$ is only a function of temperature.

Strengths of as-spun pitch fibers are at best only $50 \mathrm{MPa}$ (56). The tensile stress on a MP fiber during spinning ranges from $10 \%$ (10) to $30 \%$ its room temperature strength because of the fiber draw down stress required to reduce the diameter (56). If the tensile stress applied to the filament exceeds the tensile strength of the material somewhere between the spinneret and the spool, the filament will break due to cohesive fracture (10). Thus, there is a limit to the size of fiber that can be extruded without cracking.

\section{5}

\section{Impact of process variables on produced fiber}

The primary spinning variables are the winding speed, the precursor extrusion rate, the temperature of the precursor at extrusion, and the spinneret geometry. For a precursor to be spinnable, it must be able to form an unbroken filament between the spinnerette capillary exit and the wind-up device. Thus, for a given material there is normally an envelope of spinning conditions which permit the formation of an unbroken filament. However, the size of this region of spinnability depends on the process conditions and physical and rheological properties of the material being extruded into a filament (10).

Holding other variables constant, an increase in the extrusion velocity at the spinneret exit results in a decreased rate of draw down and lower axial velocity gradient. This velocity gradient diminished, will result in a larger fiber and a decreased tensile stress. Similarly, lower winder speeds yield lower DDR, thicker fibers and decreased tensile stress and therefore, reduce filament breakage (10). Figure 2.13 shows the effect of the DDR in the tensile stress in a melt spinning experiment performed in a comercial liquid crystalline polymer. 


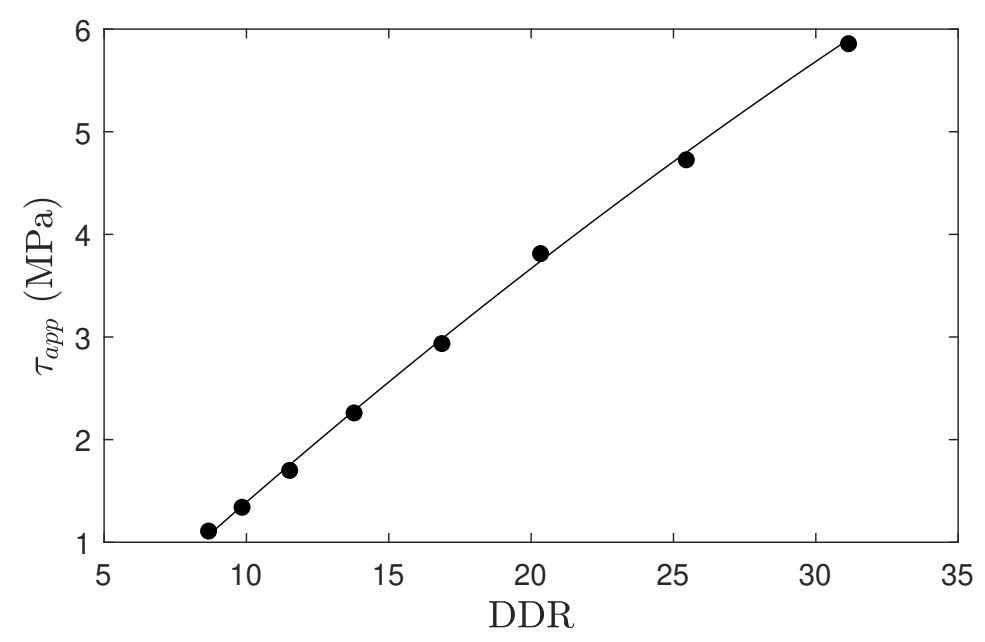

Figure 2.13: Extensional stress as a function of DDR for the liquid crystalline polymer Vectra $\mathrm{B} 950$ at $310^{\circ} \mathrm{C}$ and $\dot{\gamma}=2000 \mathrm{~s}^{-1}$. Adapted from (57).

Jiang et al. (12) employed DoE to observe the influence of simultaneous modification of process parameters in fiber's final diameter and degree of orientation. Higher spinning temperature, reduced winding speed and increased extrusion pressure were found to produce thicker carbon fibers with improved preferred orientation. This result is consistent with the thermodynamic disorder of mesophase pitch molecules theory explained by Diefendorf (56): a pitch fiber with a smaller diameter is cooled more rapidly during spinning, reducing the aligning time and resulting in a lower degree of preferred orientation.

Other authors have previously investigated the relation of fiber diameter and orientation with spinning conditions, but frequently, studying only one process variable at a time. Lu, Blanco and Rand (11) reported a gain in orientation by changing the draw down ratio to obtain larger fibers, but noted that diameters from $50 \mu \mathrm{m}$ upwards show little improvement in the preferred orientation of mesophase molecules along the fibre axis. Hamada et. al found a similar correlation between diameter and orientation but modifying spinning temperature. Figure 2.14 shows the relation between fiber diameter and the degree of orientation of the molecules with relation to pitch filaments axis for two different MP. 


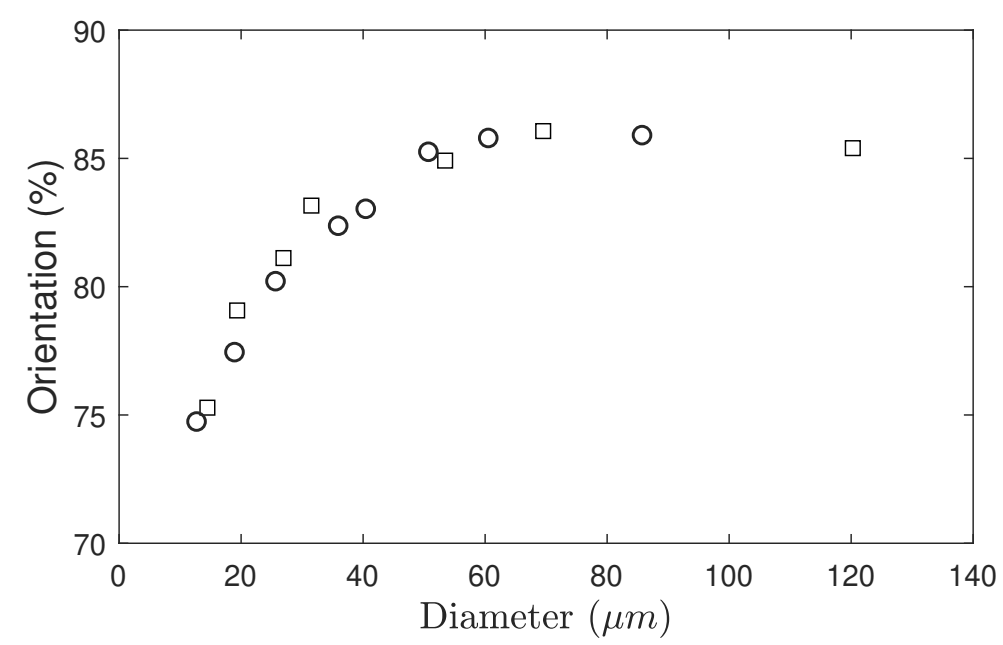

Figure 2.14: Pitch fiber orientation as a function of diameter produced varying spinning temperatures ( $\circ$, from (58)) and draw down ratios ( $\square$, from (11)).

The spinning temperature have a negligible effect on the fiber draw down and the axial velocity gradient; but, since increasing the spinning temperature decreases the elongational viscosity, the tensile stress whithin the filament during spinning can be greatly reduced with heating (10). However, if the melt temperature is too high, the extruding jet of material would form drops, instead of filaments. According to Mitsubishi's process (25), it is preferred to conduct spinning at temperature of at least $40^{\circ} \mathrm{C}$ above the softening point of a pitch, because a low spinning temperature would cause a rapid solidification of the extruded pitch and would shorten the time for molecular orientation (10). Yoon, Korai and Mochida reached an increase of 5 to $8 \%$ of preferred orientation on MP filaments using a rise in spinning temperature of 30 to 40 degrees above the softening point of the precursor (14).

Despite the fact that the thickness of the fiber improves the axis alignment of molecules, there is a limiting diameter at which the diffusion of oxygen, needed to form stabilized fibers, do not occur. Consequently, the diameters of round-shaped carbon fibers that can be achieved in commercial processes are restricted by the time-consuming stabilization process. Thus, it is of critical importance to strictly control the extrusion parameters to form filaments with a high degree of orientation but as thin as required for further processing. 


\section{3}

\section{Materials and Methods}

\section{1}

\section{Chemical properties of pitch}

The separation of the isotropic and anisotropic phases were performed at in a high temperature centrifuge to verify the mesophase content of the pitch. Pitch density $(\rho)$ was calculated in a gas Pycnometer Ultrapycnometer 1000 (Quantachrome) following ASTM D2320 (59). Pitch heat capacity $\left(c_{p}\right)$ was determined using the laser flash analysis method, where the bottom surface of a sample were heated by a laser pulse and the resulting temperature rise on the top surface of the sample were measured using an infrared detector. This characterization was performed at $30^{\circ} \mathrm{C}$ in a LFA 457 MicroFlash equipment (NETZSCH).

The study of the extractive ability of organic solvents with pitches is an usual way to identify the nature and composition of pitches. The most common solvents used are quinoline and toluene (7). The toluene insolubles (TI) components typically have a molecular weight range of $650-2000 \mathrm{~g} / \mathrm{mol}$. The quinoline insolubles (QI) are high molecular weight materials $>2000$ $\mathrm{g} /$ mol. QI are composed of primary components such as condensed aromatic hydrocarbons and secondary components like mesophase spheres. Calculation of insolubles contents (toluene - TI, quinoline - QI) followed ASTM D4072 (60) and D2318 (61), respectively.

During thermal treatment of petroleum pitch in an inert atmosphere, volatile matter is released as a result of distillation of smaller constituents and the thermal decomposition of the material. At temperatures above $500^{\circ} \mathrm{C}$, the remaining matter is mainly coke and weight loss is minimal (62). Therefore, the coking value is a useful quantity that indicates the relative coke-forming propensities, i. e., the lasting amount of carbon of the heat treated samples. The coking value of pitch was found through ASTM D2416 (63).

The chemical properties of the pitch used to produce carbon fibers are listed in Table 3.1.

Table 3.1: Pitch properties.

\begin{tabular}{ccccccc}
\hline \multirow{2}{*}{$\mathbf{c}_{\mathbf{p}}$} & \multicolumn{2}{c}{ Insolubles } & \multirow{2}{*}{$\mathbf{C V}$} & $\begin{array}{c}\text { Mesophase } \\
\text { Content }\end{array}$ & SP \\
\cline { 3 - 4 } & & TI & QI & & $90 \%$ & $297^{\circ} \mathrm{C}$ \\
\hline $1.36 \mathrm{~g} / \mathrm{cm}^{3}$ & $1290 \mathrm{~J} / \mathrm{K}$ & $75.5 \%$ & $70.6 \%$ & $83.4 \%$ & $90 \%$ & \\
\hline
\end{tabular}




\section{2}

\section{Shear flow experiments}

Rheological experiments were taken on a rotational rheometer MCR 302 (Anton Paar). It was used a parallel plate geometry with a diameter of $35 \mathrm{~mm}$ and a gap of $1 \mathrm{~mm}$ between the plates. In order to control the temperature of eletronic parts, a chiller was used. To reach higher temperatures without damaging the samples, a furnace was employed with a nitrogen atmosphere. All experiments were repeated at least three times for a given condition with fresh samples in the rheometer. A conditioning time of 30 minutes under inert atmosphere was provided, to ensure temperature stability.

The apparent viscosity as a function of temperature was measured at a shear rate of $1 \mathrm{~s}^{-1}$. The Arrhenius fit was performed at Origin 2019b (OriginLab, US). Its softening point (SP) was considered to be the temperature which the dynamic viscosity reaches 1000 Pa.s (47). Frequency sweep tests were used to obtain the loss $\left(G^{\prime}\right)$ and storage $\left(G^{\prime \prime}\right)$ modulus and complex viscosity in the linear viscoelastic region. Frequencies from 0,1 to $100 \mathrm{~Hz}$ and temperatures of $327,331,337,343$ and $347^{\circ} \mathrm{C}$ with a stress amplitude of $10 \mathrm{~Pa}$ were used in those tests. Flow curves were performed at rate-sweep experiments in the range of $0.1 \mathrm{~s}^{-1}$ to $100 \mathrm{~s}^{-1}$ at 331,337 and $343^{\circ} \mathrm{C}$.

\section{3}

\section{Design of experiments (DoE)}

Optimizing refers to improving the performance of a system, a process, or a product in order to obtain the maximum benefit from it. Traditionally, optimization has been carried out by monitoring the influence of one factor at a time on an experimental response, changing only one parameter, while keeping others at a constant level. The major disavantage of this optimization technique is that it does not include the interactive effects among the variables studied. As a consequence, it does not reflect the complete effects of the parameter on the response. Another disadvantage of the one-factor optimization is the increase in the number of experiments necessary to conduct the research, which leads to an increase of time and expenses as well as an increase in the consumption of reagents and materials (15).

In order to overcome the disavantages associated with the one variable-ata-time technique, the optimization of analytical procedures has recently been carried out by using multivariate statistic techniques. It consists of a collection of mathematical and statistical techniques based on the fit of a polynomial equation to the experimental data, with the objective of to simultaneously 
optimize the levels of several variables to attain the best system performance (15).

For a design of experiments, it is first necessary to choose a model that will define which experiments should be carried out in the region being studied (15). The simplest polynomial model contains only linear terms and describes only the linear relationship between the experimental variables and the responses (16). A linear model of three variables is:

$$
y=f\left(x_{1}, x_{2}, x_{3}\right)+e=a_{0}+a_{1} x_{1}+a_{2} x_{2}+a_{3} x_{3}+e,
$$

where $\mathrm{y}$ is the parameter to be modeled (or experimental response); $x_{1}, x_{2}$, and $x_{3}$ are the reduced independent factors (or variables), whose impact must be assessed; $a_{0}$ is a constant term; $a_{1}, a_{2}$, and $a_{3}$ are the coefficients associated to the linear contribution of each factor; and $e$ is the residual of the model, i.e., the difference between the calculated and the experimental result. The next level of polynomial models contains additional terms that describe the interaction between different experimental variables (16). Thus, an interaction model for three variables, known as full factorial design, may be written as

$$
y=a_{0}+a_{1} x_{1}+a_{2} x_{2}+a_{3} x_{3}+a_{12} x_{1} x_{2}+a_{13} x_{1} x_{3}+a_{23} x_{2} x_{3}+a_{123} x_{1} x_{2} x_{3}+e,
$$

where $a_{12}, a_{13}$ and $a_{23}$ are the coefficients of the interaction (or rectangular) terms between two factors and $a_{123}$ is the interaction between all factors.

In a multivariate approach, the influences of all experimental variables, factors, and interaction effects on the response are investigated. The levels of the factors are given by - (minus) for low level and + (plus) for high level. Therefore, $\mathrm{k}$ variables investigated at two levels form a set of $2^{k}$ experiments, as show in Table 3.2. Three or four center experiments, in which all variables are set at their mid value (zero-level), are frequently included in factorial designs in order to minimize the risk of missing non-linear relationships and to help determining confidence intervals (16).

In factorial designs all variables are normalized to vary between +1 and -1 . Since all variables used in the model are normalized in this way, the relative change of a variable is directly related to the modulus of its regression coefficient, except for the constant term which is the average value of the experiments on the center of the experimental domain. If the value of a coefficient is positive, that means that an increase of its related variable (or variables) promotes an expansion of the response, whereas a negative value has exactly the opposed effect (inhibition of the response). Null or very low values compared to other parameters indicate that the effect has no or insignificant influence on the process (17). 
Table 3.2: Full factorial design matrix of three variables at two levels, adapted from (16).

\begin{tabular}{cccc}
\hline \multirow{2}{*}{$\operatorname{Exp} \mathbf{n}^{\mathbf{0}}$} & \multicolumn{3}{c}{ Variables } \\
\cline { 2 - 4 } & $\mathbf{x}_{\mathbf{1}}$ & $\mathbf{x}_{\mathbf{2}}$ & $\mathbf{x}_{\mathbf{3}}$ \\
\hline 1 & - & - & - \\
2 & + & - & - \\
3 & - & + & - \\
4 & + & + & - \\
5 & - & - & + \\
6 & + & - & + \\
7 & - & + & + \\
8 & + & + & + \\
\hline
\end{tabular}

Full factorial designs can be used when the data set does not present curvature. However, to approximate a response function to experimental data that cannot be described by linear functions, experimental designs for response surfaces can be used, such as Box-Behnken, central composite, and Doehlert designs (15). The polynomial function

$$
\begin{array}{r}
y=a_{0}+a_{1} x_{1}+a_{2} x_{2}+a_{3} x_{3}+a_{11} x_{1}^{2}+a_{22} x_{2}^{2}+a_{33} x_{3}^{2}+a_{12} x_{1} x_{2}+ \\
a_{13} x_{1} x_{3}+a_{23} x_{2} x_{3}+e
\end{array}
$$

describes a quadratic model with interaction of second order for three variables. Coefficients associated to the quadratic contributions of variables $a_{11}, a_{22}$ and $a_{33}$ are included, whilst coefficients associated to third or higher order interactions are neglected.

A central composite design is a quadractic model that consists of a complete or a fraction of a full factorial design and an axial portion containing $2 \mathrm{k}$ points located on the axis of each control variable at a distance of $\alpha$ from the center of the experimental region. This design is developed in a manner consistent with the sequential nature of a response surface investigation in starting with a first-order design, followed by the addition of design points to fit the larger second-degree model. The first-order design serves in a preliminary phase to get initial information about the response system and to assess the importance of the factors in a given experiment. The additional experimental runs are chosen for the purpose of getting more information that can lead to the determination of optimum operating conditions (64). A two factors scheme of these points is represented in Figure 3.1. 


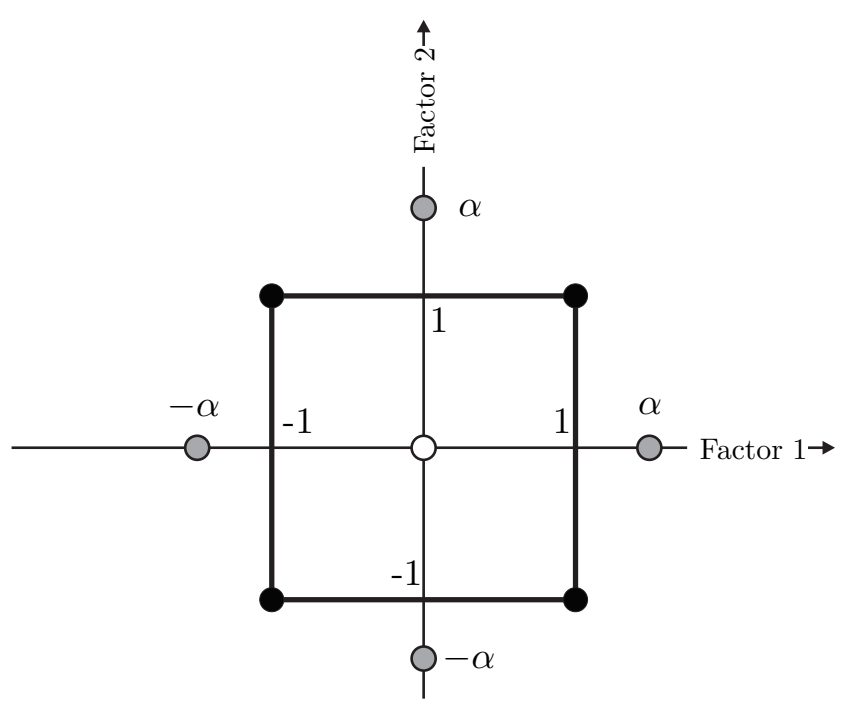

Figure 3.1: Composite design of two factors. Adapted from (65).

The values of $\alpha$ and the number of center-point replications, are chosen so that the composite design can acquire certain desirable properties. For example, choosing $\alpha=2^{k} / 4$, where $2^{k}$ is the number of experiments in the full factorial portion, causes a rotability effect in the design. A rotatable model has a constant variance at all points that fall on the surface of a hypersphere centered at the origin. The advantage of this property is that the prediction variance remains unchanged under any rotation of the coordinate axes. The number of replications in the center of the studied region can be chosen to enable the near-orthogonality property (64). The advantage of coupling the rotability with this condition is that the predicted variance of the experiments inside the factorial portion remains fairly unchanged and the variance outside the factorial range increases smoothly with the radial distance from the center of the experimental domain.

One of the main objectives of a DoE is the determination of the optimum settings of the control variables that result in a maximum or a minimum response over a certain region of interest. This requires having a good fitting model that provides an adequate representation of the experiment (64). The more reliable way to evaluate the quality of the model fitted is by the application of analysis of variance (ANOVA)(15).

The central idea of ANOVA is to compare the variation due to the treatment (change in the combination of variable levels) with the variation due to random errors inherent to the measurements of the generated responses. The parameters used in this evaluation are the deviation that each observation present in relation to the media and also the deviation between the observed 
parameter and the theoretical result from the model. From this comparison, it is possible to evaluate the significance of the regression used to predict future experimental responses (15).

The sum of the square for all observation deviations in relation to the media is called the total sum of the squares, $\sum(y-\bar{y})^{2}$. It can be dismembered in the sum of the square due to the fitted mathematical model, that is, due to regression, and in the sum of the square due to residuals generated by the model, $\sum e^{2}$. When the division of the sum of the square for each source of variation is made by its respective numbers of degrees of freedom, the "mean square" are obtained. The significance of regression can be evaluated by the ratio between the mean square of regression and the mean square of residuals and by comparing these variation sources using the Fisher distribution (15) and the parameter p-value, that measures the probability that an event is rare and therefore determines the significance of the result. This ratio allows the calculation of the probability that the two mean squares are not equal. In other words, if the F-ratio is high (small probability that the model is only due to the effect of the mean), the variations of the observed responses are likely due to variations in the factors. If the F-ratio is low (strong probability that the model is not due to the effects), the variations of the observed responses are comparable to those of the residuals (65). Table 3.3 shows how the statistical parameters are calculated for ANOVA.

Table 3.3: Calculation of parameters in ANOVA.

\begin{tabular}{ccccc}
\hline Source & $\begin{array}{c}\text { Degree } \\
\text { of } \\
\text { freedom }\end{array}$ & $\begin{array}{c}\text { Sum } \\
\text { of } \\
\text { squares }\end{array}$ & $\begin{array}{c}\text { Mean } \\
\text { Square }\end{array}$ & F-ratio \\
\hline Model & $\mathrm{p}-1$ & $\sum(y-\bar{y})^{2}-\sum e^{2}$ & $\frac{\sum(y-\bar{y})^{2}-\sum e^{2}}{p-1}$ & $\left(\frac{\sum(y-\bar{y})^{2}}{\sum e^{2}}-1\right)\left(\frac{n-p}{p-1}\right)$ \\
Error & $\mathrm{n}-\mathrm{p}$ & $\sum e^{2}$ & $\frac{\sum e^{2}}{n-p}$ & $\begin{array}{c}\text { p-value } \\
\text { prob } \geqslant \text { F-ratio }\end{array}$ \\
Total & $\mathrm{n}-1$ & $\sum(y-\bar{y})^{2}$ & - & \\
\hline
\end{tabular}

The analysis of variance allows the calculation of a very useful statistic: $\mathrm{R}$-squared $\left(R^{2}\right)$. This statistic is the ratio of the sum of squares of the predicted responses (corrected for the mean) to the total sum of squares:

$$
R^{2}=1-\frac{\sum e^{2}}{\sum(y-\bar{y})^{2}}
$$

R-squared plays the role of indicating the quality of a linear model, provided that there are more experimental points than coefficients in the postulated model, i.e. residuals (e) are not zero (65). Adjusted R-squared $\left(R_{a d j}^{2}\right)$ regulate this parameter for the number of terms in the model, 


$$
R_{a d j}^{2}=1-\left(1-R^{2}\right) \frac{n}{n-p},
$$

where $n$ is the number of experiments and $p$ the number of coefficients in the model. Hence, $R_{a d j}^{2}$ is used to compare the fitting in regression models that contain differing numbers of independent variables. Thus, a good fit would exhibit low model p-value, high lack of fit p-value, and high $\mathrm{R}$-squared values (65).

\subsection{1}

\section{Design of Experiments in Fiber Extrusion}

A laboratory-scale spinning apparatus which consisted of a modular torque rheometer (Haake Polylab OS) adapted with a spin pack containing a twelve-holes spinneret $\left(D_{0}=0.02 \mathrm{~mm}\right)$ was used in the fiber spinning experiments (Figure 3.2). Pitch was placed in a filler that dropped the raw material into the heating chamber that held a screw. The continuous drop of the melt in the spin pack was due to the motion of the rotating screw. The emerging extrudate was drawn by a take-up spool of $10 \mathrm{~cm}$ in diameter placed $70 \mathrm{~cm}$ below the spin pack. The collecting time of the fibers was only enough to provide sufficient samples for characterization, about 3 minutes for each condition. The spinneret geometry and the spinline length were kept fixed during the tests.

The strategy used in the optimization was based on a response surface investigation starting with a full factorial design using three and nine centre experiments in order to search for non-linear relationships and to help determining confidence intervals, followed by the addition of design points to fit the larger second-degree model, chosen as a rotable central composite design with near orthogonality property, using nine repetitions at the center of the experimental domain and $\alpha=-1.682$. The impact of screw velocity $\left(X_{1}\right)$, spinning temperature $\left(X_{2}\right)$, and winding speed $\left(X_{3}\right)$ in diameter of fibers $(\mathrm{y})$ was assessed. The values of the independent investigated factors were chosen to represent realistic extrusion conditions:

- Screw Velocity $\left(X_{1}\right)$ : Chosen close to the equipment inferior limit in order to achieve higher draw down ratios.

- Spinning Temperature $\left(X_{2}\right)$ : The center of the domain was chosen based on literature(25), while inferior limit was set based on dynamic viscosity test.

- Winding Speed $\left(X_{3}\right)$ : Chosen within equipment capacity to be closer to a conventional pilot plant line speed. 


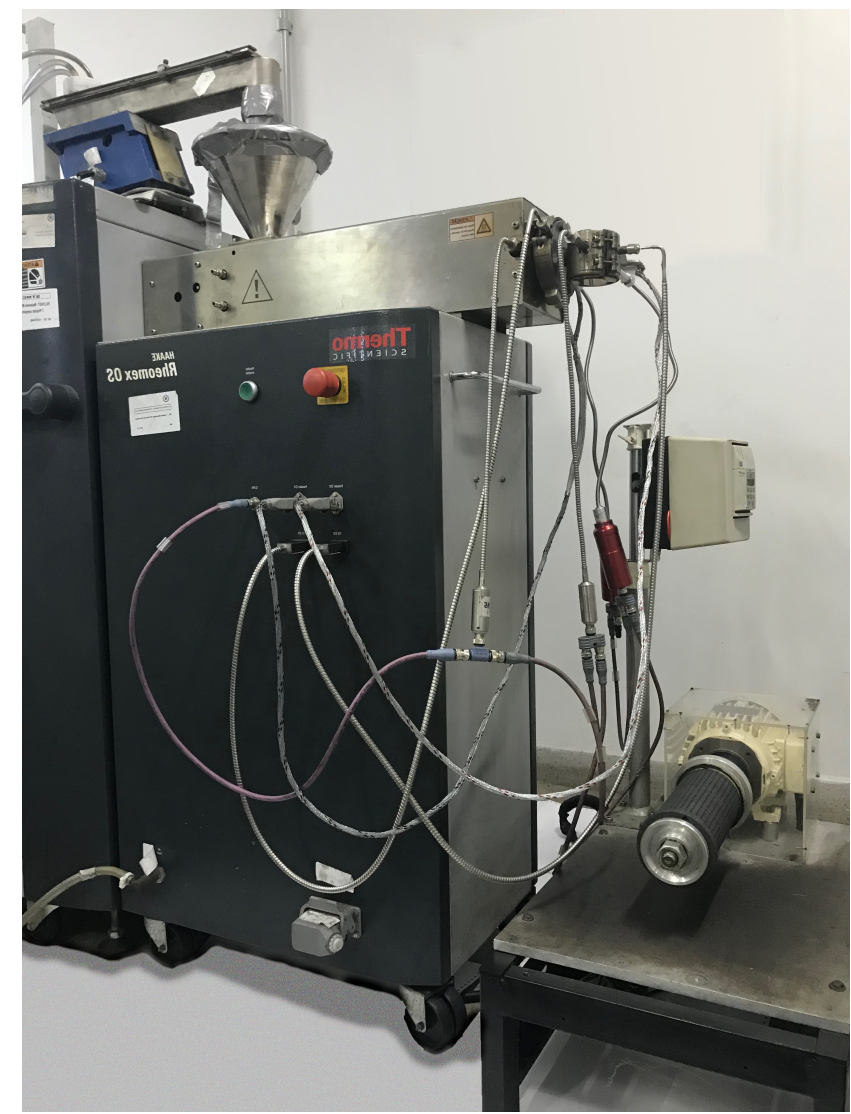

Figure 3.2: Fiber extrusion apparatus.

The levels of the factors and the correspondent conditions are listed in Table 3.4 .

Table 3.4: Assignment of levels to the factors.

\begin{tabular}{cccc}
\hline Level & $\begin{array}{c}\left(\mathrm{X}_{\mathbf{1}}\right) \text { Screw } \\
\text { velocity } \\
(\mathbf{r p m})\end{array}$ & $\begin{array}{c}\left(\mathrm{X}_{\mathbf{2}}\right) \text { Spinning } \\
\text { temperature } \\
\left({ }^{\circ} \mathbf{C}\right)\end{array}$ & $\begin{array}{c}\left(\mathrm{X}_{\mathbf{3}}\right) \text { Winding } \\
\text { speed } \\
(\mathbf{r p m})\end{array}$ \\
\hline$-\alpha=-1.682$ & 0.3 & 327 & 70 \\
-1 & 1 & 331 & 96.4 \\
0 & 2 & 337 & 135 \\
1 & 3 & 343 & 173.6 \\
$\alpha=1.682$ & 3.7 & 347 & 200 \\
\hline
\end{tabular}

All variables are normalized to vary between $+\alpha$ and $-\alpha$. Each real variable $X_{i}$ was transformed into a reduced (or normalized) variable $x_{i}$ through

$$
x_{i}=\frac{X_{i}-X_{i}^{0}}{\Delta X_{i}} .
$$

$\Delta X_{i}$ is half of the interval between the limit values of the real variables and $X_{i}^{0}$ is the value of the real factor when $X_{i}=0$ (center of the experimental region). To investigate the role of the selected spinning variables on the diameter of the filaments, 15 different process conditions were tested, as shown in table 
3.5. Experiments 1 to 8 and 15 to 17 were used in factorial design with three repetitions on the center of the experimental domain (FF3). Experiments 1 to 8 and 15 to 23 were used in factorial design with nine repetitions on the center of the experimental domain (FF9). Central composite (CC) design required all experiments from 1 to 23.

Table 3.5: Experiment Design.

\begin{tabular}{cccc}
\hline Exp. $\mathbf{n}^{\mathbf{0}}$ & $\begin{array}{c}\left(\mathbf{x}_{\mathbf{1}}\right) \text { Reduced } \\
\text { screw } \\
\text { velocity }\end{array}$ & $\begin{array}{c}\left(\mathbf{x}_{\mathbf{2}}\right) \text { Reduced } \\
\text { spinning } \\
\text { temperature }\end{array}$ & $\begin{array}{c}\left(\mathbf{x}_{\mathbf{3}}\right) \text { Reduced } \\
\text { winding } \\
\text { speed }\end{array}$ \\
\hline 1 & -1 & -1 & -1 \\
2 & 1 & -1 & -1 \\
3 & -1 & 1 & -1 \\
4 & 1 & 1 & -1 \\
5 & -1 & -1 & 1 \\
6 & 1 & -1 & 1 \\
7 & -1 & 1 & 1 \\
8 & 1 & 1 & 1 \\
9 & -1.682 & 0 & 0 \\
10 & 1.682 & 0 & 0 \\
11 & 0 & -1.682 & 0 \\
12 & 0 & 1.682 & 0 \\
13 & 0 & 0 & -1.682 \\
14 & 0 & 0 & 1.682 \\
$15-23(9 \mathrm{x})$ & 0 & 0 & 0 \\
\hline
\end{tabular}

These three models were compared in terms of R-squared and R-squared adjusted to the degree of freedom. The results were also analysed by: estimating the standardized effects of the factors using Fisher distribution; implementing the analysis of variance (ANOVA); and comparing predicted values to experimental measures. The Design-Expert software, version 9.0.6 (Stat-Easy Inc) and Matlab (Mathworks) were used for calculus and statistical plots.

\section{4}

\section{Green fibers characterization}

\subsection{1}

\section{Diameter}

Fibers from all experiments were observed in a scanning electron microscope EVO MA 10 (ZEISS), in order to determine its average diameter. For each fiber batch, it was used 20 results to calculate the mean and deviation of diameters. 


\subsection{2 \\ Orientation}

The orientation of the graphene planes of the fibers was measured in a XRD-7000 diffractometer (Shimadzu) with $\mathrm{CuK} \alpha$ radiation (wavelength: 1.5418 A) by performing an azimuthal scan at a fixed Bragg position. The displacement $2 \theta$ of $26.5^{\circ} \mathrm{C}$ - a theoretical value expected for graphite structure (66) - was searched with translational freedom at a scan rate of $10^{\circ} / \mathrm{min}$ at a power of $40 \mathrm{kV}$ and $40 \mathrm{~mA}$. For each batch from experiments 1 to 14 and for the center of the experimental domain, here taken as a sample from experiment 15, three measurements were performed using 20 aligned fibers with lengths of 8 mm. X-ray diffraction patterns were analyzed using Origin 2019b (OriginLab, US) to perform gaussian fits on the experiments. The degree of orientation was calculated as a function of the displacement angle from fiber axis, used as the full width at half maximum (FWHM) of the obtained peaks: $\frac{180^{\circ}-F W H M}{180^{\circ}}(32)$.

\subsection{3}

\section{Mechanical strength}

The fiber strength analysis system is comprised of a LDS0200 laser scan micrometer, LEX 810 tensile tester, and is controlled by UV-Win software (Dia-stron, UK). Fibers were pre-mounted with a length of $4 \mathrm{~mm}$, and the fiber diameter was automatically measured in the equipment using laser diffraction. After measuring the diameter, the LEX 810 tensile tester stretches the fiber at a rate of $0.1 \mathrm{~mm} / \mathrm{s}$, with an initial load of $0.2 \mathrm{gmf}$ and set at a maximum force of $200 \mathrm{gmf}$. Calculated results of tensile strength are reported based on the minimum cross-sectional area which is the most likely break-point for the sample. For each fiber batch, 10 tensile results were used in the calculation.

\section{5}

\section{Extensional viscosity}

The material functions were calculated through the use of winding speed and fiber diameter as a basis for calculations of flow rate $\mathrm{Q}(54)$ :

$$
Q=\frac{\pi D_{L}^{2}}{4} \pi D_{s} \omega=\frac{\pi D_{0}^{2}}{4} v_{0}
$$

where $D_{L}$ is the fiber diameter, $D_{s}$ the spool diameter, $\omega$ the winding speed, $D_{0}$ and $v_{0}$ are, respectively, the diameter and average extrusion velocity at the spinneret exit.

The total stress at spinline was estimated by considering a constant tensile force and using an interaction routine with a steady-state newtonian approach to simultaneously solve the energy, momentum and continuity balance 
equations. Correlations 2-1, 2-5, 2-6, 2-8 and 2-9 are applied in equations 2-4 and 2-7, which become, respectively

$$
\frac{d T_{z}}{d z}=-\frac{0.42 k^{0}}{\rho c_{p}}\left(\frac{2}{v^{0}}\right)^{0.334}\left(\frac{\pi}{Q}\right)^{0.833}\left(T_{z}-T_{a i r}\right) v_{z}^{0.167},
$$

and

$$
\frac{d v_{z}}{d z}=\frac{F v_{z}}{3 Q \mu_{r} \exp \left[\frac{E_{a}}{R}\left(\frac{1}{T_{z}}-\frac{1}{T_{r}}\right)\right]} .
$$

Pitch density and heat capacity are considered not to vary along the fiber formation process. The boundary conditions depend on the experiment variables. The code shown in Appendix B solves the extension for experiment 3. The initial guess was $30 \%$ of the force measured in tensile experiments. If the predicted velocity at the spool is not equal to the winding speed, the assumed force is corrected.

From the estimated force and calculated velocity and velocity derivative at several axial distances, the extensional viscosity was plotted as a function of extension rate,

$$
\eta_{E, z}=\frac{F}{A_{z} \dot{\varepsilon}_{z}}=\frac{F v_{z}}{Q}\left(\frac{1}{d v_{z / d z}}\right) .
$$

A characteristic apparent uniaxial extensional viscosity for each experiment was calculated as (54)

$$
\eta_{E, a p}=\frac{F L}{Q} .
$$

The flow rate along with the spinneret geometry and the distance between spinneret and spool, $L$, were used to find an apparent rate of extension for the process (54),

$$
\dot{\varepsilon}_{a p}=\frac{4 Q}{\pi L}\left(\frac{1}{D_{L}^{2}}-\frac{1}{D_{0}^{2}}\right) .
$$

The melt strength and drawability of the pitch were estimated by plotting the extensional stress, taken as $\eta_{E, a p} \dot{\varepsilon}_{a p}$, as a function of the draw down ratio at different temperatures.

\section{6}

\section{Stabilization and carbonization of fibers}

Fibers from experiments 1 to 8 and from central domain were all stabilized and carbonized in the same conditions. Each fiber batch, of approximated length of $15 \mathrm{~cm}$, was suspended and held by its ends on a graphite support in order to allow oxygen diffusion in all directions. The graphite plate was inserted in a ceramic tube furnace (Nabertherm), and heated at a constant rate of $5^{\circ} \mathrm{C} / \mathrm{min}$ from $25^{\circ} \mathrm{C}$ to $250^{\circ} \mathrm{C}$ in a synthetic air atmosphere with a gas flow of $100 \mathrm{l} / \mathrm{h}$. The as-spun fibers were submitted for 3 hours to the stabilization temperature of $250^{\circ} \mathrm{C}$, which was below the softening point of the mesophase 
pitch. Despite having a slightly higher softening point than the precursor pitch, due to volatilisation in spinning, this stabilization temperature was chosen to avoid loss of dimensional stability. After the stabilization, the fibers were left to cool down to room temperature. A sample of each set of fibers that passed through the stabilization process was carbonized in the same furnace under an inert nitrogen atmosphere, with a gas flow of $100 \mathrm{l} / \mathrm{h}$, by heating at a rate of 1 ${ }^{\circ} \mathrm{C} / \mathrm{min}$ from $25^{\circ} \mathrm{C}$ to $1200^{\circ} \mathrm{C}$. No step time was used in the carbonization, i.e., after reaching $1200^{\circ} \mathrm{C}$, the heating resistor was shut down. During the cooling process, the nitrogen gas flow was interrupted at $150^{\circ} \mathrm{C}$ because no undesirable reaction takes place below that temperature.

\section{7}

\section{Carbon fibers characterization}

The produced carbon fibers had their morphology and microstructure qualitatively investigated in a scanning electron microscope FEG SUPRA 40 (ZEISS). Tensile testing of fibers was carried out at LEX 810 (Dia-stron), as described in section 3.5, with a length of $4 \mathrm{~mm}$, rate of stretching of $0.1 \mathrm{~mm} / \mathrm{s}$, and initial load of $2 \mathrm{gmf}$. 


\section{Results}

\section{1}

\section{Shear flow}

Figure 4.1 is a plot of viscosity in terms of the inverse temperature at a shear rate of $1 s^{-1}$. The found activation energy of $267 \mathrm{kJ.mol}^{-1}$ is

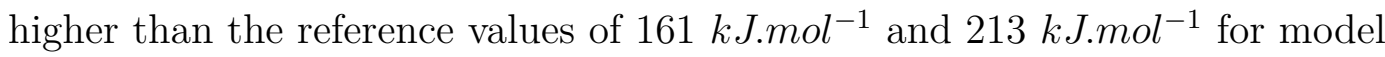
isotropic and model anisotropic (100\% mesophase content) naphtalene-derived pitches, respectively (37). The softening point (SP) was considered to be the temperature at which the dynamic viscosity reaches 1000 Pa.s (47), around $297^{\circ} \mathrm{C}$.

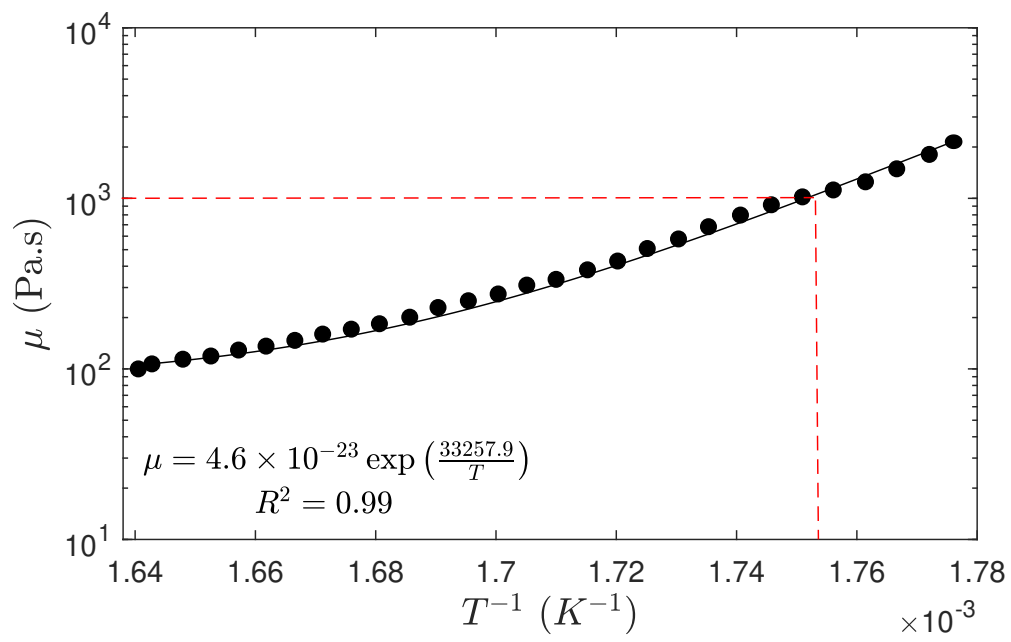

Figure 4.1: Viscosity as a function of temperature.

Figure 4.2 displays storage $\left(G^{\prime}\right)$ and loss $\left(G^{\prime \prime}\right)$ modulus as a function of frequency at (a) 327,331 and $337^{\circ} \mathrm{C}$; (b) 343 and $347^{\circ} \mathrm{C}$. The plots show that $G^{\prime \prime}$ is higher than $G^{\prime}$ over the entire frequency range, i.e., there is no crossover between those functions. Therefore, viscous stresses dominate over elastic stresses. At a given frequency, the values of $G^{\prime}$ and $G^{\prime \prime}$ are higher at lower temperatures. For a given temperature, an increase of $G^{\prime \prime}$ was observed with increasing frequency. $G^{\prime}$ also grows with frequency, displaying higher slopes at lower values of frequencies. This tendency is more evident at 343 and $347^{\circ} \mathrm{C}$, which at higher frequency appear to develop a rubber-like plateau. A similar behaviour was found by Kundu and Ogale (67). As the rate of growth of $G^{\prime}$ diminishes in comparison with that from $G^{\prime \prime}$, values of the loss angle $\left(\delta=\frac{G^{\prime \prime}}{G^{\prime}}\right)$ 
approaches $\pi / 2$. From this flatening profile of $G^{\prime}$, it is possible to infer that a viscous behaviour is stronger at higher frequencies in higher temperatures.

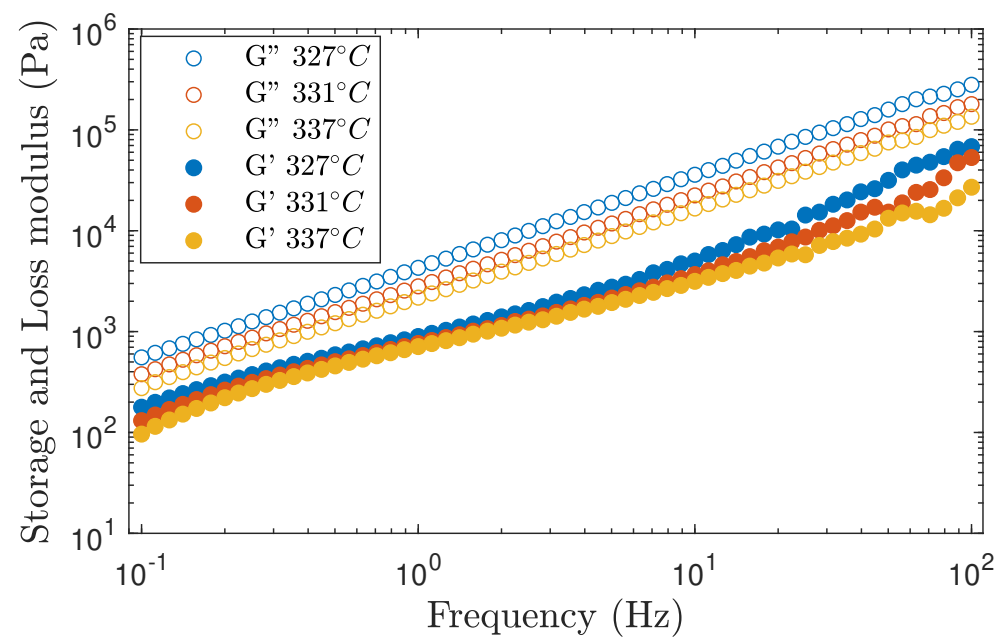

(a) $327^{\circ} \mathrm{C}, 331^{\circ} \mathrm{C}$ and $337^{\circ} \mathrm{C}$

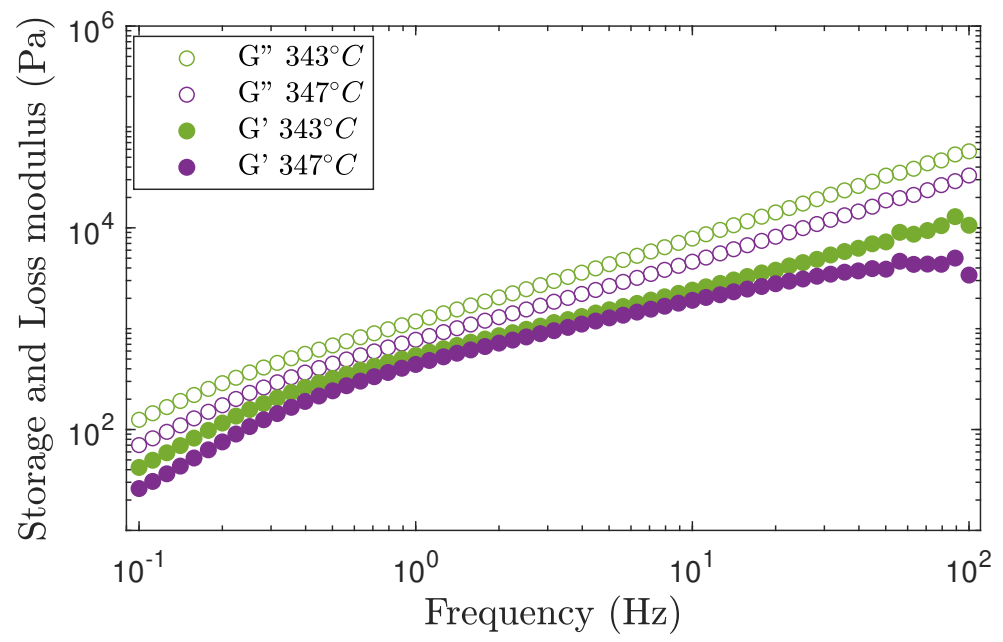

(b) $343^{\circ} \mathrm{C}$ and $347^{\circ} \mathrm{C}$

Figure 4.2: Loss $\left(G^{\prime \prime}\right)$ and storage $\left(G^{\prime}\right)$ modulus at processing temperatures.

Steady shear viscosities are displayed in figure 4.3. The three region flow curve is observed at all temperatures. The viscosity in Region I was found to vary with shear rate to the power exponent between -0.4 and -0.5 . $\eta=585.9 \dot{\gamma}^{-0.45}$, at $331^{\circ} \mathrm{C} ; \eta=211.0 \dot{\gamma}^{-0.43}$ at $337^{\circ} \mathrm{C}$. And at $343{ }^{\circ} \mathrm{C}$ the relation $\eta=105.9 \dot{\gamma}^{-0.42}$ is observed. The -0.5 exponent is expected in the first region if domains deform under shear flow without any coalescence or breakup. Some authors also reported a deviation from the theoretical -0.5 exponent $(48,68)$. In region II the polydomain structures are fully deformed and shear viscosity remains relatively constant. Shear-thinning is again present in region III, meaning that molecular orientation increases at higher rates of shear (41). 


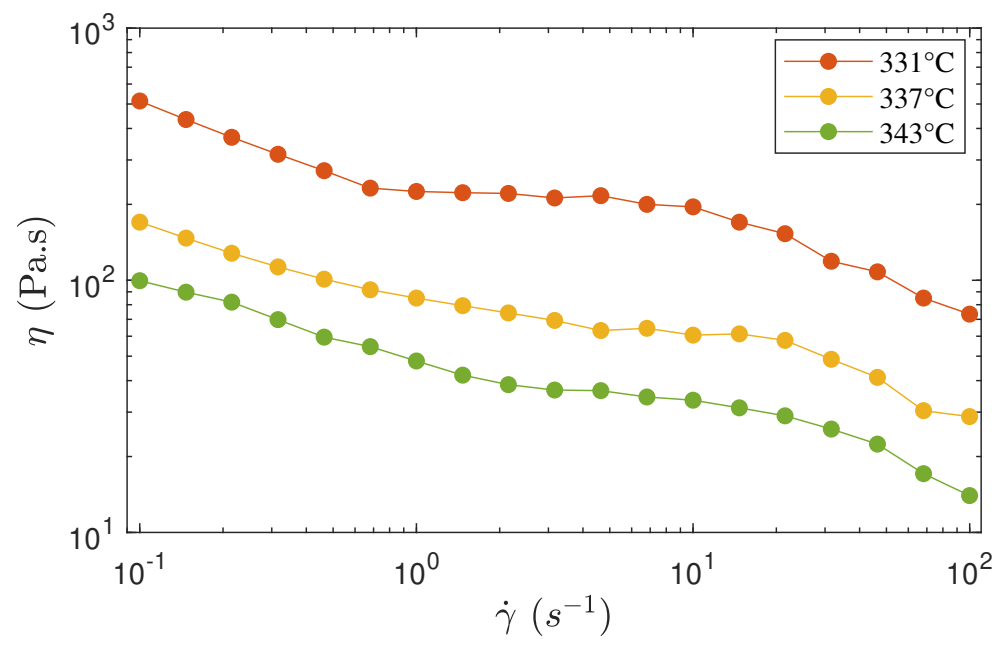

Figure 4.3: Viscosity as a function of shear rate at 331,337 and $343^{\circ} \mathrm{C}$.

This three region regime is more pronounced at lower temperatures. The transition between the first shear thinning region and the newtonian plateau occurs at, approximately, $1 \mathrm{~s}^{-1}$ for $331^{\circ} \mathrm{C}$. The clear plateau at $331^{\circ} \mathrm{C}$ indicates that some of the polydomains are retained. On the other hand, at $343^{\circ} \mathrm{C}$ the transitions are so smooth that is hard to distinguish region I from region III. That indicates that at higher temperatures, most of liquid crystalline domains are aligned.

The primary normal stress difference $(N 1)$ was also measured during the rate-sweep experiments and the results are displayed in figure 4.4. For all temperatures, the magnitude of $N 1$ was negative at small shear rates. Similar observations were found for other mesophase pitches (41) and also melts composed of graphene sheets (69).

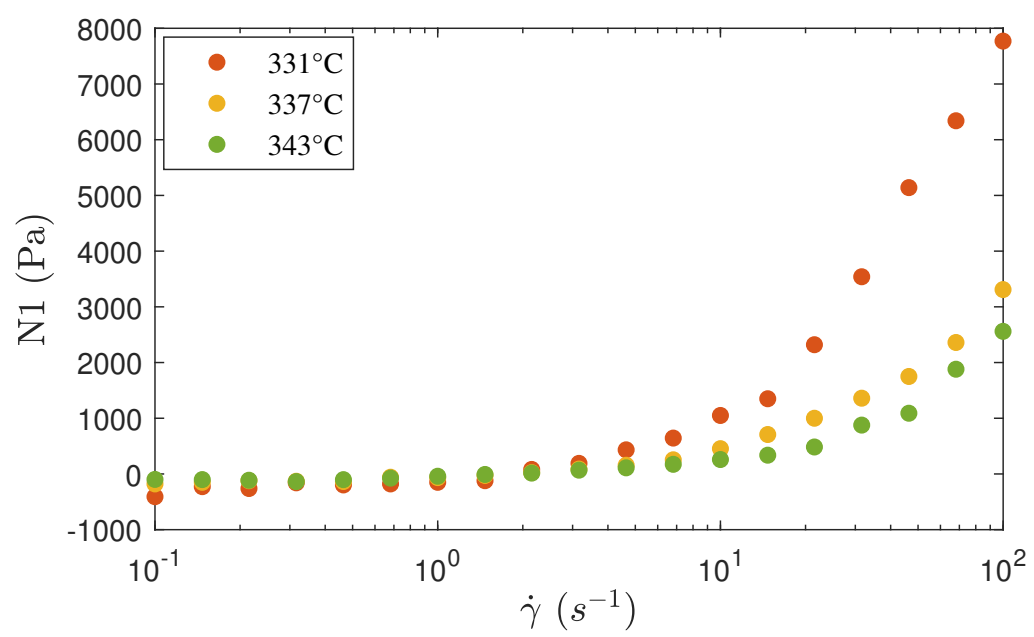

Figure 4.4: First normal stress difference as a function of shear rate at 331, 337 and $343^{\circ} \mathrm{C}$. 


\section{2}

\section{Pitch fiber diameter investigation}

The experimental data of the response (diameter) based on the independent normalized variables for full factorial and center composite designs are presented in table 4.1. For each experimental condition, average value and standard deviation were calculated for all models. The diameters of the carbon fibers were obtained in the range of 20 to $100 \mu \mathrm{m}$. The relative error within each run was between $3 \%$ and $9 \%$, indicating that the experiments are well controlled and that stable spinning was achieved, providing results with high repeatability.

Table 4.1: Reduced variables, experimental and predicted diameter for the models used.

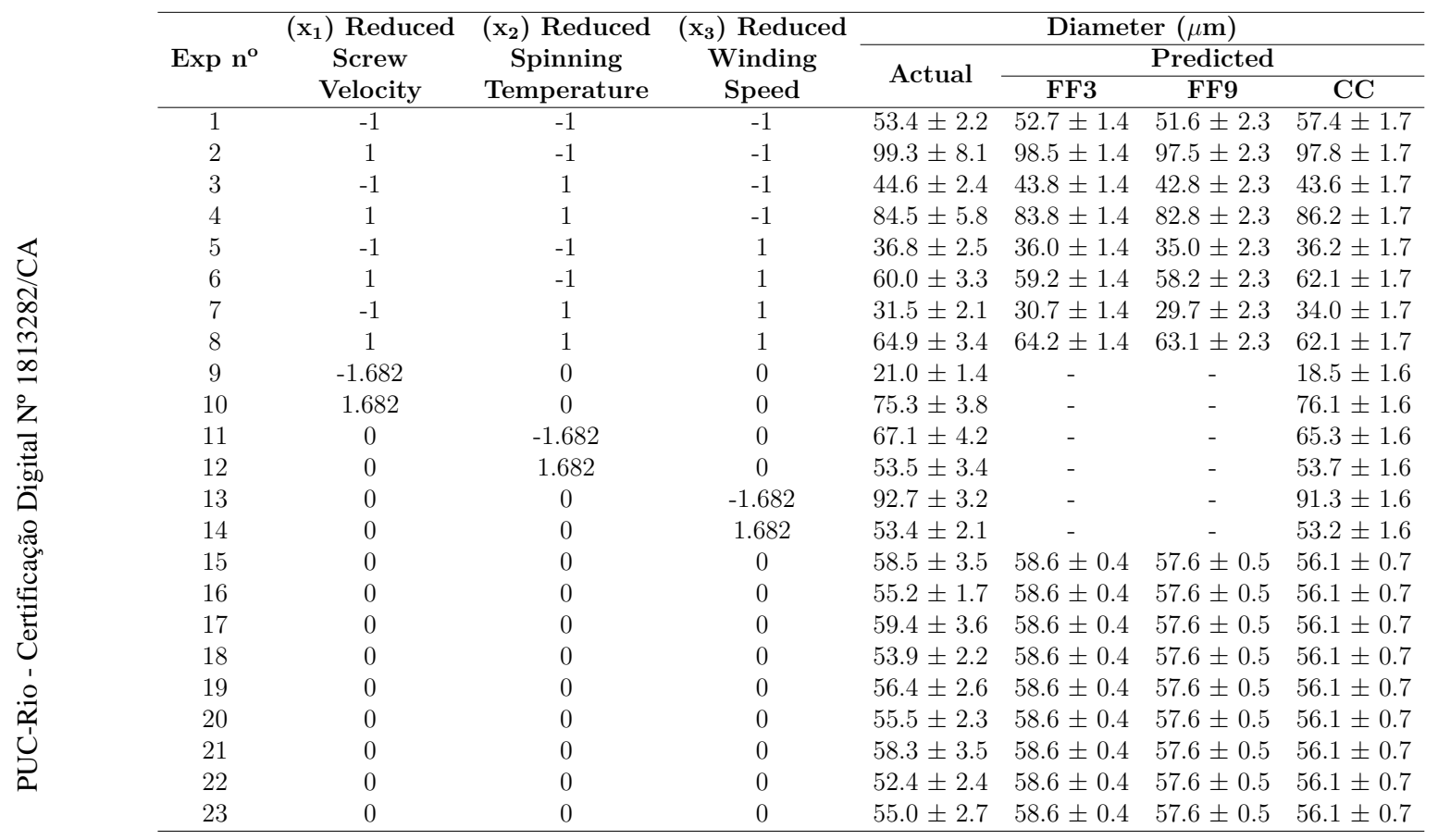

Predicted values of experiments 9 to 14 were not calculated for full factorial designs because $\alpha$ points are located outside the range of these models. Experiments on central domain (15 to 23 ) indicate that amongst full factorial designs, FF9 predicts better near this region, since its value of $57.6 \mu \mathrm{m}$ is closer to the medium $56.1 \mu \mathrm{m}$ than the diameter of $58.6 \mu \mathrm{m}$ estimated with FF3. The designs were evaluated in terms of their $R^{2}, \mathrm{~F}$-values and p-values. Table 4.2 shows ANOVA results for the models studied. 
Table 4.2: $R^{2}$ and p-values of models studied.

\begin{tabular}{cccccc}
\hline \multirow{2}{*}{ Design } & \multicolumn{2}{c}{$\mathbf{R}^{\mathbf{2}}$} & \multicolumn{2}{c}{ Model } & Lack of Fit \\
\cline { 2 - 6 } & $\mathbf{R}^{\mathbf{2}}$ & $\mathbf{R}^{\mathbf{2}}$ adj & F-value & p-value & p-value \\
\hline FF3 & 0.9916 & 0.9719 & 50.40 & 0.0042 & 0.2818 \\
FF9 & 0.9770 & 0.9591 & 54.66 & 0.0001 & 0.0192 \\
CC & 0.9861 & 0.9764 & 102.18 & 0.0001 & 0.1909 \\
\hline
\end{tabular}

Adjusted R-squared values higher than 0.95 indicate that the experimental data is in good agreement with predicted values. Model p-values of 0.05 or less imply significance and also small probability of errors due to noise. The models adequacy were tested through Lack of Fit p-values. The Lack of Fit was significant in FF9 on account of its p-value of 0.0304 .

\subsection{1}

\section{Impact of Variables on Diameter}

Regression coefficients and uncertainties and their p-values for full factorial and central composite designs are shown in Table 4.3.

Table 4.3: Coefficients estimated for models used.

\begin{tabular}{ccccccc}
\hline \multirow{2}{*}{ Parameters } & \multicolumn{2}{c}{ FF3 } & \multicolumn{2}{c}{ FF9 } & \multicolumn{2}{c}{ CC } \\
\cline { 2 - 7 } & Estimate & p-value & Estimate & p-value & Estimate & p-value \\
\hline$a_{0}$ & $58.92 \pm 1.49$ & 0.0015 & $57.83 \pm 1.32$ & $<0.0001$ & $56.10 \pm 1.4$ & $<0.0001$ \\
$a_{1}$ & $17.81 \pm 1.61$ & 0.0002 & $17.81 \pm 1.59$ & $<0.0001$ & $17.12 \pm 1.26$ & $<0.0001$ \\
$a_{2}$ & $-3.00 \pm 1.61$ & 0.0353 & $-3.00 \pm 1.59$ & 0.0247 & $-3.44 \pm 1.26$ & 0.0004 \\
$a_{3}$ & $-11.09 \pm 1.61$ & 0.0009 & $-11.09 \pm 1.59$ & $<0.0001$ & $-11.32 \pm 1.26$ & $<0.0001$ \\
$a_{12}$ & $0.54 \pm 2.61$ & 0.5574 & $0.52 \pm 1.59$ & 0.6393 & $0.54 \pm 1.42$ & 0.5833 \\
$a_{13}$ & $-3.64 \pm 1.61$ & 0.0213 & $-3.64 \pm 1.59$ & 0.0097 & $-3.64 \pm 1.42$ & 0.0022 \\
$a_{23}$ & $2.90 \pm 1.61$ & 0.0385 & $2.90 \pm 1.59$ & 0.0286 & $2.90 \pm 1.42$ & 0.0098 \\
$a_{11}$ & - & - & - & - & $-3.19 \pm 1.22$ & 0.0005 \\
$a_{22}$ & - & - & - & - & $1.21 \pm 1.22$ & 0.0996 \\
$a_{33}$ & - & - & - & - & $5.72 \pm 1.22$ & $<0.0001$ \\
$a_{123}$ & $2.02 \pm 1.61$ & 0.0907 & $2.02 \pm 1.59$ & 0.1032 & - & - \\
\hline
\end{tabular}

The significant terms are the parameters that contribute to $95 \%$ of the effects, i.e. those with a p-value lower than 0.05. For FF3 and FF9, all terms in the equations but the interaction term between temperature and screw velocity $\left(x_{1} x_{2}\right)$ and the interaction term of all variables $\left(x_{1} x_{2} x_{3}\right)$ are statistically significant; which leads to the belief that a third order interaction is negligible, as assumed in quadratic models. CC pointed out all terms were significant, with the exception of the interaction term between temperature and screw velocity $\left(x_{1} x_{2}\right)$ and the quadratic contribution of temperature $\left(x_{2}^{2}\right)$.

All models indicate that the linear dependency with screw velocity $\left(x_{1}\right)$ is the most significant factor in the process. This factor has a direct relationship 
with the response: the smaller revolution per minute used, the smaller the amount of material is delivered to the spinning pack and hence, the thinner the diameter.

All results showed that temperature has an inverse influence on diameter and that would suggest that a minimum of $40^{\circ} \mathrm{C}$ above the softening point should be used, in accordance with Mitsubishi's patent for this process (25). The spinning temperature must be chosen so that the melted pitch would not break into drops nor solidify too near the spinneret. However, as showed in dynamic viscosity test, a small variation in temperature causes a dramatic change in pitch viscosity.

The restricted range of temperatures that can be used in MP melt spinning is the first reason why this factor exhibited a lower impact than the other two variables studied on the diameter and it is why its quadratic contribution appears not to be significant. Besides, the laws of mass and energy conservation indicate that there is no direct influence of temperature on the fiber thickness, but temperature impacts the solidifying distance of the filament, at which it reaches its final diameter and viscosity. Therefore, the interaction between this variable and winding speed $\left(x_{2} x_{3}\right)$ is significant for the process.

The models also show that the linear dependency with winding speed $\left(x_{3}\right)$ has an inverse influence on diameter. For a given flow rate, the final axial filament velocity, primarily governed by the winding speed, opposes to filament cross sectional area, as expected from mass conservation law. Additionally, its interaction with screw velocity $\left(x_{1} x_{3}\right)$ emphasize the importance of the draw down ratio in fiber spinning.

Quadratic terms on screw velocity and winding speed have the same order as the linear term in temperature. This means that a first-degree model seems not to be sufficient to describe the phenomenon. Improvement of robustness of models can be achieved by considering only the significant coefficients. Response models for FF designs and $\mathrm{CC}$ can be respectively reduced to

$$
y=58.6+17.8 x_{1}-3.0 x_{2}-11.1 x_{3}-3.6 x_{1} x_{3}+2.9 x_{2} x_{3},
$$

and

$$
y=56.8+17.1 x_{1}-3.4 x_{2}-11.3 x_{3}-3.1 x_{1}^{2}+5.7 x_{3}^{2}-3.6 x_{1} x_{3}+2.9 x_{2} x_{3}
$$

for reduced variables or

$$
y=775.1+30.6 X_{1}-2.2 X_{2}-4.3 X_{3}-0.09 X_{1} X_{3}+0.01 X_{2} X_{3},
$$


and

$$
\begin{array}{r}
y=857.3+42.3 X_{1}-2.3 X_{2}-5.4 X_{3}-3.1 X_{1}^{2}+0.004 X_{3}^{2}- \\
0.09 X_{1} X_{3}+0.01 X_{2} X_{3}
\end{array}
$$

for real variables.

\subsection{2}

\section{Fitting and Optimizing}

Due to its high R-squared values, p-values and significance of coefficients, it can be inferred that Central Composite is the one in better agreement with the diameter experimental data, being the model with best robustness and prediction. This means that it also has a good precision and can be used to navigate the design space.

Figures C.1, C.2, C.3, C.4 and C.5 from Appendix C show surface and contour plots of the diameter as a function of reduced screw velocity $\left(x_{1}\right)$ and reduced winding speed $\left(x_{3}\right)$ in central composite design. These surfaces are parts of hyperbolic paraboloids. For a given temperature, diameter tends to diminish with combination of decreasing screw velocity and winding speed set near experiment's central domain. Even though it has a negative impact on diameter, the contributions of second order degree and interaction with screw velocity orient the optmized condition to a small positive winding speed value. There is a tendency to assess lower diameters as temperature grows, when comparing the extent of blue of surfaces from Figures C.1a through C.5a. This trend is smooth, considering that temperature has lower impact in comparison with the other two factors.

Figures D.1, D.2, D.3, D.4 and D.5 from Appendix D show surface and contour plots of the diameter as a function of reduced spinning temperature $\left(x_{2}\right)$ and reduced winding speed $\left(x_{3}\right)$ in central composite design. These surfaces are also parts of hyperbolic paraboloids. For screw velocities from $0.3 \mathrm{rpm}$ to $2 \mathrm{rpm}$, diameter tends to diminish with combination of increasing spinning temperature and winding speed set near experiment's central domain. For higher velocities, a increasing in winding speed is needed to avoid larger fibers. An evident trend is observed in surface plots: Figure D.1a is essentially blue, showing that at a screw velocity of $0.3 \mathrm{rpm}$ diameters are in their lower value; Figure D.3a has a wider range of colors, indicating that when screw velocity is set in the center of domain diameters from 50 to $100 \mu \mathrm{m}$ can be achieved; Figure D.5a exhibits a poor region of greater diameters. This clear tendency is due to the large impact this parameter has on the model. 
The optimizer tool was used to predict a fiber with minimum diameter according to central composite design. Within -1 and +1 levels region, the minimum diameter of $32.1 \mu \mathrm{m}$ is obtained for screw velocity of $1 \mathrm{rpm}$ (normalized as -1); spinning temperature of $343^{\circ} \mathrm{C}$ (normalized as 1); and winding speed of $151.2 \mathrm{rpm}$ (normalized as 0.42 ). Another trial was attempted with the following combination of variables: screw velocity of $0.3 \mathrm{rpm}$ (corresponding to level $-\alpha$ or -1.682 ); spinning temperature of $347^{\circ} \mathrm{C}$ (corresponding to level $\alpha$ or 1.682); and winding speed of $136 \mathrm{rpm}$ (corresponding to level 0.026). The predicted diameter achieved with that selection of variables is $14.1 \mu \mathrm{m}$. The large predicted deviation associated to this set of conditions is because it is outside both the full factorial range and the sphere with radius $\alpha$. Variables, expected and validated responses are shown in table 4.4 .

Table 4.4: Optimized parameters: predicted and actual values.

\begin{tabular}{cccccccc}
\hline \multirow{2}{*}{$\operatorname{Exp~}^{\circ}$} & \multicolumn{3}{c}{ Reduced } & \multirow{2}{*}{ Experimental } & \multicolumn{3}{c}{ Predicted } \\
\cline { 2 - 4 } & $\mathbf{x}_{\mathbf{1}}$ & $\mathbf{x}_{\mathbf{2}}$ & $\mathbf{x}_{\mathbf{3}}$ & & FF3 & FF9 & CC \\
\hline 24 & -1 & 1 & 0.42 & $30.8 \pm 2.0$ & $33.5 \pm 1.1$ & $34.2 \pm 1.7$ & $32.1 \pm 1.3$ \\
25 & -1.682 & 1.682 & 0.026 & $14.3 \pm 1.6$ & - & - & $14.1 \pm 3.0$ \\
\hline
\end{tabular}

The first experiment used as validation trial indicated that amongst the models, CC exhibited the lower deviation from the actual value. The latter trial confirmed the prediction precision of $\mathrm{CC}$, obtaining the conditions for the minimum diameter. Experiment design proved to be a powerful tool to indicate the best process conditions to manufacture thinner fibers.

\section{3}

\section{Extensional viscosity}

Figure 4.5 shows the numerical solution for the extensional viscosity based on experimental conditions of full factorial designs (number 0 represents an average value of all repetitions on the central domain) as a function of extension rate. Viscosity varies with extension rate in a decreasing tendency. Gotsis and Odrizola (50) and $\mathrm{Yu}$ et al (49) also reported extension-thinning behaviour for liquid crystalline polymers. 


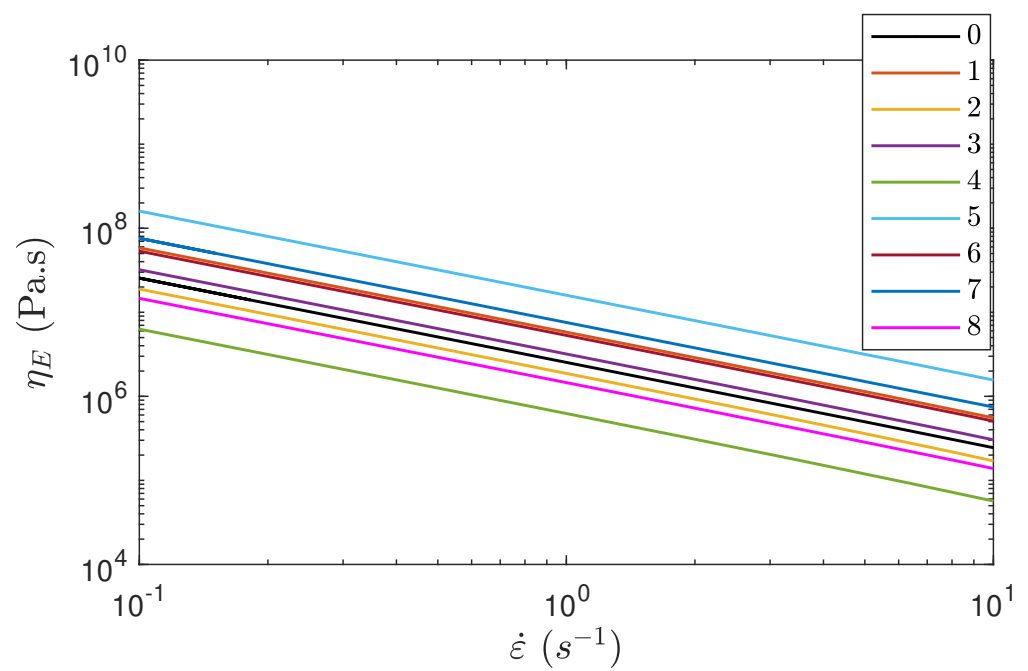

Figure 4.5: Extensional viscosity based on fiber spinning measurements.

It is important to note that in fiber extrusion, $\dot{\varepsilon}$ is not constant. The applied force to produce the filament is a result of stresses due to various strain rates along the fiber axis and even the upstream shear history in the die. For these reasons, the fiber spinning experiment is not a true rheometer, but gives an apparent uniaxial extensional viscosity of the material (54). Table 4.5 shows the averaged apparent extensional viscosity of the steady state process (calculated as equation 3-11) and total extension rate (as in equation 3-12). Apparent extensional viscosities found on experiments ranged from $8.65 \times 10^{5}$ to $2.29 \times 10^{7}$ Pa.s. The $9^{\text {th }}$ condition, that provided the thinner filaments, exhibited the higher value for the apparent extensional viscosity.

Table 4.5: Characteristic estimated viscosity and extension rate of experiments.

\begin{tabular}{ccc}
\hline Exp $\mathbf{n}^{\mathbf{o}}$ & $\dot{\varepsilon}_{a p}\left(\mathbf{s}^{-\mathbf{1}}\right)$ & $\eta_{E, a p}$ \\
\hline 1 & 0.67 & 76.08 \\
2 & 0.54 & 19.70 \\
3 & 0.69 & 39.08 \\
4 & 0.59 & 8.65 \\
5 & 1.25 & 116.67 \\
6 & 1.18 & 39.77 \\
7 & 1.26 & 55.47 \\
8 & 1.16 & 11.28 \\
9 & 0.99 & 229.61 \\
10 & 0.87 & 15.69 \\
11 & 0.89 & 51.20 \\
12 & 0.94 & 14.77 \\
13 & 0.41 & 14.16 \\
14 & 1.39 & 29.50 \\
0 & 0.93 & 29.26 \\
\hline
\end{tabular}


The 13th experiment, set at a screw velocity of $2 \mathrm{rpm}\left(x_{1}=0\right), 337^{\circ} \mathrm{C}$ $\left(x_{2}=0\right)$ and a $70 \mathrm{rpm}\left(x_{3}=-\alpha\right)$ winding speed, has the lower value of extension rate. The reduced winding speed used in that trial might not have been sufficient to stretch and tension the fiber along the spinneret-spool distance. The sampling time was short to notice the discrete looseness that may have happened during the experiment. The slow take-up velocity reflected in the augmented average diameter of the $13^{\text {th }}$ experiment of $92.7 \mu \mathrm{m}$, which was larger than fibers produced at higher screw velocities.

The tests 1,2,3 and 4 that were performed at a winding speed of 96,4 rpm $\left(x_{3}=-1\right)$ are grouped together in a lower-rate region. A similar observation may be pointed for the bunch composed of 5, 6, 7 and 8 experiments, set at $173,6 \mathrm{rpm}\left(x_{3}=1\right)$, which are located at the right-hand side of the graph. While the first group ranged from 0.53 to $0.67 \mathrm{~s}^{-1}$, the other one reached values of extension rates of $1.2 \mathrm{~s}^{-1}$. Experiments of winding speed held at center domain are in-between those two groups. This indicates that the streching upon winding has an important hole in the tensile stress on the fiber during spinning.

To correlate the effects induced by the processing conditions on the melt strength and the drawability of the pitch, the estimated stress generated at the spinning line was plotted as a function of the draw down ratio (Figure 4.6). The results show that temperature has also an important hole in the force applied to form the fiber. At a fixed spinning temperature, the stresses tend to diminish by decreasing the drawn down ratio. Furthermore, at a given DDR, the tension declines at higher temperatures. 


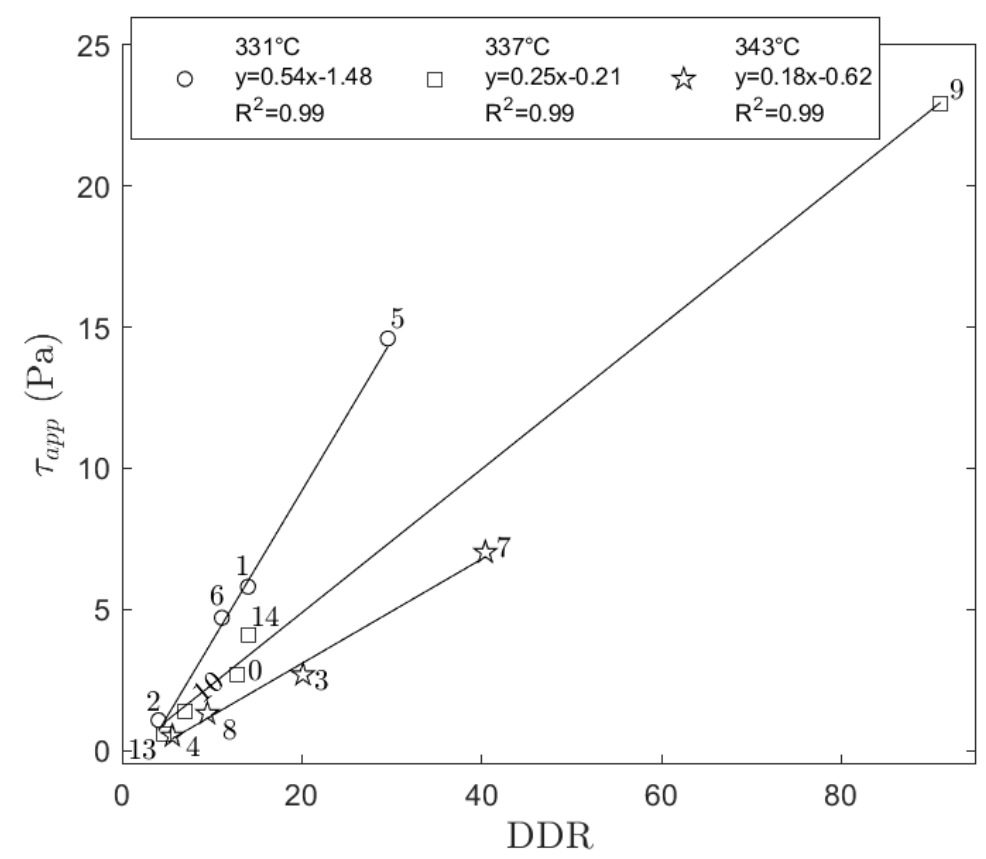

Figure 4.6: Estimated extensional stress as a function of drawn down ratio from fiber extrusion measurements at different spinning temperatures.

The smallest draw down ratios were a result of increased screw velocity and lower winding speeds. As presented previously in the evaluation of impacts of the DoE (subsection 4.2.1), this combination results in thicker diameters. It is easier to produce larger fibers, because on those, the breakage is reduced (10). Most of the fibers were produced at a drawn ratio inferior to 20. In all of them, diameters above $50 \mu \mathrm{m}$ were generated.

Due to the temperature dependency of viscosity, three trending lines could be identified in Figure 4.6. The slope of the fitted data is higher at lower temperatures. The stresses at higher draw down ratios can be predicted by extrapolating the trending lines that represent spinning temperatures of $331^{\circ} \mathrm{C}\left(x_{2}=-1\right), 337^{\circ} \mathrm{C}\left(x_{2}=0\right)$ and $343^{\circ} \mathrm{C}\left(x_{2}=1\right)$. Fibers produced at the same draw down ratio of the 9 th set $\left(x_{1}=-1.682\right.$ and $\left.x_{3}=0\right)$, which should result in a similar diameter, but extruded at $331^{\circ} \mathrm{C}$ and $343^{\circ} \mathrm{C}$, would experience, respectively, 51.2 $\mathrm{MPa}$ and $17.4 \mathrm{MPa}$. A value of $51.2 \mathrm{MPa}$ is on the range of the tensile strength of the pitch fiber and represents a value too huge to be beared while processing. That set of conditions would possibly break the filament. On the other hand, 17.4 MPa within the filament is close to that generated in experiment 5 , indicating that this combination of process variables would result in a stable experiment. 


\section{4}

\section{Pitch fiber orientation}

X-ray diffraction patterns for crystal alignment are extremely dependent on sample preparation. If fibers are overlaped, peaks will appear for each angle between the filaments. Therefore, for an accurate measurement, samples must be perfectly axially aligned and straightened, but not under tension, otherwise it may induce crystal deformation and provide values different from the actual degree of orientation. During the first trials, samples were put together following the sample holder line-guide and fixed by their ends with the apparatus clamps. Angular misalignment and fiber breakage resulted in multi-peaks with broad angles. No preferred orientation results were found on those tests.

Then, it was decided to insert two plastic tabs prepared by injection molding with a "V" slit to ensure the fibers were held parallel to one another. The tabs were placed on top of the previous fiber sample holder, using the drawn line as a reference. Due to the poor mechanical strength of green fibers, most of the samples broke during straightening. To overcome this problem, glue was used on their tips to held them together. As the result was based on the full width at half maximum (FWHM) of the obtained peaks, regardless of the $\psi$ displacement, there was no need to ensure that the tabs were stack on the very same position for each measure. Consequently, the peaks around $90^{\circ}$ and $270^{\circ}$ for different samples are not perfectly aligned, as shown in Figure 4.7 .

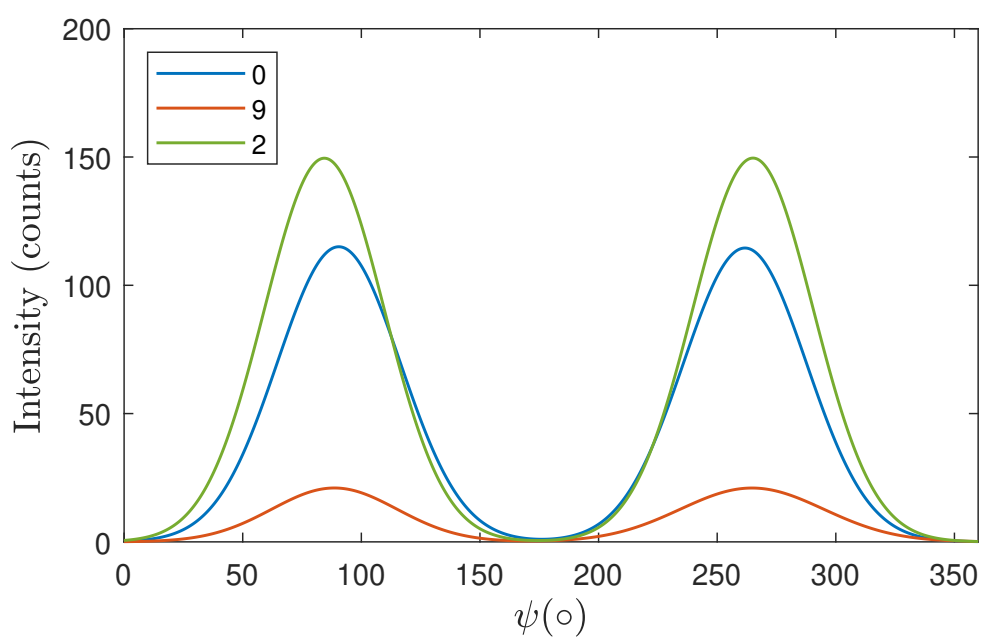

Figure 4.7: X-ray diffraction subtracted baseline gaussian fit for pitch filaments from 2, 9 and for central domain experiments.

Figure 4.7 shows 2 peaks separated from $180^{\circ}$, reflecting the axial 
alignment of graphene sheets. Experiment 2 exhibit a higher intensity because these samples have larger amounts of material. The results from the azimuthal scan show that the degree of orientation of pitch fibers range from $62 \%$ to $68 \%$ (Figure 4.8). Due to the necessary background corrections, the relative error was between 0,5 and $2 \%$. It is possible to see that larger fibers reached higher values of alignment. This trend was previously reported and explained based on the fact that the larger fibers take longer to solidify and there is more time for molecular orientation occur (56). Despite having the second largest diameter, fibers from experiment 13 displayed degrees of orientation close to the thinners samples. As noted in the previous section, the lowered winding speed might have led to a molecular orientation relaxation. The looseness in fiber formation increased the molecular mobility that deviated the mesophase from the axial alignment.

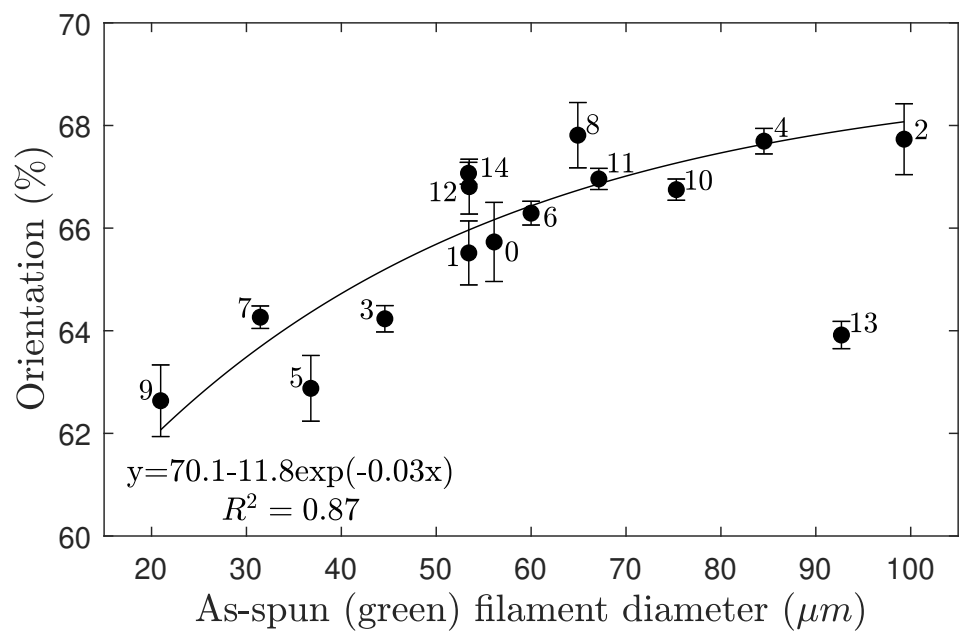

Figure 4.8: Crystal axial alignment as a function of averaged precursor fiber diameter.

Some authors have reported around $80 \%$ of crystal alignment for 100 $\mu \mathrm{m}$ MP green fibers $(11,32)$. The deviation of the values obtained with the reported on literature for thick fibers may be a result of: 1) differences on fiber stretching; 2) tilt in the x-ray beam-sample angle due to the slight gain in hight with the usage of the tabs. Even though the obtained fibers have exhibited lower orientation values, crystal alignment may still raise (up to to $20 \%$, as reported by Ogale et al. (32)) with further heat treatments. Moreover, a theoretical expected value of 82 to $88 \%$ for a carbon fiber is consistent with comercial grades $(70)$. 


\section{5 \\ Carbon Fibers}

Fibres from experiments 1 to 8 and from central domain were stabilized and carbonized under the same conditions. The thinnest fibers observed came from experiment 7 and showed diameters below $30 \mu \mathrm{m}$, as in Figure 4.9a. Figures $4.9 \mathrm{~b}$ and $4.9 \mathrm{c}$ show radial-aligned sheets for carbon fibers of the order of $30 \mu \mathrm{m}$. Fibers from those three experiments underwent a significant shrinkage of about $20 \%$ from the precursor green fibers without damaging their round shape. The microstructure presented in those thinner fibers show no significant differences across the cross-section. Thus, there is a strong evidence that those fibers were properly stabilized.

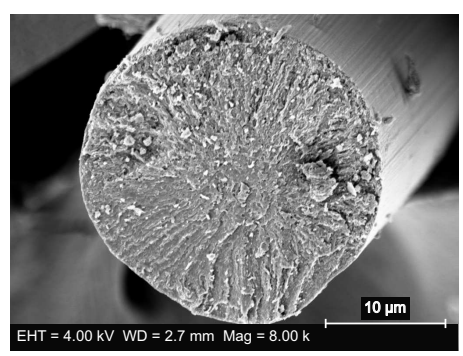

(a) 7

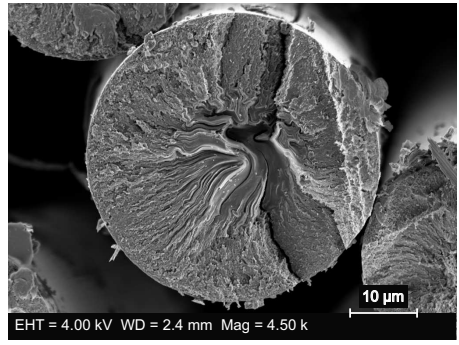

(d) 1

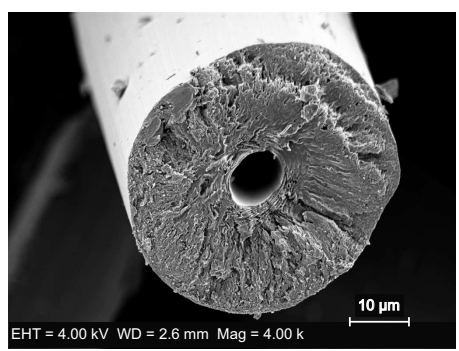

(g) 8

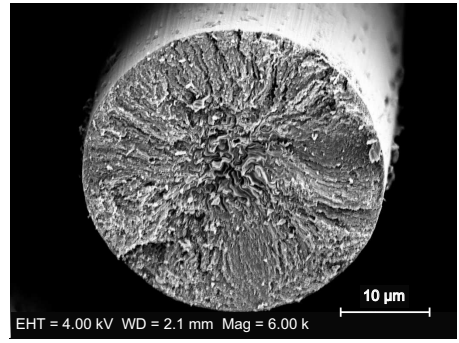

(b) 5

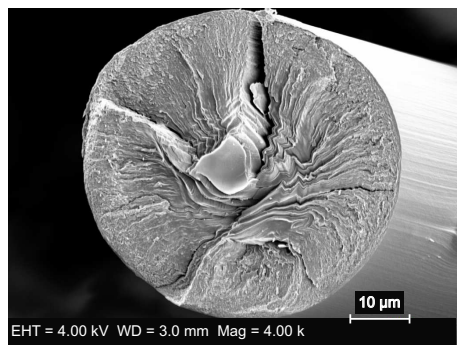

(e) 15

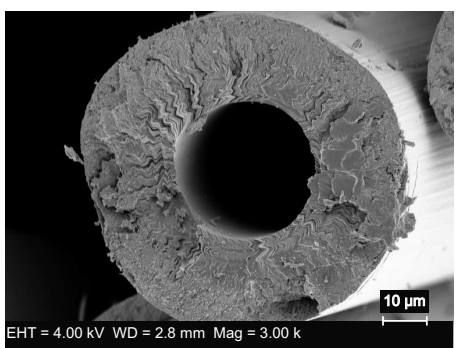

(h) 4

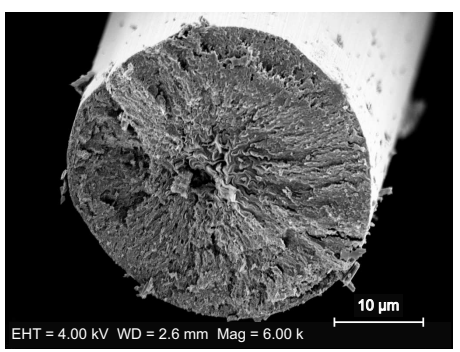

(c) 3

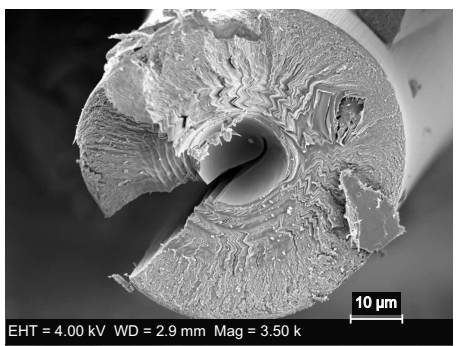

(f) 6

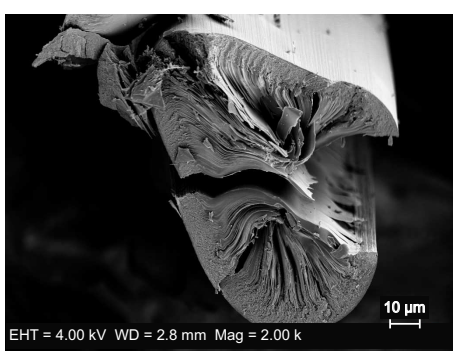

(i) 2

Figure 4.9: Carbon fibers from melt spinning experiments displayed in ascending order of diameter.

Carbon fibers derived from pitch filaments of $50 \mu \mathrm{m}$ to $60 \mu \mathrm{m}$, represent a transition of well-arranged, stabilized carbon fibers to larger defective fibers. Cracks or slits appear in the cross-section of these carbon fibers, which is the 
result of the expulsion of volatiles through the orientated carbon layers, as shown in sample from central domain experiments (32) (Figure 4.9e). Carbon fibers from experiment 6 exhibit "Pac-man" cracks and sunken non-oriented centers, as displayed by Figure 4.9f.

Large diameter pitch fibers are prone to form "skin-core" structures in the stabilization process (30). Figures $4.9 \mathrm{~d}$ and $4.9 \mathrm{e}$ show that the outer region of carbon fibers with diameter around $50 \mu \mathrm{m}$ have a structure very similar to that encountered in the thinner fibers. That stabilized region composed of radial-oriented sheets has a thickness of around $10 \mu \mathrm{m}$. The well-defined and more extended structures that follow that outer layer were previously reported for fibers derived from synthetic MP by Lu, Blanco and Rand (11). They explained that result by the diffusive nature of the stabilization process: fewer oxygen atoms reach the central area, allowing a softening of the core and the development of a larger texture of the mesophase domain (11).

The unstabilized central area of the thick fibers melt during the process, which allows structural rearrangement in this region and results in changes of the crystallites orientation (30). However, in some cases, the center of these fibers are entirely consumed in the carbonization process, resulting in a hollow central region (Figures $4.9 \mathrm{~g}$ and $4.9 \mathrm{~h}$ ). Green fibers of $80 \mu \mathrm{m}$ or more exhibit severe deformation behavior. Most of those have their circular cross section changed into oval or triangular shape. The lack of homogeneity in their structure impacts their integrity, as found in fibers from experiment 2 (Figure 4.9i), which broke during sample preparation.

Figure 4.10a shows that the tensile strength decreases slightly with increasing diameter of the precursor fiber. Pitch fibers are very brittle, and could stand an average of $48 \mathrm{MPa}$ or $23 \mathrm{MPa}$ (from samples 7 and 2, respectively). On the other hand, Figure $4.10 \mathrm{~b}$ display a huge difference between the thinnest fibers from experiment 7 , that reached strengths above $1000 \mathrm{MPa}$, and fibers from experiment 2, which tolerated only around $170 \mathrm{MPa}$. Cracks and hollows are the main mechanisms of failure of carbon fibers and lead to poor mechanical properties and tensile strength of carbon fibers exhibit significant fiber size dependence (35): larger diameters fibers have more and bigger voids and entrances due to poor oxygen diffusion, low thermal stability and release of volatiles that will directly affect the maximum tension beared. 


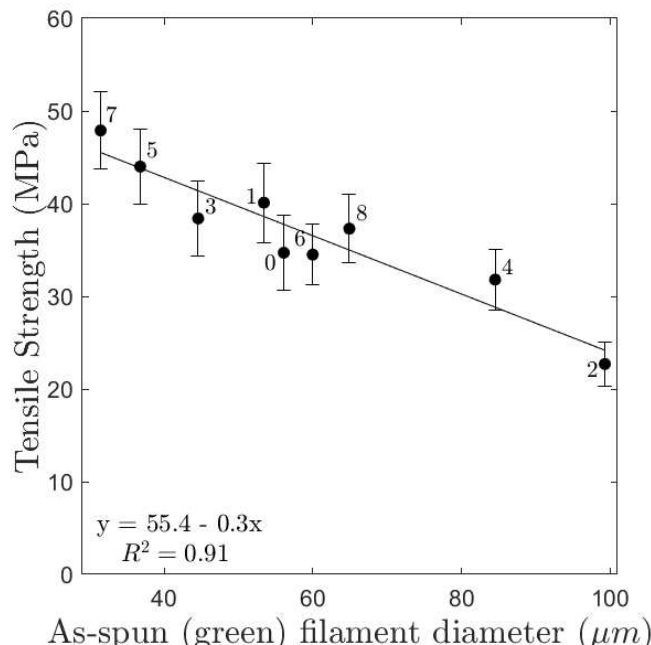

(a) Pitch filaments

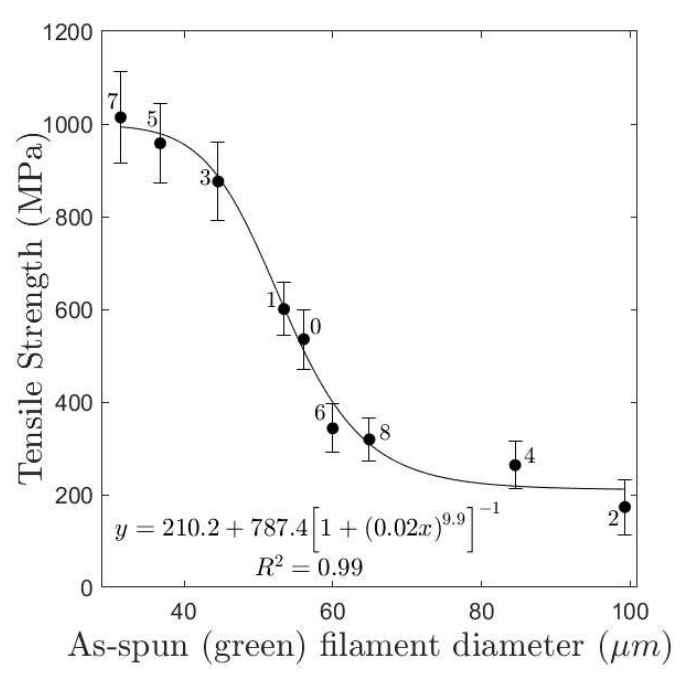

(b) Carbon fibers

Figure 4.10: Tensile strength as a function of averaged precursor fiber diameter for as-spun (a) and carbonized (b) samples.

Young's modulus of carbon fibers are displayed in Figure 4.11. A similar trend of Graph 4.10b was observed, except for the higher values from experiment 3, in comparison to those achieved in experiment 5. Filaments from experiments 3 and 7 were produced $12^{\circ} \mathrm{C}$ above the ones in experiment 5 . As temperature has a major impact in mesophase orientation during spinning (14), that temperature difference may be the reason why the fibers from the $5^{\text {th }}$ experiment reached an averaged modulus 10 GPa below the ones from experiments 3 and 7, despite having a similar average diameter. As indicated on the shear measurements, at $343^{\circ} \mathrm{C}$, liquid crystalline domains are more aligned. The only difference in the extrusion of fibers from 3 and 7 was the winding speed. A higher winding speed and lower screw velocity led to a higher draw down ratio and smaller diameters for the 7th experiment. On the other hand, the combination of lower winding speeds and higher temperatures allowed more time to molecular orientation during spinning for the 3rd set, making that batch reach the highest values of Young's modulus. 


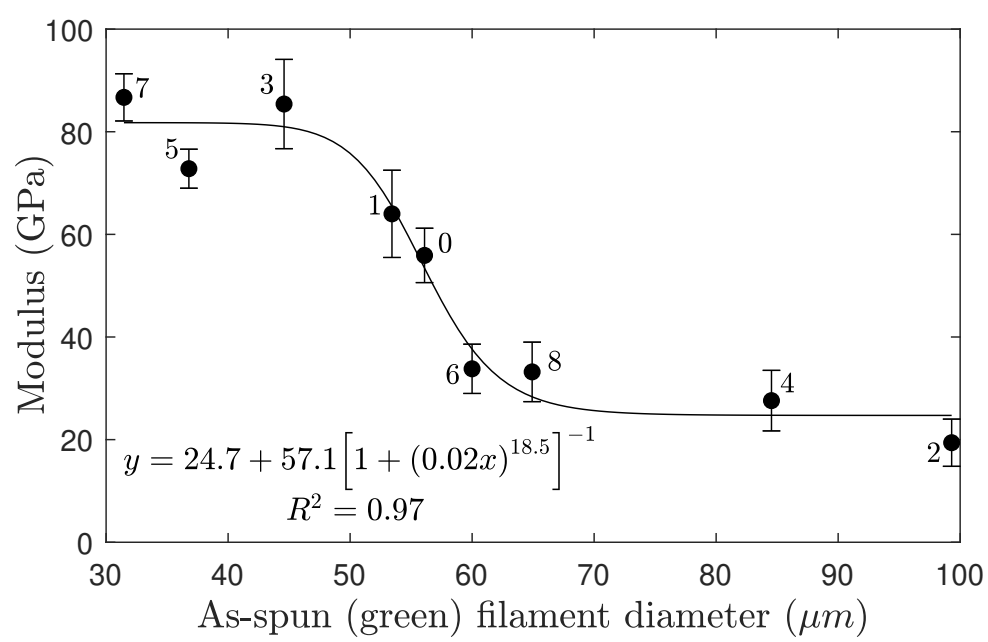

Figure 4.11: Young's modulus as a function of averaged precursor fiber diameter for carbonized samples.

Carbon Fibers derived from experiment 7 are closer to modulus and strength of $170 \mathrm{GPa}$ and $1700 \mathrm{MPa}$ targeted for automotive industry (71). These fibers are classified as general purpose grade and could be used, for example, as thermal insulation for high-temperature furnaces (72). The achieved values are compatible with the $11 \mu \mathrm{m}$ MP petroleum-based fiber produced by Jeon et al at a carbonization temperature of $1100^{\circ} \mathrm{C}$ with respective average modulus and strength of $120 \mathrm{GPa}$ and $1200 \mathrm{MPa}$. The same authors reported a $200 \mathrm{GPa}$ and $2000 \mathrm{MPa}$ batch using $1700^{\circ} \mathrm{C}$ in the heat treatment (71). The mechanical properties of the fibers can still be improved by optimizing conditions of stabilization and carbonization; and also graphitization treatment. 


\section{5}

\section{Conclusions and future work}

This study discussed the use of design of experiment statistics techniques in melt spinning of petroleum derived mesophase pitch. Full factorial designs proved to fit experimental data; however, their predictability could be enhanced. The rise in domain range made to support a rotable central composite design with near orthogonality property was useful to improve robustness and prediction. Central composite design performed better than full factorial designs in predicting the values of diameter, due to its high $R^{2}$ value of 0.98 , proving to be effective to analyse process conditions.

The effects of three processing variables were explored over twenty-five experiments. The relative importance of the variables has been identified. Smaller screw velocity, higher spinning temperature and augmented winding speed led to thinner pitch filaments. Screw velocity was found to be the most important factor affecting the diameter, followed by winding speed and then spinning temperature. An expected result, since the spinning temperature have a negligible effect on the fiber draw down ratio and on the axial velocity gradient.

Melt spinning data was used to characterize the pitch studied under extensional flow. Extensional viscosity plots suggest the fluid behaves in an extension thinning manner. Maximum tensile strength at which the material can be subjected under extrusion without breaking was also evaluated. Draw down ratios less then 20 produced larger fibers, while DDR higher than 30 provided the best filaments. It was found that a small increase in temperature would generate less stresses within the filament. Useful data of stresses and extension rates generated in experimental conditions may be applied to the design of further extrusion tests. The degree of orientation of the pitch filaments exhibited only a small fluctuation between the experiments, but it was possible to see that it grows with diameter.

The importance on the optimization of spinning conditions was verified on the carbon fibers produced under the same heat treatment: samples above $50 \mu \mathrm{m}$ were not completely stabilized. While thinner fibers exhibited wellarranged radial-aligned graphene sheets, the larger ones presented "skin-core" structures with voids and cracks. The existence of structural defects reflected on their mechanical properties. Tensile strength was found to grow with decreasing diameter for both green and carbon fibers. Young's modulus of the samples showed a similar trend, with the exception of the second thinnest 
samples, which was produced in a lower spinning temperature level. This result evidenced the importance of the spinning temperature in the microstructure of the carbon fiber, as the modulus depends on the crystalline arrangement of the graphene layers across de fiber axis.

The following are the proposed recommendations for future research based on the current study:

1. Similiar DoE techniques can be applied in pitches from different feedstocks to see if thinner filaments are produced in similar process conditions;

2. Other extrusion parameters such as spinneret design and quenching air may be included in the DoE;

3. Rheometrics extensional rheometer or an extensional viscosity fixture can be used to verify the behaviour of the pitch studied under extensional flow. Rheotens can be used to confirm the applied force whithin the filament and estimate the pitch tensile strength;

4. An optimization of the measurement of the degree of orientation of the pitch filaments may be achieved by observing the spectra variation at scanning angles near the $2 \theta$ used. It might minimize the deviations caused by the changes in the sample holder;

5. A deeper study on the orientation degree of fibers can be achieved by performing the XRD azimuthal scan on the produced stabilized fibers and carbonized fibers and studying the evolution of their structure with thermal treatments;

6. Pitch filaments produced on experiments 9 to 14 can be stabilized and carbonized under the same conditions to have their morphologies studied. Carbon fibers derived from the 9th experiment may also have their mechanical properties investigated to see if they meet the actual demand for this material;

7. Stabilization and carbonization can be performed differently on thicker fibers to prevent the defect-induced structures;

8. Stabilized samples can be subjected to higher carbonization temperatures and graphitization treatment at temperatures above $2800^{\circ} \mathrm{C}$ to improve their crystal alignment and achieve higher carbon content. Better mechanical properties are expected in graphite fibers. 


\section{References}

[1] GILL, A. S; VISOTSKY, D; MEARS, L ; SUMMERS, J. D. Cost estimation model for polyacrylonitrile-based carbon fiber manufacturing process. Journal of Manufacturing Science and Engineering, 139:041011, 2017. $1,1,2.1,2.2$

[2] GIURGIUTIU, V. Chapter 1 - introduction. In: STRUCTURAL HEALTH MONITORING OF AEROSPACE COMPOSITES, p. 1 - 23. Academic Press, Oxford, 2016. 1

[3] TIMMIS, A. J; HODZIC, A; KOH, L; BONNER, M; SOUTIS, C; SCHAFER, A. W ; DRAY, L. Environmental impact assessment of aviation emission reduction through the implementation of composite materials. The International Journal of Life Cycle Assessment, 20(2):233243, Feb 2015. 1

[4] CALLISTER, W. D; RETHWISCH, D. G. Materials science and engineering: an introduction. 2014. 1

[5] HOLMES, M. Global carbon fibre market remains on upward trend. Reinforced Plastics, 58(6):38 - 45, 2014. (document), 1, 1.1

[6] MOON, M; YUN, Y; YOO, M; SONG, J; OH, J. Chapter 34 carbon fiber manufacturing and applications as a benchmark for nanotube superfiber development. In: Schulz, M. J; Shanov, V; Yin, $Z$; Cahay, M, editors, NANOTUBE SUPERFIBER MATERIALS (SECOND EDITION), Micro and Nano Technologies, p. 879 - 896. William Andrew Publishing, second edition edition, 2019. 1

[7] CASTRO, L. D. D. Anisotropy and mesophase formation towards carbon fibre production from coal tar and petroleum pitches : a review. Journal of the Brazilian Chemical Society, 17:1096 - 1108, 10 2006. $1,2.2,3.1$

[8] APICElla, B; TREgrossi, A; StAZIOnE, F; CIAJOLO, A ; RUSSO, C. Analysis of petroleum and coal tar pitches as large pah. Chemical Engineering Transactions, 57:775-780, 2017. 1

[9] PÉREZ, M; GRANDA, M; MORGAN, R. S. T ; MENÉNDEZ, R. A thermoanalytical study of the co-pyrolysis of coal-tar pitch and petroleum pitch. Fuel, 83(9):1257 - 1265, 2004. 1 
[10] EDIE, D; DUNHAM, M. Melt spinning pitch-based carbon fibers. Carbon, 27(5):647 - 655, 1989. Carbon Fibers and Composites. (document), $1,2.2,2.2,2.3,2.7,2.4,2.5,2.5,4.3$

[11] LU, S; BLANCO, C ; RAND, B. Large diameter carbon fibres from mesophase pitch. Carbon, 40:2109-2116, 12 2002. (document), 1, 2.2, $2.5,2.14,4.4,4.5$

[12] JIANG, Z; OUYANG, T; YAO, X; FEI, Y. The effect of the spinning conditions on the structure of mesophase pitch-based carbon fibers by taguchi method. Carbon letters, 19:89-98, 07 2016. 1, 2.2, 2.5

[13] XIE, G; CHEN, Z; RAMAKRISHNA, S ; LIU, Y. Orthogonal design preparation of phenolic fiber by melt electrospinning. Journal of Applied Polymer Science, 132(38). 1

[14] YOON, S.-H; KORAI, Y ; MOCHIDA, I. Spinning characteristics of mesophase pitches derived from naphthalene and methylnaphthalene with hf/bf3. Carbon, 31(6):849-856, 1993. 1, 2.5, 4.5

[15] BEZERRA, M. A; SANTELLI, R. E; OLIVEIRA, E. P; VILLAR, L. S ; ESCALEIRA, L. A. Response surface methodology (rsm) as a tool for optimization in analytical chemistry. Talanta, 76(5):965 - 977, 2008. $1,3.3,3.3,3.3$

[16] LUNDSTEDT, T; SEIFERT, E; ABRAMO, L; THELIN, B; ÅSA NYSTRÖM; PETTERSEN, J ; BERGMAN, R. Experimental design and optimization. Chemometrics and Intelligent Laboratory Systems, 42(1):3 - 40, 1998. (document), 1, 3.3, 3.3, 3.3, 3.2

[17] PIŃKOWSKA, H; WOLAK, P ; OLIVEROS, E. Application of doehlert matrix for determination of the optimal conditions of hydrothermolysis of rapeseed meal in subcritical water. Fuel, 106:258 - 264, 2013. $1,3.3$

[18] PRADELLE, F; BRAGA, S. L; DE AGUIAR MARTINS, A. R. F; TURKOVICS, $F$; PRADELLE, R. N. C. Certainties and challenges in modeling unwashed and washed gums formation in brazilian gasoline--ethanol blends. Chemical Engineering Research and Design, 122:77 $-96,2017.1$

[19] HUANG, X. Fabrication and properties of carbon fibers. Materials, 2:2369-2403, 2009. 2.1, 2.1, 2.2, 2.2 
[20] JONES, J; B. BARR, J; E. SMITH, R. Analysis of flaws in high strength carbon fibers from mesophase pitch. A Journal of Materials Science, 15:2455-2465, 1980. 2.1, 2.2

[21] HONDA, H. Carbonaceous mesophase: History and prospects. Carbon, 26(2):139-156, 1988. 2.2

[22] CHEN, L; FEI, Y; FAN, X ; JIANG, Z. Coalescence of mesophase spheres and microstructure of graphitic carbon revealed by scanning electron microscopy. Journal of Materials Science, p. 1-14, 07 2017. (document), 2.3

[23] MOCHIDA, I; YOON, S.-H ; KORAI, Y. Mesoscopic structure and properties of liquid crystalline mesophase pitch and its transformation into carbon fiber. Chemical record (New York, N.Y.), 2:81-101, 03 2002. 2.2

[24] BEYREUTHER, R; BRÜNIG, H. Dynamics of Fibre Formation and Processing. 2007. 2.2, 2.4

[25] IWAO YAMAMOTO, TOSHIHIRO FUKAGAWA, A. Y; MUROI, M. Pitch based carbon fibers, 2001. US6303096B1. 2.2, 2.5, 3.3.1, 4.2.1

[26] FATHOLLAHI, B; CHAU, P ; WHITE, J. Injection and stabilization of mesophase pitch in the fabrication of carbon-carbon composites: Part ii. stabilization process. Carbon, 43(1):135 - 141, 2005. 2.2

[27] DIEFENDORF, R. 1.02 - pitch precursor carbon fibers. In: Kelly, A; Zweben, C, editors, COMPREHENSIVE COMPOSITE MATERIALS, p. 35 83. Pergamon, Oxford, 2000. 2.2

[28] YUAN, G; LI, X; XIONG, X; DONG, Z; WESTWOOD, A; LI, B; YE, C; MA, G; CUI, Z; CONG, Y; ZHANG, J; LI, Y. A comprehensive study on the oxidative stabilization of mesophase pitch-based tape-shaped thick fibers with oxygen. Carbon, 115:59-76, 2017. 2.2

[29] LIM, T. H; KIM, M. S; YEO, S. Y ; JEONG, E. Preparation and evaluation of isotropic and mesophase pitch-based carbon fibers using the pelletizing and continuous spinning process. Journal of Industrial Textiles, 48(7):1242-1253, 2019. 2.2

[30] ZHANG, X; LI, X; YUAN, G; DONG, Z; MA, G ; RAND, B. Large diameter pitch-based graphite fiber reinforced unidirectional carbon/carbon composites with high thermal conductivity densified by chemical vapor infiltration. Carbon, 114:59 - 69, 2017. 2.2, 4.5 
[31] MOCHIDA, I; YOON, S.-H; TAKANO, N; FORTIN, F; KORAI, Y ; YOKOGAWA, K. Microstructure of mesophase pitch-based carbon fiber and its control. Carbon, 34(8):941 - 956, 1996. 2.2

[32] OGALE, A; LIN, C; ANDERSON, D ; KEARNS, K. Orientation and dimensional changes in mesophase pitch-based carbon fibers. Carbon, 40(8):1309 - 1319, 2002. 2.2, 3.4.2, 4.4, 4.5

[33] YUE, Z; LIU, C ; VAKILI, A. Meltblown solvated mesophase pitchbased carbon fibers: Fiber evolution and characteristics. Journal of Carbon Research, 3:26, 08 2017. (document), 2.5

[34] FAN, Z; CAO, M; BING YANG, W; PENG ZHU, S ; HAI FENG, Z. The evolution of microstructure and thermal conductivity of mesophase pitch-based carbon fibers with heat treatment temperature. New Carbon Materials, 34(1):38 - 43, 2019. (document), 2.6

[35] TAGAWA, T; MIYATA, T. Size effect on tensile strength of carbon fibers. Materials Science and Engineering: A, 238(2):336 - 342, 1997. 2.2, 4.5

[36] EDIE, D. D. Carbon Fiber Processing and Structure/Property Relations, p. 163-181. Springer Netherlands, Dordrecht, 2001. 2.3, 2.3, 2.3

[37] NAZEM, F. Flow of molten mesophase pitch. Carbon, 20(4):345 354, 1982. 2.3, 2.3, 2.3, 4.1

[38] HUSON, M. 3 - High-performance pitch-based carbon fibers, p. 31 - 78. Woodhead Publishing Series in Textiles. Woodhead Publishing, Oxford, 2017. (document), 2.7

[39] GE, C; YANG, H; MIYAWAKI, J; MOCHIDA, I; YOON, S.-H; QIAO, W; LONG, D ; LING, L. Synthesis and characterization of highsoftening-point methylene-bridged pitches by visible light irradiation assisted free-radical bromination. Carbon, 95:780 - 788, 2015. (document), 2.7

[40] LOUVEM, FABIANA R. V.; SOUZA MENDES, P. R. Rheological Characterization of petroleum pitches precursors of carbon fibers. PhD thesis, Pontifícia Universidade Católica do Rio de Janeiro, 2015. 2.3

[41] D. CATO, A; EDIE, D ; M. HARRISON, G. Steady state and transient rheological behavior of mesophase pitch, part i: Experiment. Journal of Rheology, 49:161, 01 2005. (document), 2.3, 2.8, 2.3, 4.1, 4.1 
[42] ONOGI, S; ASADA, T. Rheology and Rheo-Optics of Polymer Liquid Crystals, p. 127-147. Springer US, Boston, MA, 1980. 2.3

[43] CATO, A. D; EDIE, D. D. Flow behavior of mesophase pitch. Carbon, 41(7):1411 - 1417, 2003. 2.3

[44] FLEUROT, O; EDIE, D. D. Steady and transient rheological behavior of mesophase pitches. Journal of Rheology, 42(4):781-793, 1998. 2.3

[45] LEE, S; EOM, Y; KIM, B.-J; MOCHIDA, I; YOON, S.-H ; KIM, B. C. The thermotropic liquid crystalline behavior of mesophase pitches with different chemical structures. Carbon, 81:694 - 701, 2015. (document), 2.3, 2.9

[46] ACIERNO, D; COLlYER, A. A. Rheology and processing of liquid crystal polymers. Polymer Liquid Crystals Series, 2(10):30-48, 1997. 2.3

[47] TURPIN, M; CHEUNG, T ; RAND, B. Controlled stress, oscillatory rheometry of a petroleum pitch. Carbon, 32(2):225 - 230, 1994. (document), 2.3, 2.10, 3.2, 4.1

[48] KUNDU, S; OGALE, A. A. Rheostructural studies on a synthetic mesophase pitch during transient shear flow. Carbon, 44(11):2224 $-2235,2006.2 .3,4.1$

[49] YU, R; YU, W; ZHOU, C ; FENG, J. Extensional viscosity of a thermotropic liquid crystalline polymer measured by thread disintegration method. Polymer Testing, 24(4):513 - 518, 2005. 2.3, 4.3

[50] GOTSIS, A. D; ODRIOZOLA, M. A. Extensional viscosity of a thermotropic liquid crystalline polymer. Journal of Rheology, 44(5):12051223, 2000. 2.3, 4.3

[51] KERNICK, W. A; WAGNER, N. J. Transient viscosity and molecular order of a thermotropic polyester lcp in uniaxial elongational flow. Macromolecules, 32(4):1159-1166, 1999. (document), 2.3, 2.11

[52] MATOVICH, M. A; PEARSON, J. R. A. Spinning a molten threadline. steady-state isothermal viscous flows. Industrial \& Engineering Chemistry Fundamentals, 8(3):512-520, 1969. 2.4

[53] KASE, S; MATSUO, T. Studies on melt spinning. ii. steady-state and transient solutions of fundamental equations compared with 
experimental results. Journal of Applied Polymer Science, 11(2):251-287, 1967. 2.4

[54] MACOSKO, C. W. Rheology Principles, Measurements, and Applications. Wiley-VCH, 1994. 2.4, 3.5, 3.5, 3.5, 4.3

[55] SOUZA MENDES, P. R; PADMANABHAN, M; SCRIVEN, L. E ; MACOSKO, C. W. Inelastic constitutive equations for complex flows. Rheologica Acta, 34(2):209-214, Mar 1995. 2.4

[56] DIEFENDORF, R. Pitch Precursor Carbon Fibers, p. 35-83. 122000. $2.4,2.5,4.4$

[57] WAGNER, M. H; IXNER, T; GEIGER, K. A note on the melt strength of liquid crystalline polymer. Journal of Rheology, 41(5):1087-1093, 1997. (document), 2.13

[58] HAMADA, T; FURUYAMA, M; SAJIKI, Y; TOMIOKA, T ; ENDO, M. Preferred orientation of pitch precursor fibers. Journal of Materials Research, 5(6):1271-1280, 1990. (document), 2.14

[59] ASTM-D2320-98. Standard test method for density (relative density) of solid pitch (pycnometer method). Technical report, ASTM, 2017. 3.1

[60] ASTM-D4072-98. Standard test method for toluene-insoluble (ti) content of tar and pitch. Technical report, ASTM, 2018. 3.1

[61] ASTM-D2318-15. Astm d2318-15 standard test method for quinoline-insoluble (qi) content of tar and pitch. Technical report, ASTM, 2015. 3.1

[62] TOTTEN, G; WESTBROOK, S ; SHAH, R. Fuels and Lubricants Handbook: Technology, Properties, Performance, and Testing. 06 2003. 3.1

[63] ASTM-D2416-84(2015)E1. Standard test method for coking value of tar and pitch (modified conradson). Technical report, ASTM, 2015. 3.1

[64] KHURI, A. I; MUKHOPADHYAY, S. Response surface methodology. WIREs Comput. Stat., 2(2):128-149, Mar. 2010. 3.3, 3.3

[65] GOUPY, J; CREIGHTON, W. L ; INSTITUTE, S. Introduction to design of experiments with JMP examples. Cary, N.C. : SAS Institute, 3rd 
ed edition, 2007. Includes bibliographical references (p. [431]-438) and index. (document), 3.1, 3.3, 3.3, 3.3

[66] LI, Z; LU, C; XIA, Z; ZHOU, Y ; LUO, Z. X-ray diffraction patterns of graphite and turbostratic carbon. Carbon, 45(8):1686 - 1695, 2007. 3.4 .2

[67] KUNDU, S; OGALE, A. Microstructural effects on the dynamic rheology of a discotic mesophase pitch. Rheologica Acta, 46:12111222, 12 2007. 4.1

[68] DUMONT, M; DOURGES, M; PAILLER, R ; BOURRAT, X. Mesophase pitches for 3d-carbon fibre preform densification: rheology and processability. Fuel, 82(12):1523 - 1529, 2003. 4.1

[69] IL JUN, S; SANG LEE, H. Negative normal stress differences in graphene/polycarbonate composites. Applied Physics Letters, 100(16):164108, Apr. 2012. 4.1

[70] PARIS, O; LOIDL, D ; PETERLIK, H. Texture of pan- and pitch-based carbon fibers. Carbon, 40(4):551-555, 2002. 4.4

[71] KO, S; CHOI, J.-E; LEE, C. W ; JEON, Y.-P. Preparation of petroleum-based mesophase pitch toward cost-competitive highperformance carbon fibers. Carbon Letters, Jul 2019. 4.5

[72] INAGAKI, M; KANG, F. Chapter 3 - engineering and applications of carbon materials. In: Inagaki, M; Kang, F, editors, MATERIALS SCIENCE AND ENGINEERING OF CARBON: FUNDAMENTALS (SECOND EDITION), p. 219 - 525. Butterworth-Heinemann, Oxford, second edition edition, 2014. 4.5 
A

\section{Experimental summary}

Table A.1: Experimental conditions and results.

\begin{tabular}{|c|c|c|c|c|c|c|c|}
\hline Exp no. & $\begin{array}{c}\text { Screw } \\
\text { Velocity } \\
(\mathrm{rpm})\end{array}$ & $\begin{array}{c}\text { Spinning } \\
\text { Temperature } \\
\left({ }^{\circ} \mathrm{C}\right)\end{array}$ & $\begin{array}{l}\text { Winding } \\
\text { Speed } \\
(\text { rpm })\end{array}$ & $\begin{array}{c}\text { Flow } \\
\text { Rate }^{a} \\
\left(\mathrm{~mm}^{3} / \mathrm{s}\right)\end{array}$ & $\begin{array}{l}\text { Diameter }^{b} \\
\qquad(\mu \mathbf{m})\end{array}$ & $\begin{array}{c}\text { Tensile } \\
\text { Strengh }^{c} \\
(\mathrm{MPa})\end{array}$ & $\begin{array}{c}\text { Degree of } \\
\text { Orientation }^{d} \\
(\%)\end{array}$ \\
\hline 1 & 1 & 331 & 96.4 & 1.1 & 53.4 & 40.1 & 65.5 \\
\hline 2 & 3 & 331 & 96.4 & 3.9 & 99.3 & 22.7 & 67.7 \\
\hline 3 & 1 & 343 & 96.4 & 0.8 & 44.6 & 38.4 & 65.0 \\
\hline 4 & 3 & 343 & 96.4 & 2.8 & 84.5 & 33.8 & 67.7 \\
\hline 5 & 1 & 331 & 173.6 & 1.0 & 36.8 & 44.0 & 64.3 \\
\hline 6 & 3 & 331 & 173.6 & 2.6 & 60.0 & 34.5 & 66.3 \\
\hline 7 & 1 & 343 & 173.6 & 0.7 & 31.5 & 47.9 & 64.3 \\
\hline 8 & 3 & 343 & 173.6 & 3.0 & 64.9 & 40.3 & 67.8 \\
\hline 9 & 0.3 & 337 & 135 & 0.2 & 21.0 & 53.8 & 62.6 \\
\hline 10 & 3.7 & 337 & 135 & 3.1 & 75.3 & 31.8 & 66.7 \\
\hline 11 & 2 & 327 & 135 & 2.5 & 67.1 & 37.6 & 67.0 \\
\hline 12 & 2 & 347 & 135 & 1.6 & 53.5 & 35.8 & 66.8 \\
\hline 13 & 2 & 337 & 70 & 2.5 & 92.7 & 25.3 & 63.9 \\
\hline 14 & 2 & 337 & 200 & 2.3 & 53.4 & 38.6 & 67.0 \\
\hline 15 & 2 & 337 & 135 & 1.9 & 58.5 & 31.3 & 65.0 \\
\hline 16 & 2 & 337 & 135 & 1.7 & 55.2 & 28.8 & 65.9 \\
\hline 17 & 2 & 337 & 135 & 2.0 & 59.4 & 33.6 & 66.0 \\
\hline 18 & 2 & 337 & 135 & 1.6 & 53.9 & 37.4 & 65.5 \\
\hline 19 & 2 & 337 & 135 & 1.8 & 56.4 & 38.9 & 65.7 \\
\hline 20 & 2 & 337 & 135 & 1.7 & 55.5 & 37.9 & 65.8 \\
\hline 21 & 2 & 337 & 135 & 1.9 & 58.3 & 35.2 & 65.3 \\
\hline 22 & 2 & 337 & 135 & 1.5 & 52.4 & 36.8 & 65.2 \\
\hline 23 & 2 & 337 & 135 & 1.7 & 55.0 & 34.7 & 66.3 \\
\hline
\end{tabular}

${ }^{a}$ Calculated as equation 3-7.

${ }^{b}$ Averaged values obtained from microscope observations, as in section 3.4.1.

${ }^{c}$ Averaged values obtained in tensile tests for mesophase pitch fibers, as described in section 3.4.3.

${ }^{d}$ Averaged values calculated as reported in section 3.4.2. 
B

\section{Extension codes}

Code 1: Mean code

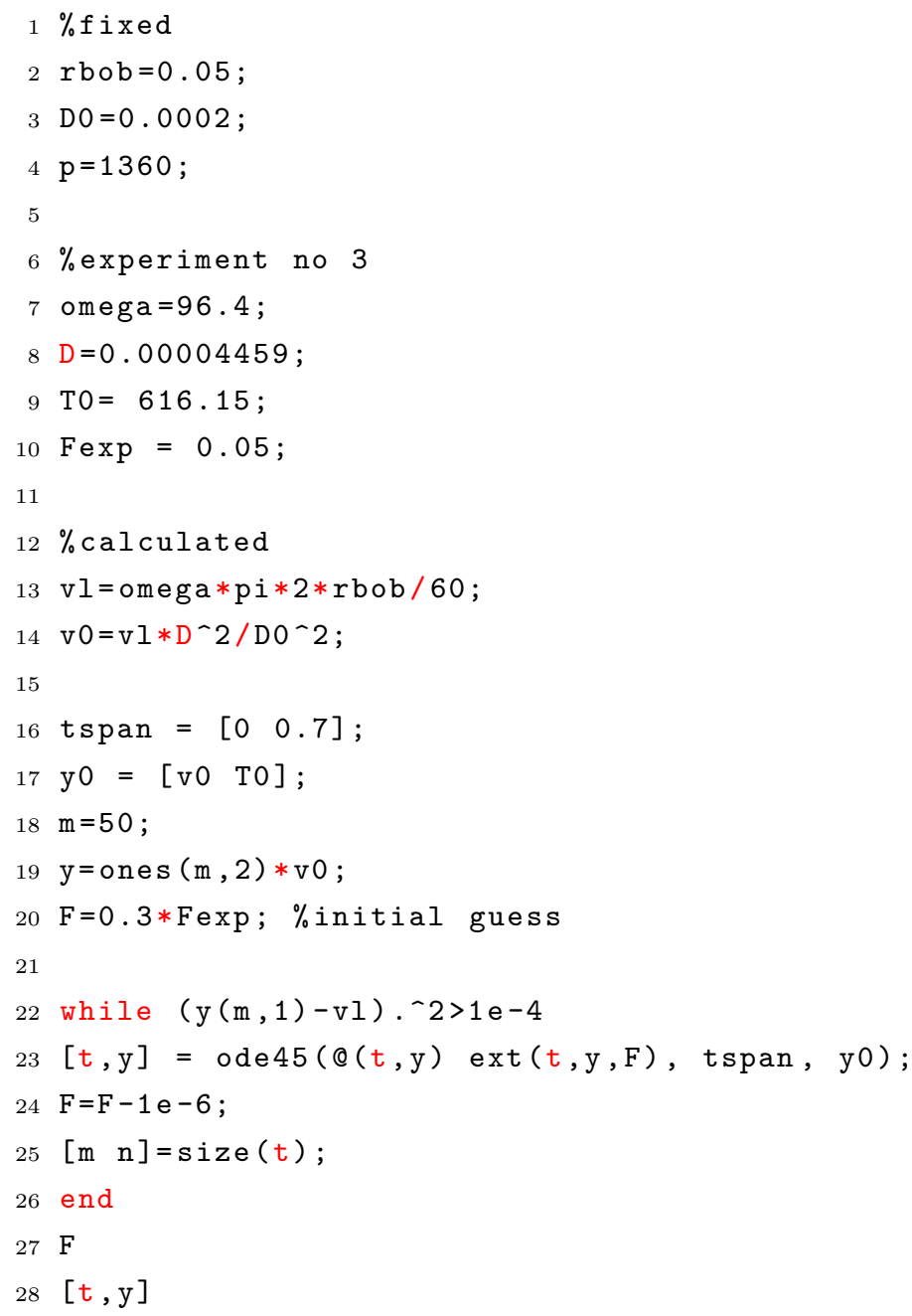


Code 2: Equations of motion, energy and momentum

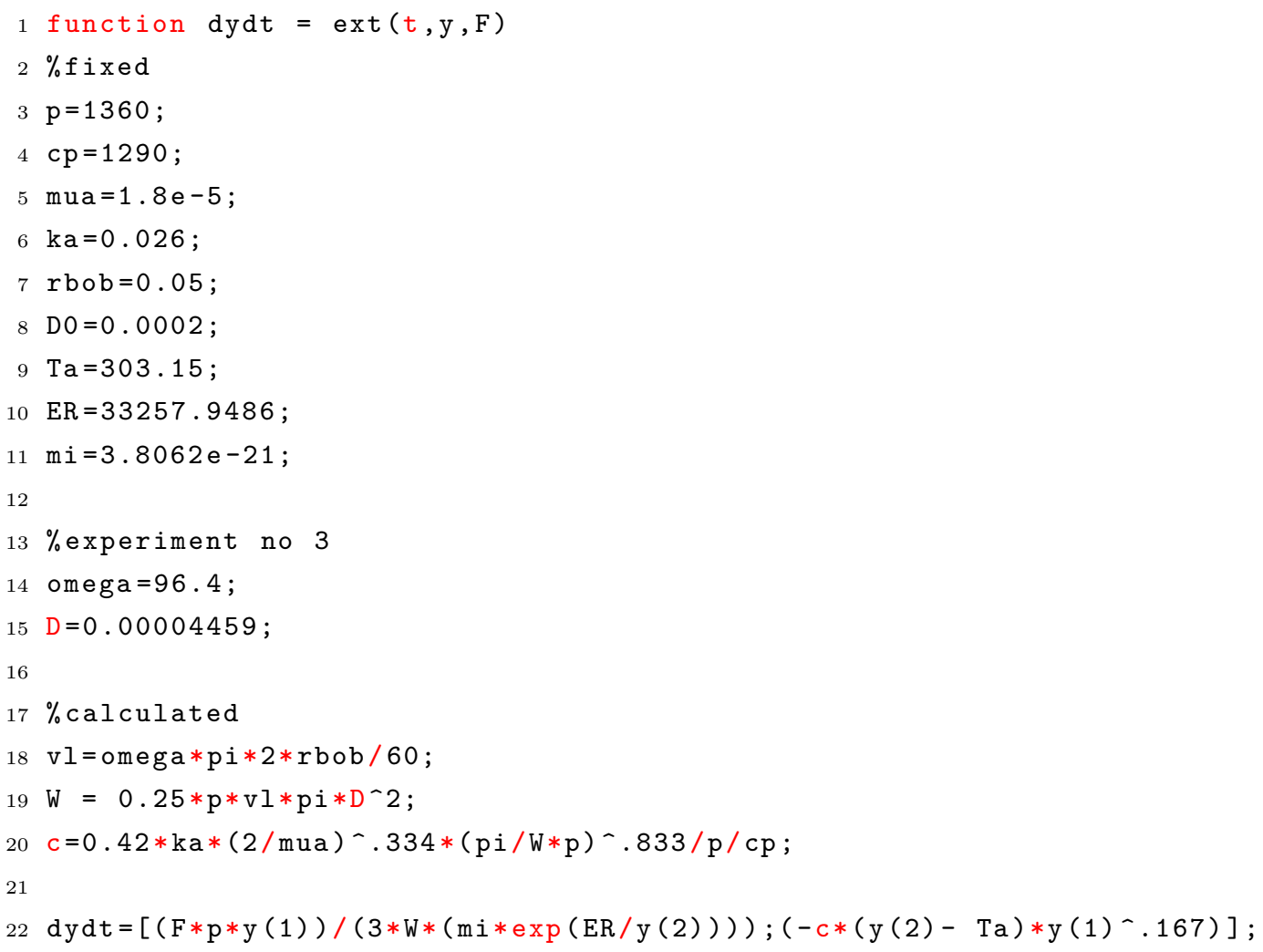


C

Surface and contour plots with fixed temperature

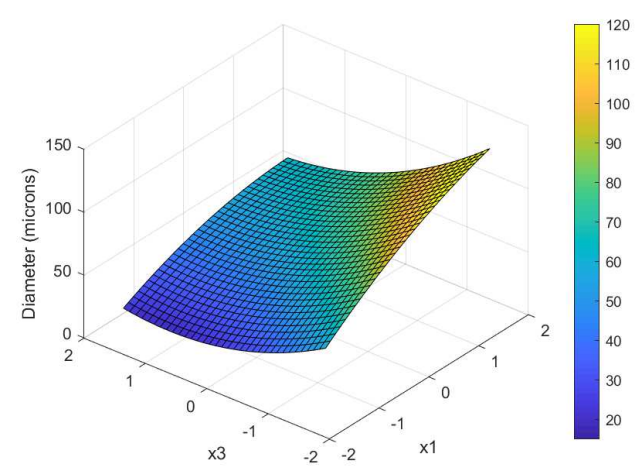

(a) Response surface

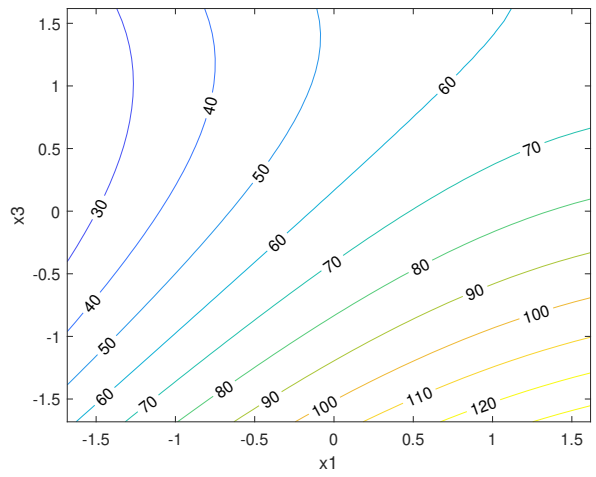

(b) Contour plot

Figure C.1: Diameter in central composite design as a function of coded screw velocity $\left(x_{1}\right)$ and coded winding speed $\left(x_{3}\right)$ with fixed spinning temperature of $327^{\circ} \mathrm{C}\left(x_{2}=-\alpha\right)$.

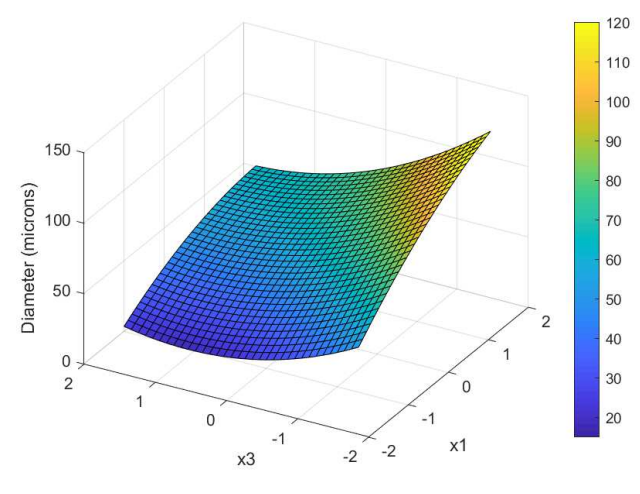

(a) Response surface

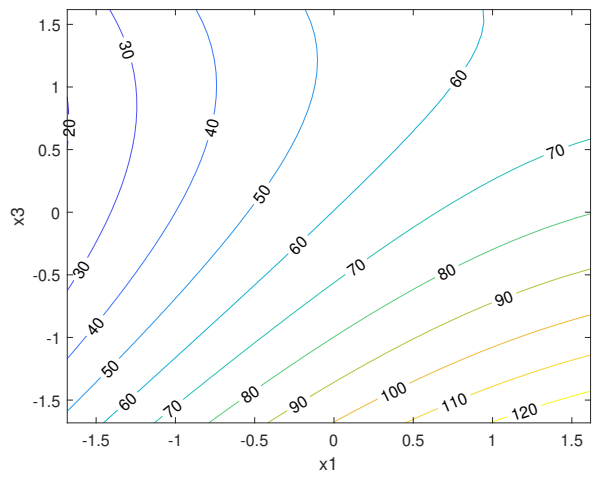

(b) Contour plot

Figure C.2: Diameter in central composite design as a function of coded screw velocity $\left(x_{1}\right)$ and coded winding speed $\left(x_{3}\right)$ with fixed spinning temperature of $331^{\circ} \mathrm{C}\left(x_{2}=-1\right)$. 


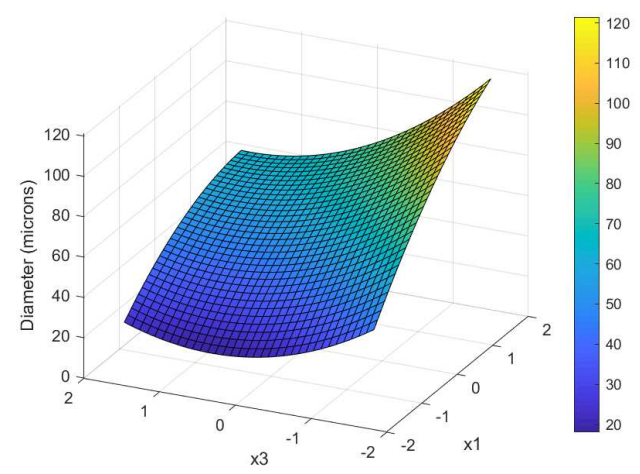

(a) Response surface

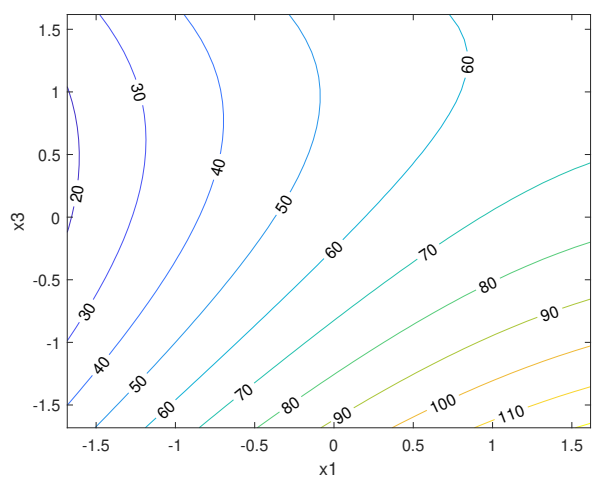

(b) Contour plot

Figure C.3: Diameter in central composite design as a function of coded screw velocity $\left(x_{1}\right)$ and coded winding speed $\left(x_{3}\right)$ with fixed spinning temperature of $337^{\circ} \mathrm{C}\left(x_{2}=0\right)$.

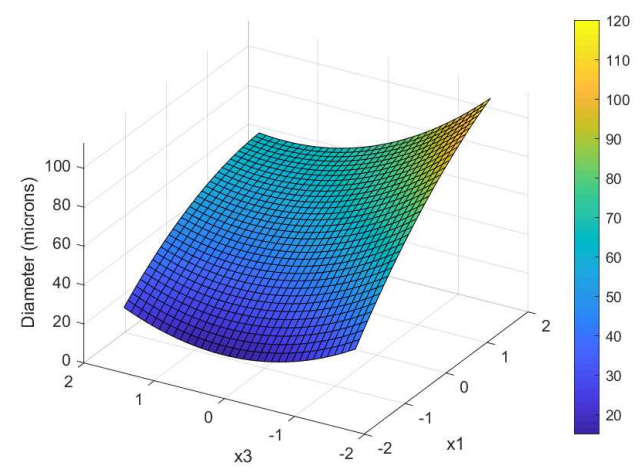

(a) Response surface

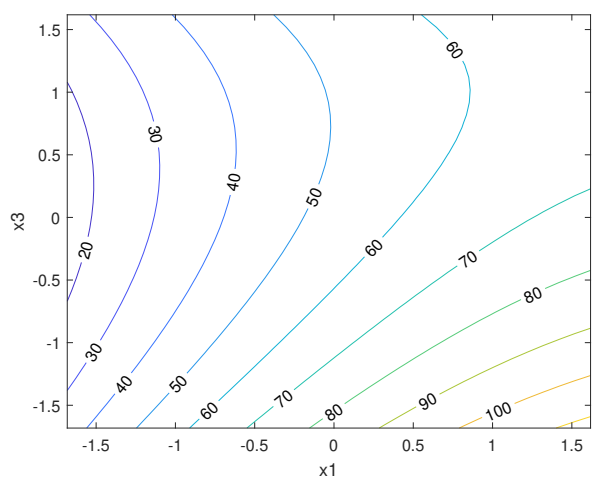

(b) Contour plot

Figure C.4: Diameter in central composite design as a function of coded screw velocity $\left(x_{1}\right)$ and coded winding speed $\left(x_{3}\right)$ with fixed spinning temperature of $343^{\circ} \mathrm{C}\left(x_{2}=1\right)$.

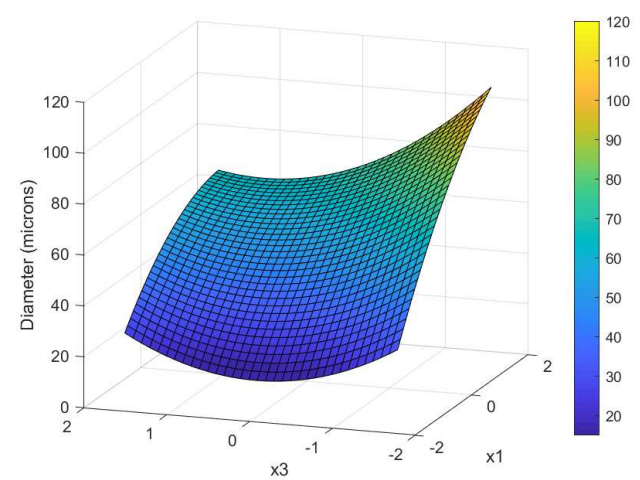

(a) Response surface

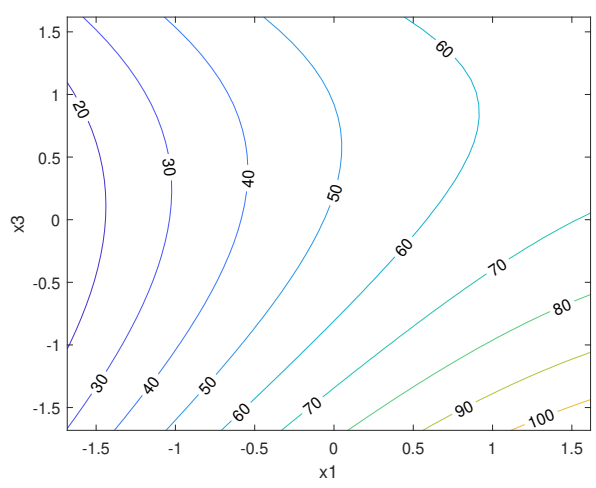

(b) Contour plot

Figure C.5: Diameter in central composite design as a function of coded screw velocity $\left(x_{1}\right)$ and coded winding speed $\left(x_{3}\right)$ with fixed spinning temperature of $347^{\circ} \mathrm{C}\left(x_{2}=\alpha\right)$. 
D

\section{Surface and contour plots with fixed screw velocity}

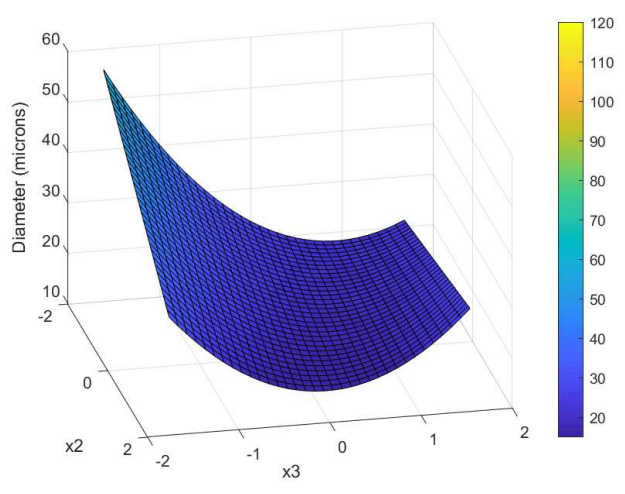

(a) Response surface

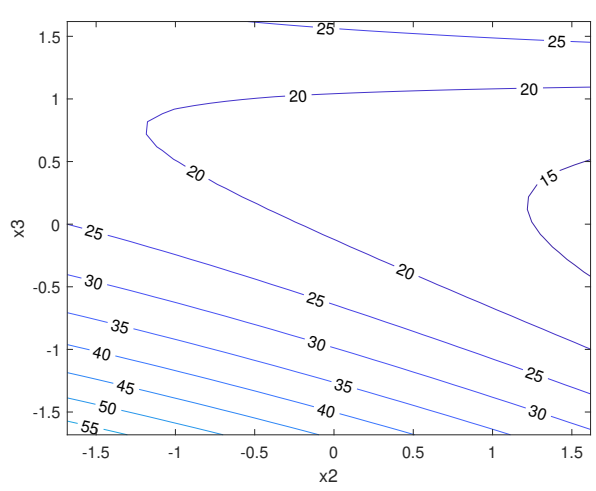

(b) Contour plot

Figure D.1: Diameter in central composite design as a function of coded spinning temperature $\left(x_{2}\right)$ and coded winding speed $\left(x_{3}\right)$ with fixed screw velocity of $0.3 \mathrm{rpm}\left(x_{1}=-\alpha\right)$.

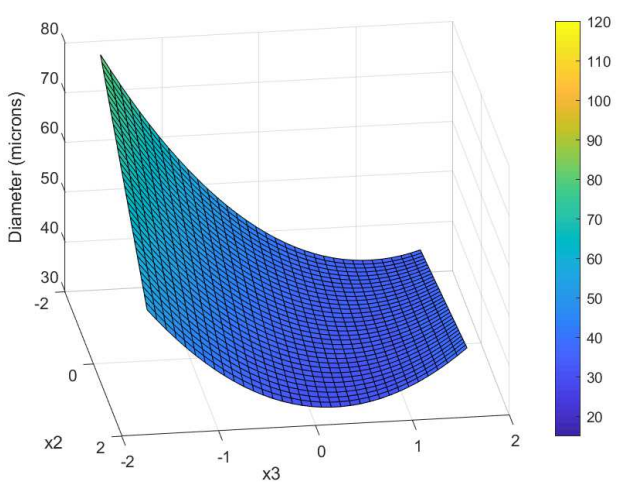

(a) Response surface

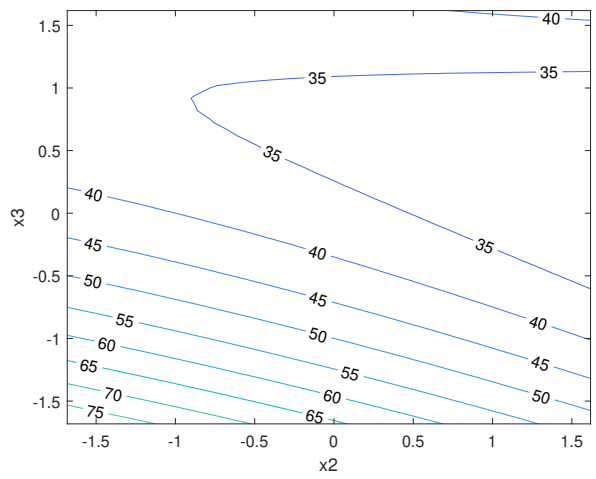

(b) Contour plot

Figure D.2: Diameter in central composite design as a function of coded spinning temperature $\left(x_{2}\right)$ and coded winding speed $\left(x_{3}\right)$ with fixed screw velocity of $1 \mathrm{rpm}\left(x_{1}=-1\right)$. 


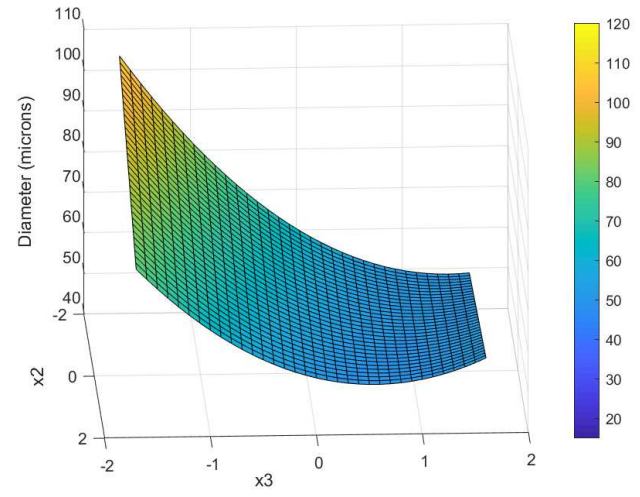

(a) Response surface

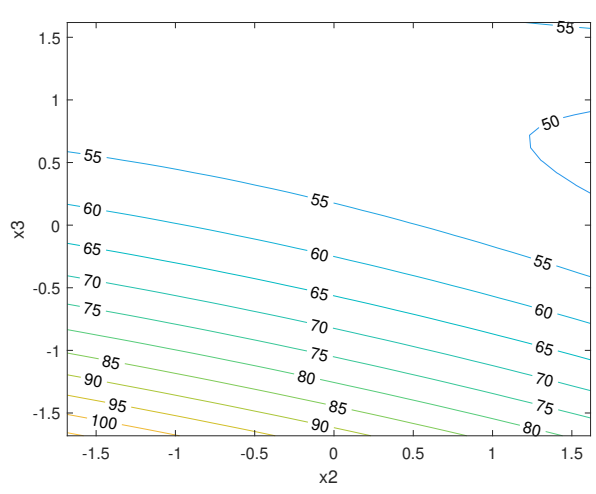

(b) Contour plot

Figure D.3: Diameter in central composite design as a function of coded spinning temperature $\left(x_{2}\right)$ and coded winding speed $\left(x_{3}\right)$ with fixed screw velocity of $2 \mathrm{rpm}\left(x_{1}=0\right)$.

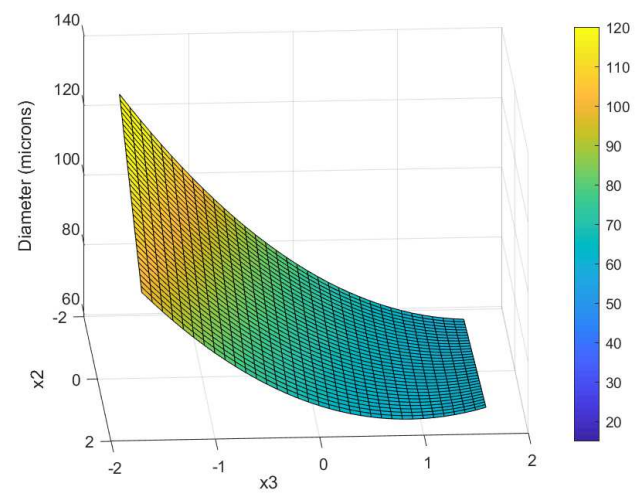

(a) Response surface

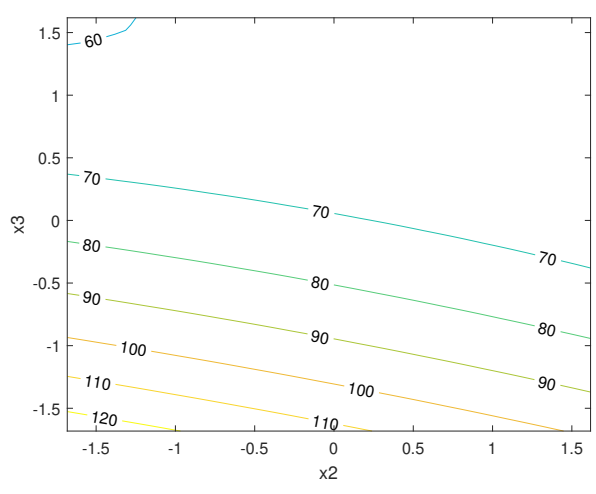

(b) Contour plot

Figure D.4: Diameter in central composite design as a function of coded spinning temperature $\left(x_{2}\right)$ and coded winding speed $\left(x_{3}\right)$ with fixed screw velocity of $3 \mathrm{rpm}\left(x_{1}=1\right)$.

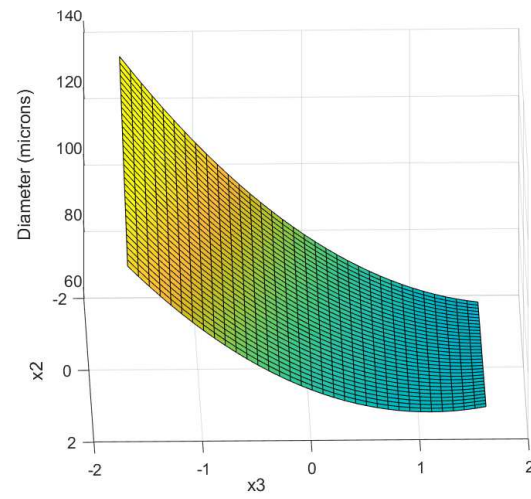

(a) Response surface

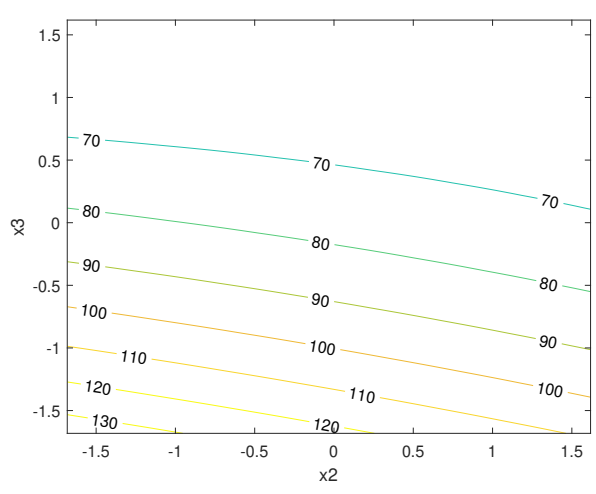

(b) Contour plot

Figure D.5: Diameter in central composite design as a function of coded spinning temperature $\left(x_{2}\right)$ and coded winding speed $\left(x_{3}\right)$ with fixed screw velocity of $3.7 \mathrm{rpm}\left(x_{1}=\alpha\right)$. 